\title{
Origins and Evolution of Inorganic-Based and MOF-Based Mixed-Matrix Membranes for Gas Separations
}

\author{
Edson V. Perez, Chamaal Karunaweera, Inga H. Musselman, Kenneth J. Balkus, Jr. \\ and John P. Ferraris * \\ Department of Chemistry and Biochemistry, The University of Texas at Dallas, Richardson, TX 75080, USA; \\ edson.perez@utdallas.edu (E.V.P.); cxk140730@utdallas.edu (C.K.); imusselm@utdallas.edu (I.H.M.); \\ balkus@utdallas.edu (K.J.B.) \\ * Correspondence: ferraris@utdallas.edu; Tel.: +1-972-883-2905
}

Academic Editors: Angelo Basile and Catherine Charcosset

Received: 30 June 2016; Accepted: 23 August 2016; Published: 12 September 2016

\begin{abstract}
Gas separation for industrial, energy, and environmental applications requires low energy consumption and small footprint technology to minimize operating and capital costs for the processing of large volumes of gases. Among the separation methods currently being used, like distillation, amine scrubbing, and pressure and temperature swing adsorption, membrane-based gas separation has the potential to meet these demands. The key component, the membrane, must then be engineered to allow for high gas flux, high selectivity, and chemical and mechanical stability at the operating conditions of feed composition, pressure, and temperature. Among the new type of membranes studied that show promising results are the inorganic-based and the metal-organic framework-based mixed-matrix membranes (MOF-MMMs). A MOF is a unique material that offers the possibility of tuning the porosity of a membrane by introducing diffusional channels and forming a compatible interface with the polymer. This review details the origins of these membranes and their evolution since the first inorganic/polymer and MOF/polymer MMMs were reported in the open literature. The most significant advancements made in terms of materials, properties, and testing conditions are described in a chronological fashion.
\end{abstract}

Keywords: gas separations; membranes; mixed-matrix membrane; MMM; zeolite; molecular sieves; metal-organic framework; MOF; ZIF; MOF-MMM

\section{Introduction}

Gas separations are important processes for a variety of applications. In the petrochemical, natural gas, and fuel industry [1,2], for example, the purification of commodity gases, like propane, propylene, hydrogen, methane, and ammonia, is vital for the production of other goods like fuels (e.g., propane, hydrogen, methane) [3-11], polymers (e.g., polypropylene from propylene) [12-15], and fertilizers (e.g., ammonium salts) [16,17]. Recently, environmental applications for gas separations have also been explored mainly for the capture and sequestration of carbon dioxide from the burning and gasification of coal in the generation of electricity and the production of hydrogen [18-20]. Another environmental application for gas separations targets the separation of oxygen from nitrogen (air separation) for the oxycombustion of coal, aiming to reduce the amount of carbon dioxide emitted. Owing to the physical properties of the gases to be separated (e.g., kinetic diameter, critical temperatures, shape), shown in Table 1, the processes designed for their separation (e.g., amine scrubbing, distillation, pressure and temperature swing adsorption) could become expensive due to the amount of energy spent in the separation [21], or even become not viable due to the lack of an efficient and cost effective technology [14,22]. 
Table 1. Physical properties of permanent gases and organic vapors.

\begin{tabular}{ccccc}
\hline Gas & Kinetic Diameter $(\AA \AA)$ & Critical Temperature $\left({ }^{\circ} \mathrm{C}\right)$ & Critical Pressure (Bar) & Vapor Pressure $\left(\right.$ Bar at $\left.\left({ }^{\circ} \mathbf{C}\right)\right)$ \\
\hline $\mathrm{C}_{3} \mathrm{H}_{6}$ & 4.5 & 91.75 & 45.55 & $8.4(21.1)$ \\
$\mathrm{C}_{3} \mathrm{H}_{8}$ & 4.3 & 96.74 & 42.51 & $8.0(21.0)$ \\
$\mathrm{CH}_{4}$ & 3.8 & -82.59 & 45.99 & - \\
$\mathrm{CO}$ & 3.76 & -140.45 & 34.94 & - \\
$\mathrm{N}_{2}$ & 3.64 & -146.95 & 33.51 & - \\
$\mathrm{O}_{2}$ & 3.46 & -118.55 & 49.7 & $60(22.4)$ \\
$\mathrm{CO}_{2}$ & 3.3 & 30.98 & 73.0 & $0.025(21.0)$ \\
$\mathrm{H}_{2}$ & 2.89 & -232.60 & 12.69 & $8.76(21.0)$ \\
$\mathrm{H}_{2} \mathrm{O}$ & 2.65 & 373.80 & 217.7 & - \\
$\mathrm{NH}_{3}$ & 2.6 & 132.25 & 113.3 & - \\
$\mathrm{He}$ & 2.6 & -267.96 & 2.24 & - \\
\hline
\end{tabular}

Therefore, the search for other separation methods has extended to the use of membranes in which the separation is afforded by the differential in concentration of the gases between the two sides of the membrane (Figure 1). This difference in concentration is typically expressed, and in practice is carried out, in terms of a differential pressure between the high pressure side $\left(\mathrm{P}_{\text {feed }}\right)$ and the low pressure side $\left(\mathrm{P}_{\text {permeate}}\right)$ of the membrane.

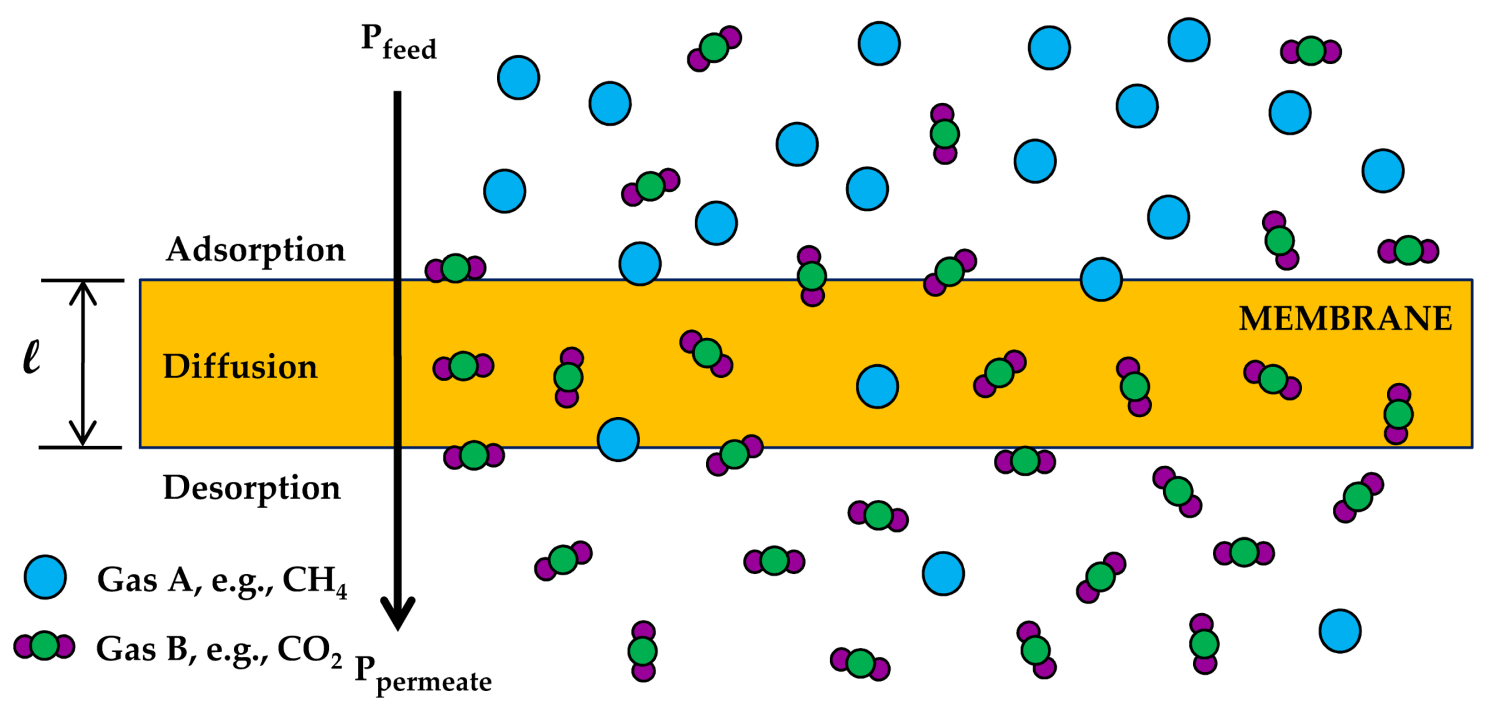

Figure 1. Gas transport in polymer membranes according to the solution-diffusion model showing the adsorption, diffusion, and desorption of the gas molecules through a membrane with thickness $l$.

Several mathematical expressions have been developed to describe gas transport in different types of membranes. For example, in a dense polymer membrane, gas transport is described by the solution-diffusion model (1) that combines the solubility (S) and diffusivity (D) properties of the gases in the membrane to calculate their permeability $(\mathrm{P})$ [23-28]. A good discussion of how to calculate diffusivity and the interpretation of the units for permeability can be found in the work of H. Yasuda [29].

$$
\mathrm{P}=\mathrm{S} \times \mathrm{D},
$$

In this model, the gases are adsorbed on the high-pressure side of the membrane, diffuse through the membrane with thickness $l$, and then desorb from the low-pressure side of the membrane. For these type of membranes, it can be inferred that to increase the selectivity $\left(\alpha_{\mathrm{A}} / \mathrm{B}=\mathrm{P}_{\mathrm{A}} / \mathrm{P}_{\mathrm{B}}\right)$ of a membrane for gas $\mathrm{A}$, the properties of the polymer membrane need to be modified to increase the diffusivity, the solubility, or both properties of gas $\mathrm{A}$ in the membrane. The strategy to be adopted depends largely on the physical properties of the gases. For example, if $\mathrm{H}_{2}$ is to be separated from $\mathrm{CO}_{2}$, keeping $\mathrm{CO}_{2}$ in the retentate side, then the best strategy is to increase the diffusivity of $\mathrm{H}_{2}$ in the 
membrane, taking advantage of its small size $(2.89 \AA)$ and low critical temperature $\left(-232.60{ }^{\circ} \mathrm{C}\right)$ (Table 1). To further improve this strategy, eliminating functional groups from the polymer that adsorb $\mathrm{CO}_{2}$ could reduce the solubility of $\mathrm{CO}_{2}$ in the polymer.

The potential application of membranes to gas separations has become an important technological advance in recent years owing to their reduced energy consumption and ease of operation when compared to traditional separation processes (e.g., cryogenic distillation, pressure and temperature swing adsorption, amine absorption, etc.), which are typically energy intensive processes. The simplicity of a membrane-based gas separation plant results in a footprint smaller than that required for other separation processes, making it an attractive alternative. A variety of industrial, energy, and environmental membrane-based gas separation applications have been targeted, some already at the industrial scale. Separations such as $\mathrm{H}_{2} / \mathrm{N}_{2}, \mathrm{H}_{2} / \mathrm{CO}_{2}, \mathrm{He} / \mathrm{H}_{2}, \mathrm{CH}_{4} / \mathrm{CO}_{2}, \mathrm{~N}_{2} / \mathrm{CO}_{2}, \mathrm{O}_{2} / \mathrm{N}_{2}$, $\mathrm{NH}_{3} / \mathrm{H}_{2} / \mathrm{N}_{2}, \mathrm{~N}_{2} / \mathrm{CH}_{4}, \mathrm{C}_{3} \mathrm{H}_{6} / \mathrm{C}_{3} \mathrm{H}_{8}$ [11], $\mathrm{C}_{3} \mathrm{H}_{8} / \mathrm{N}_{2}$ [5], $\mathrm{C}_{3} \mathrm{H}_{6} / \mathrm{C}_{3} \mathrm{H}_{8} / \mathrm{N}_{2}$ [12], and $\mathrm{C}_{2} \mathrm{H}_{4} / \mathrm{C}_{2} \mathrm{H}_{6}$ [8,9], and other organic vapors [30-50] are some examples of where membranes could be employed to provide a cost effective separation process [51,52]. Owing to the nature of membranes as barrier materials, the operating conditions required in industry to separate a particular gas mixture impose constraints and challenges on the materials and manufacturing processes required for a membrane to be successfully used in industry. These limitations, however, open the possibility for improvements in the preparation and selection of materials for the fabrication of membranes resulting in a variety of membrane types as shown in Figure 2.

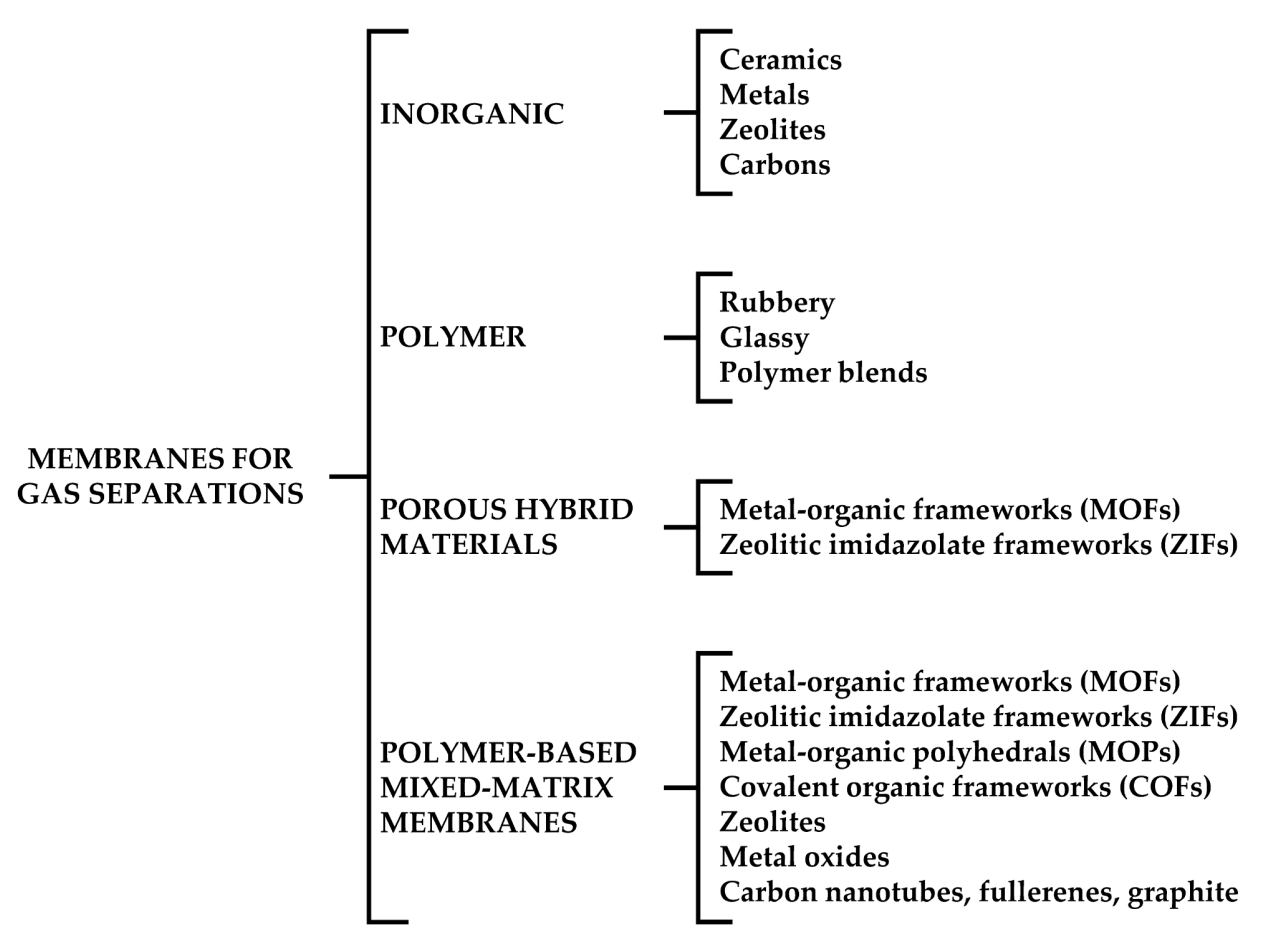

Figure 2. Types of membranes for gas separations and the materials used for their fabrication.

Inorganic membranes have been investigated extensively due to their high selectivity and flux. Unfortunately, these membranes are difficult to fabricate and are prone to mechanical failure. Polymer membranes, on the other hand, are more processable into different geometries (e.g., flat, spiral, hollow fiber) than inorganic membranes, but offer limited selectivity and flux. The advent of porous hybrid materials or MOFs presented a unique opportunity to tune the separation properties of the membranes by chemically modifying the organic component of the MOF by incorporating functional or bulky groups in the walls of the MOFs. This enabled control of the pore aperture of the MOF to perform molecular sieving. A pure MOF membrane, however, would still need a support 
on which to crystallize to form a continuous layer and, as in the case of molecular sieve membranes, the fabrication process is complicated and sensitive to synthesis conditions. A new type of membranes with the potential of producing a breakthrough is the mixed-matrix matrix membranes or MMMs. This membrane combines a polymer with different types of additives (generally one of the materials listed in Figure 2) with the aim of marrying the processability of the polymer matrix with the separation properties of the additive. These membranes simplify the fabrication process because they do not require the formation of a continuous layer of the additive to perform the separation. MMMs also allow for the testing of materials that cannot form continuous layers or are too brittle to form mechanically stable films. Although MMMs can be fabricated into different membrane geometries (e.g., flat, spiral, tubular, hollow fiber), their preparation and effectiveness is limited to the compatibility of the polymer and the additive. Early attempts to introduce porous inorganic additives (mostly zeolites) resulted in the formation of non-selective voids at the additive/polymer interface that degraded the separation properties of the membranes. Another problem this type of membrane faces is the limited loading of the additive in the matrix that can be achieved before agglomeration, non-selective voids (i.e., sieve in a cage), or defects are present in the membrane (Figure 3) [53,54]. Therefore, the combination of MOFs and polymers for the preparation of MMMs for gas separations has resulted in a natural step aiming to exploit the organic character of MOFs to improve interfacial compatibility.

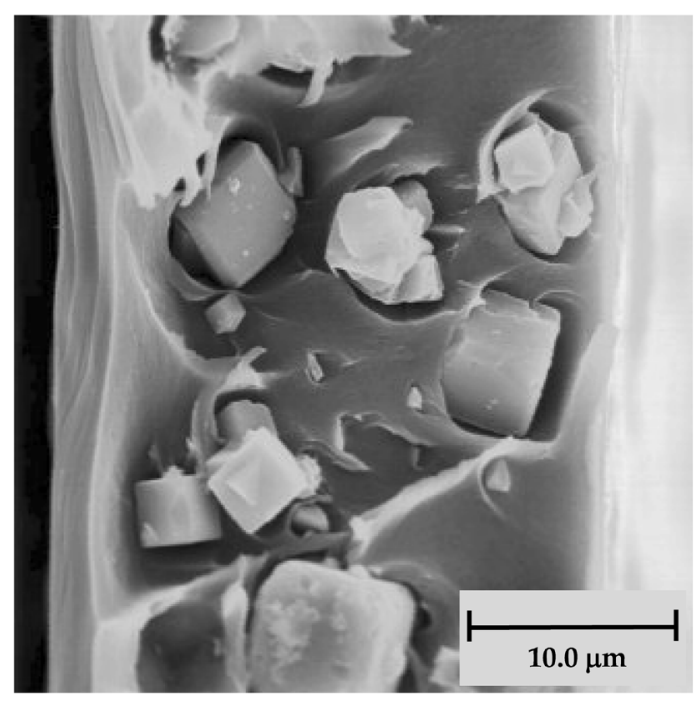

Figure 3. Non-selective voids at the zeolite $4 \mathrm{~A} / \mathrm{Ultem}^{\mathrm{TM}}$ mixed-matrix membranes (MMM) interface formed by incompatibilities between the inorganic and organic materials (sieve in a cage) [53]. Adapted with permission from [53]. Copyright, 2007, Wiley.

Since a MMM is a blend of inorganic or hybrid organic-inorganic particles (additive) with a polymer, the fabrication techniques are similar to those of conventional polymeric membranes. First, by using one of the mixing procedures shown in Figure 4, a homogenous solution of the additive and the polymer is prepared [55]. To prepare the membranes, five fabrication techniques have been used (Figure 5) [56]: solution-casting, dry phase inversion, wet phase inversion, dry/wet phase inversion, and thermally induced phase separation [57-60]. The simplest and most common technique is the solution-casting method for small scale and laboratory membrane fabrications. In this technique, the dope solution containing the inorganic additive is evenly spread on a uniform substrate with the aid of a knife or a doctor blade to form a uniform film. Then, the solvent (s) is evaporated to obtain a thin film. This simple technique can be used to obtain crystalline and isotropic membranes. The phase-inversion methods are commonly used for the preparation of asymmetric membranes (e.g., hollow fibers). In the dry phase inversion technique, the membrane is exposed to air during the evaporation of the more volatile solvent (vs) whereas in the wet phase inversion the membrane is 
directly immersed in a non-solvent (ns) coagulant as a result of having the spinneret or casting knife immersed in the coagulation bath. In the dry/wet phase inversion technique or the Loeb-Sourirajan technique, the membranes are exposed to air to form the selective layer first and then immersed in a coagulation bath to form the support for the membrane [56]. In the thermally induced phase separation technique, a phase inversion is induced by lowering the temperature of the solution. For this technique to work, the solvent should be miscible with the polymer at high temperatures but not at low temperatures.

This review describes the initial work in the preparation of MMMs and the evolution and innovations of MOF-based MMMs since the first MOF MMM was reported in the open literature. Advances and new theories to understand the interfacial and gas transport properties of MOF MMMs are presented along with their gas separation properties.

a)

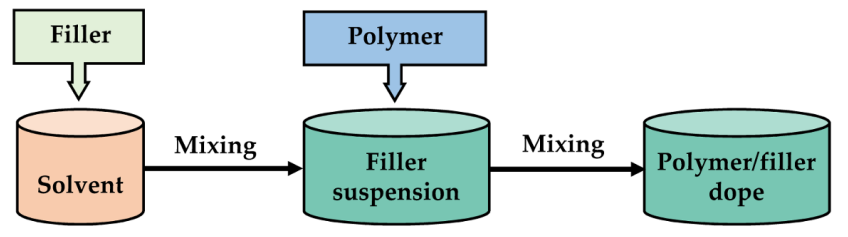

b)

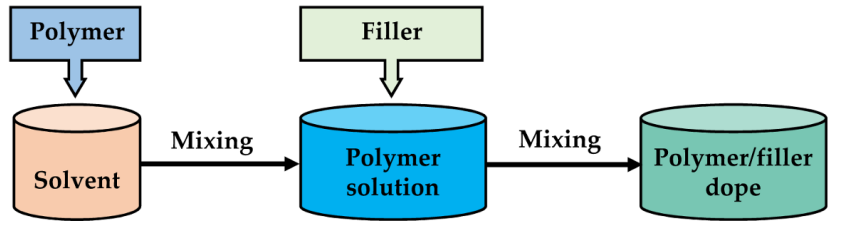

c)

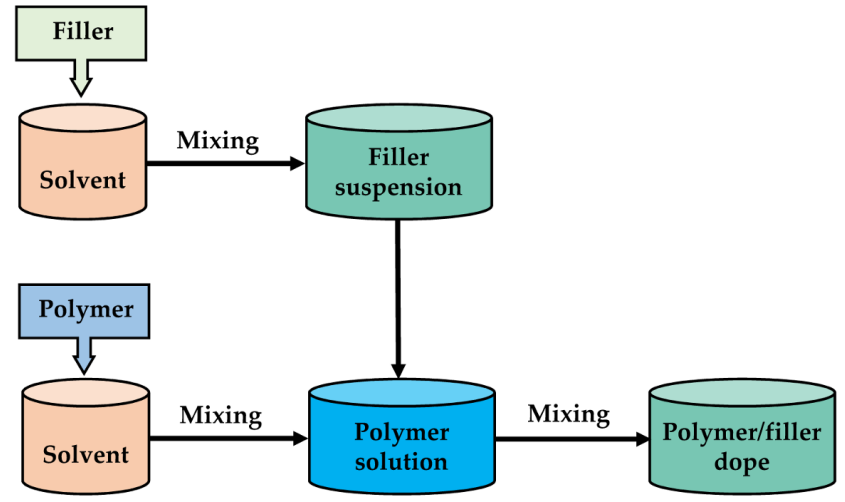

Figure 4. Methods for MMM solution preparation: (a) Polymer added to additive dispersion; (b) additive added to polymer solution; (c) mixing of additive suspension and polymer solution. Adapted with permission from [55]. Copyright, 2010, Elsevier. 
a)

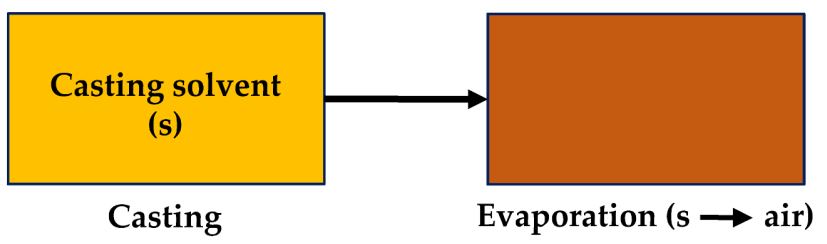

b)

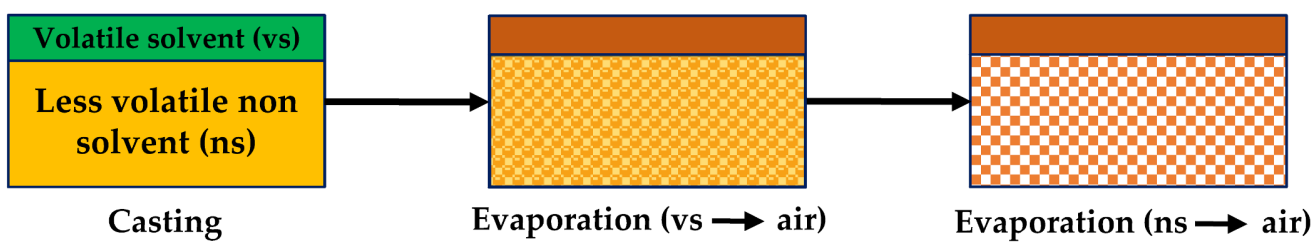

c)

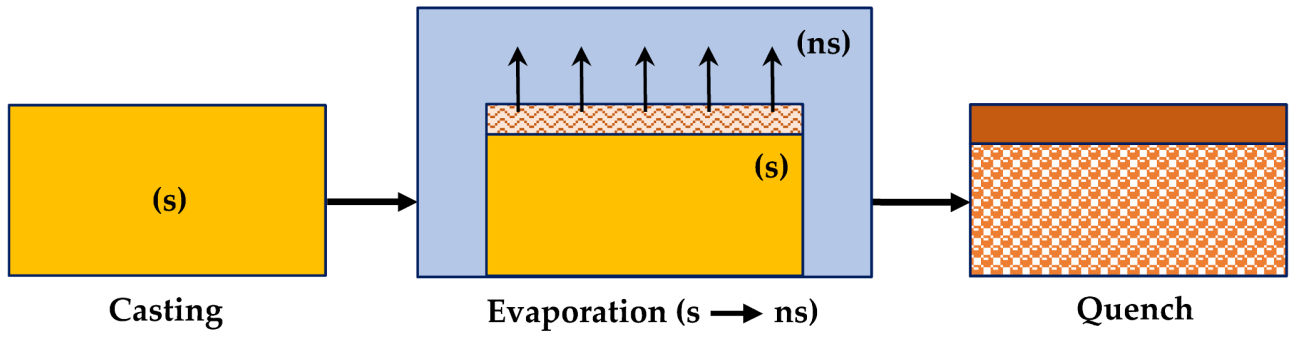

d)

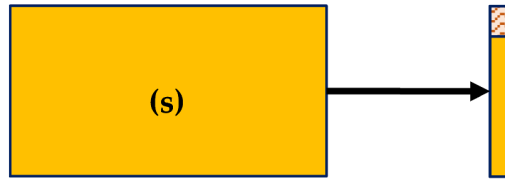

Casting
Evaporation (s $\rightarrow \mathrm{ns}$ )
Quench (s)

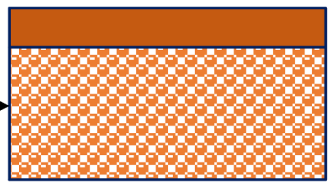

Quench

e)

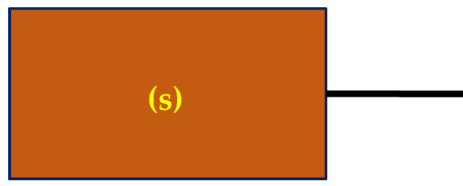

Casting (hot)
Evaporation (s $\rightarrow$ air)

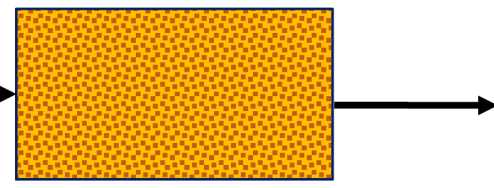

Quench (cold)

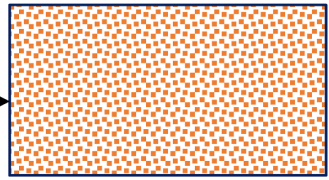

Solvent removal

Figure 5. Techniques for membrane fabrication: (a) solution casting; (b) dry phase inversion; (c) wet phase inversion; (d) dry/wet phase inversion; and (e) thermally induced phase separation [56].

\section{Origins of Inorganic-Based and MOF-Based MMMs}

\subsection{Membrane History}

The early history of membrane development was well documented in the dedicated volume to the history of membrane science in volume 100 of the Journal of Membrane Science in 1995 [61] and in the work of Bödderek $[62,63]$ about the history of membranes. In these articles, the most significant contributions to the development of membranes from 1748 to 1917 have been compiled and in some cases translated.

The earliest observations of the properties of a membrane can be traced back to experiments with pig bladders that covered flasks reported by J. A. (Abbé) Nollet in $1748[64,65]$ and the observations of de la Hire in 1688 and R. A. de Reaumur in 1714 mentioned in Nollet's work. In Nollet's own words, "I shall end this report with a description of a phenomenon that I discovered by chance, and which at first struck me as being as particular as the lowering of mercury to below its own level", the permeation phenomenon was discovered by chance when Nollet observed that pig bladders allowed water to permeate into a flask when it was immersed in a water bath. Through a series of experiments with water and 
ethanol, he observed that the bladder only allowed water to permeate but not ethanol. Later on, in 1827, R. J. H. Dutrochet used the term osmosis to describe the diffusion of liquids (endosmosis and exosmosis) across a permeable partition (membrane) that he observed. In one experiment in which pure water and albumen were separated by a membrane, Dutrochet observed that water crossed the membrane and mixed with the albumen with which it would not mix in the absence of the membrane [66,67]. Dutrochet attributed this endosmotic/exosmotic phenomenon to a phenomenon other than the affinity between the liquids since he previously observed that albumen and pure water do not mix when water is poured in a glass containing albumen. Based on the observations of Becquerel on the generation of electricity when liquids are in contact with solid materials, Dutrochet attributed the phenomenon of osmosis to electricity and rationalized that the contact of the liquids with the membrane generated electricity, " ... although I admit that I did not succeed in obtaining a reading on the galvanometer ..." Dutrochet stated. As a side note, Dutrochet used endosmosis and exosmosis in reference to the flows that occur in hollow organs made of organic tissue [66,67]. Then, T. Graham, in 1829 , described briefly the concept of the solution-diffusion mechanism of gas transport across a pig bladder [23,24]. T. Graham observed that when a partially filled bladder with coal gas (methane) or air was enclosed in an atmosphere of carbonic acid $\left(\mathrm{CO}_{2}\right)$ over water, the bladder would expand significantly. This phenomenon, however, was not observed when the bladder was partially filled with methane and enclosed in an atmosphere of air over water. T. Graham then theorized that $\mathrm{CO}_{2}$ was solubilized in water in the outer sides of the capillary canals of the bladder in contact with water and then permeated through the canals to later rise into the air or methane in the bladder, this may have been the basis for his solution-diffusion model to explain gas transport in polymer membranes he stated years later in 1866. Two years later in 1831, J. K. Mitchell described the different rates of permeation of several gases through animal and rubber membranes [68,69]. His initial observations came from floating rubber balloons filled with hydrogen that descended after a few days. This led him to believe that the gas escaped the balloons by permeating through the dense walls of rubber. With this knowledge, he performed permeability experiments with several gases and sorted the gases according to their relative facility of transmission: $\mathrm{NH}_{3}>$ sulphuretted hydrogen $\left(\mathrm{H}_{2} \mathrm{~S}\right)>$ cyanogen $\left(\mathrm{CN}_{2}\right)>$ carbonic acid $\left(\mathrm{CO}_{2}\right)>\mathrm{N}_{2} \mathrm{O}>$ arsenuretted hydrogen $\left(\mathrm{AsH}_{3}\right)>$ olefiant gas $\left(\mathrm{C}_{2} \mathrm{H}_{4}\right)>\mathrm{H}_{2}>\mathrm{O}_{2}>$ carbonic oxide $(\mathrm{CO})>\mathrm{N}_{2}$, an impressive feat considering the toxicity and flammability of the gases tested, how the apparatuses were assembled, and the conditions at which the experiments were performed (Figure 6).
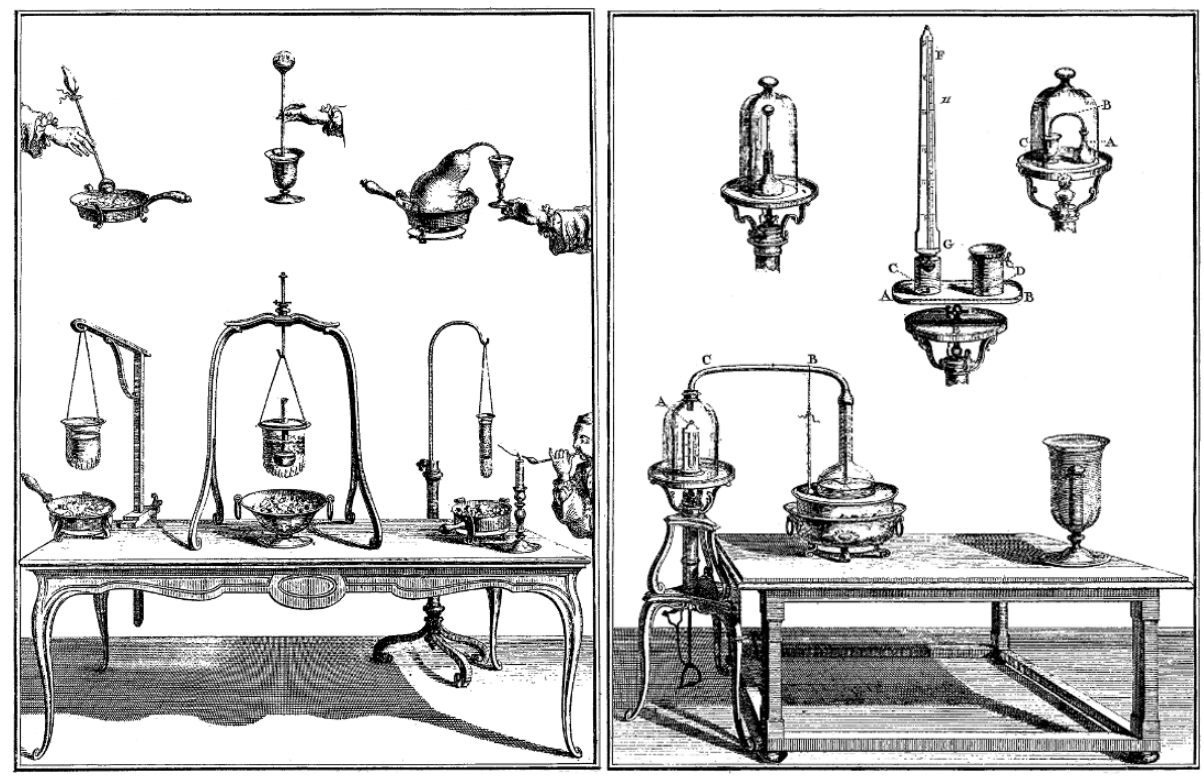

Figure 6. Nollet's illustrations of experimental setups and apparatuses for the study of water and ethanol permeation in pig bladders [64]. 
Another two years passed, and T. Graham in 1833, published his work "On the diffusion of gases" in which he states his famous law of the diffusion of gases [70-73]. Working on the observations made by Doebereiner on the escape of hydrogen through a fissure or crack in glass receivers, Graham performed experiments to measure the rate of mixing of hydrogen and other gases with air when the gas diffused through a plug made of plaster, from which he was able to deduce that the rates at which gases diffuse are inversely proportional to the square root of their densities. The next major development came in 1855 when A. Fick published his work on the diffusion of salts in water that led him to develop a fundamental law to describe diffusion (Fick's diffusion law) [74-76]. Although Fick developed this law, his work followed Graham's extensive work on the diffusion of salts in water that was published years before, in Fick's own words: "A few years ago Graham published an extensive investigation on the diffusion of salts in water... It appears to me a matter of great regret, however, that in such an exceedingly valuable and extensive investigation, the development of a fundamental law, for the operation of diffusion in a single element of space, was neglected, and I have therefore endeavoured to supply this omission." Additional important progress in membrane science came a few years later, in 1866, from T. Graham's work, "On the absorption and dialytic separation of gases by colloid septa" [25-27]. Graham performed permeability tests (penetration of rubber by gases) with several gases using a simple glass tube 1 inch in diameter capped on one side with a thin plate of stucco that acted as a porous support for a rubber membrane that was placed and secured on top of it. The apparatus (diffusiometer) was then filled with mercury and inverted to create vacuum, and the membrane was exposed to air or other gases (e.g., $\mathrm{H}_{2}, \mathrm{CO}_{2}, \mathrm{O}_{2}, \mathrm{~N}_{2}$, $\mathrm{CH}_{4}, \mathrm{CO}$ ). From the rates of the depression of the mercury column, T. Graham was able to postulate that the gases had to first condense or liquefy in the membrane due to chemical affinity with the membrane, diffuse, and later be converted into the gaseous form at the vacuum side of the membrane, the very solution-diffusion mechanism that is still used today to explain gas transport in polymer membranes. In the following years, more important developments were made by S. Wroblewski, who in 1879 studied the solubilities of gases in rubber [77], by J. H. van't Hoff's work in 1887 that introduced the idea of semipermeable membranes [78-81], and by S. L. Bigelow and A. Gemberling in 1907 with the preparation of synthetic "collodion" membranes made of pyroxylin (nitrocellulose) [82,83], the first non-rubber artificial membrane. In 1909, continuing on the works of A. Kundt [84], E. Warburg [85], and C. Christiansen [86] on the flow of gases through very narrow channels, M.H.C. Knudsen stated that viscous or molecular flow is achieved depending on the length of the mean free path of the gas and the dimensions of the channels through which the gas diffuses $[87,88]$. Another significant advance was made by F. G. Donnan in 1911 with his observations on the diffusion of ions in solution (water solutions of Congo Red sodium salt and sodium chloride) through parchment paper that gave rise to ion exchange membranes $[89,90]$ and the development of electrodialysis. An important development in the area of membranes, specifically for MMMs, was made by F. Steinitzer in 1912 with his studies of the adsorption and permeation of $\mathrm{CO}_{2}$ in rubbers compounded with mineral matter [91], probably the first gas permeation work with mixed-matrix membranes. Five years later, in 1917, P. A. Kober introduced the concept of pervaporation to describe the evaporation of water through a membrane upon the observation made by his assistant, C. W. Eberlein, that a liquid in a sealed "collodion bag" had evaporated [92,93]. Later on, in 1920, J. D. Edwards and S. F. Pickering concluded that the permeability (flux) of any gas was proportional to its partial pressure and that rubber membranes age with time and exhibit reduced permeabilities to gases [94]. This surprising early detection of membrane aging came from their gas permeation studies that compared permeabilities of fresh rubber films with films stored for up to 1 year. Although chemical aging along with physical aging may have also played a significant role in the increased brittleness and reduced permeability of their membranes, the association of decreased permeability to membrane aging was a significant observation that is still used these days to explain permeability reductions in membranes. A more rigorous analysis of the cause and effects of membrane aging would come 40 years later from the works of A. J. Kovacs (1963) [95], K. H. Illers (1969) [96], S. E. B. Petrie $(1972,1976)$ [97,98], L. C. E. Struik (1978) [99], and M. R. Tant (1981) [100,101] where it is extensively described that the properties of a polymer in the glassy state (e.g., permeability, 
free volume, enthalpy, entropy, mechanical strength) change over time and strongly depend on the thermal history of the polymer (e.g., finite rate of cooling from drying or annealing temperatures to glassy state). The result of the thermal treatment is the quenching of the polymer into a non-equilibrium conformation due a decrease in molecular mobility during the transition to the glassy state in the time frame of cooling. The effects of membrane aging on gas permeability reduction could be significant as seen in Figure 7 where $\mathrm{CO}_{2}$ permeability in PVAc at $10^{\circ} \mathrm{C}$ and $0.13 \mathrm{~atm}$ was measured at different time intervals for 20 days [102]. An interesting critical review about membrane aging that expands and complements this topic was published by D. Cangialosi, et al. in 2013 [103]. In this review the authors list the methods used to monitor physical aging and probe polymer segmental mobility and discuss the variations in the degree of aging by the presence of inorganic fillers in polymer nanocomposites, among other topics related to membrane aging.

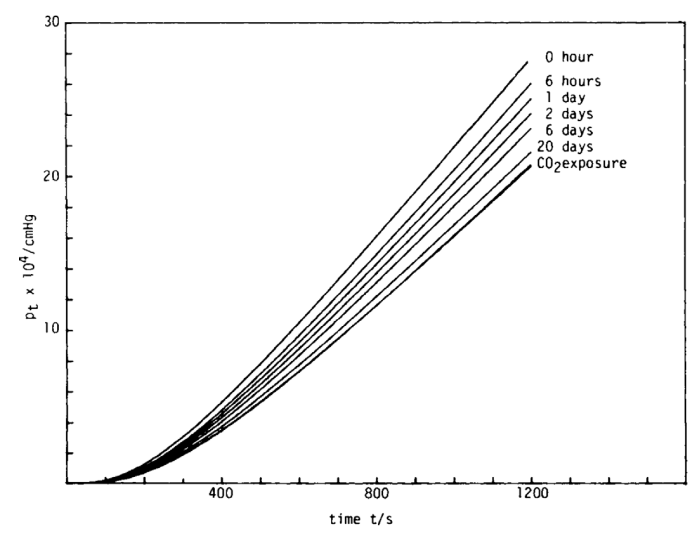

Figure 7. Time dependence of physical aging on the permeability of $\mathrm{CO}_{2}$ in polyvinyl acetate (PVAc) at $10^{\circ} \mathrm{C}$ and 0.13 bar. Reproduced with permission from [102]. Copyright, 1985, Wiley.

Back in 1920, H. A. Daynes introduced the concept of "time lag" (2) to express the time it takes for gases to achieve steady state (Figure 8) when permeating through a rubber membrane of thickness $l$ [104]. Note that the $y$ axis in Figure 8 represents the response (deflexion) of a galvanometer that measured the current from a katharometer (TCD detector) that was used to detect the flow of gases (hydrogen in Daynes' experiments) in the permeate side of the membrane. The aim was to separate the solubility component from diffusivity using permeability data. By relating the time lag (L) to the diffusivity (K), he succeeded in calculating the solubility and diffusivity constants from permeability data.

$$
\mathrm{L}=l^{2} / 6 \mathrm{~K},
$$

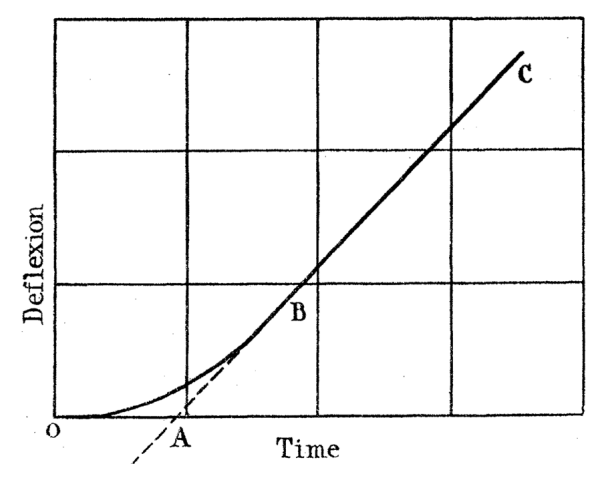

Figure 8. Dayne's time lag (OA) measurement from permeability data at the steady state (BC) in a rubber polymer [104]. 
The chronological listing of these advances and other significant progress in the field of membrane science is shown in Figure 10 at the end of this section.

\subsection{Mixed-Matrix Membrane Origins}

One of the first references of gas permeation in membranes that contained additives can be traced back to F. Steinitzer in 1912 with his work on $\mathrm{CO}_{2}$ adsorption and permeation through rubber materials containing mineral matter [91]. Although the membranes Steinitzer used were not identified as MMMs, their composition, up to $58.60 \%$ mineral matter in rubber, resembles what is known today as an MMM. Subsequent work by C.S. Venable, et al. in 1922 on the solubility of gases in rubber containing $\mathrm{ZnO}$ and sulfur provided more accurate information from direct measurements of gas solubility [105]. Their work was motivated by the rapid development of rubberized balloon fabric that in those days led to the study of the factors influencing the gas transport of gases in rubber. In 1929, T. Ohya, et al. performed a more extensive study on the permeability of $\mathrm{H}_{2}$ through compounded rubber looking for a rubber/additive combination that would reduce the diffusion of $\mathrm{H}_{2}$ [106]. In his work, Ohya added $\mathrm{ZnO}$, clays, carbon black, and softeners to rubber and performed permeability tests that yielded unwanted results: $\mathrm{H}_{2}$ diffused faster in the compounded rubber than in pure rubber. Then, in 1931, V.N. Morris performed similar experiments with air [107]. His goal was to study the effects of several fabrication parameters (milling, thickness, stretching, nature of crude rubber, vulcanization temperature, and the addition of fillers to rubber) on the diffusion of air through rubber with the potential application of inner tubes for car wheels. Morris found results contradictory to Ohya's. When adding $\mathrm{ZnO}$ to rubber, his results showed a decrease in air's permeability through the membrane as the loading of $\mathrm{ZnO}$ increased from $5 \%$ to $20 \%$. In an effort to explain the discrepancies between his results and Ohya's results when pigments were added to rubber, Morris introduced the possibility that aggregation of the additive could be making the membrane thinner in some regions thus increasing the permeability of the membrane. Extending on previous works on gas solubility in filled rubbers, G. J. Van Amerongen in 1955 performed an extensive study on the effects of fillers in gas permeation and sorption aiming to reduce the permeability of gases in rubber [108]. His findings indicated that lamellar fillers (e.g., mica, graphite, bentonite, alumina) were better in slowing the diffusion of gases than ordinary fillers (e.g., carbon blacks, iron oxide, barium sulfate). By 1959, N. A. Melikhova, et al. performed a series of nitrogen permeability experiments with natural and synthetic rubbers (e.g., sodium-polybutadiene, butadiene-styrene, butadiene-acrylonitrile) filled with minerals (e.g., ground mica, aluminum powder, silica, lamp black, channel black, kaolin) with loadings up to $20 \%$ by volume [109]. From permeability and time lag data, diffusivity and solubility values were calculated for each membrane, aiming at obtaining enough information to elucidate the nature of the interaction of synthetic rubbers with fillers and to estimate their effects on gas permeation. Results indicated that all membranes exhibited a reduction in permeability as the filler content increased. The results also indicated that the interactions were more complex than expected and depend on several factors, the volume of the filler in the membrane, the strength of the filler/rubber interactions, the wettability of the fillers by the rubber, and the shape, size, and orientation of the fillers. A key conclusion is that the filler should have a strong interaction with the rubber in order to control the permeation of gases. In 1971, G. Christen, et al. made significant progress in membrane preparation by introducing zeolites in polymers as was described in his patent [110]. G. Christen prepared mordenite/PDMS heterogeneous membranes (mixed-matrix membranes) and tested them in $\mathrm{O}_{2} / \mathrm{N}_{2}$ separations achieving a selectivity of 3.6 (Knudsen selectivity $=0.93$ ). This is probably one of the first membranes containing porous fillers reported in the open literature that stimulated the development of zeolite-based MMMs for the next 45 years. By 1973, D. R. Paul and D. R. Kemp recognized the effect that zeolites would have in gas adsorption in zeolite/polymer membranes by immobilizing gas molecules in the membrane and therefore increasing the time lag [111,112]. By adapting their work on gas diffusion, using Henry's law to describe the adsorption of mobile species, and utilizing Langmuir sorption to describe sorption of the immobile species, they developed a modified time lag 
model for gas transport in the transient state (i.e., before reaching the steady state), useful for the determination of diffusivity in zeolite/polymer membranes and in barrier membranes for coatings and packaging materials [113]. In 1987, H. J. C te Hennepe, et al. reported on pervaporation experiments with silicalite/silicone rubber membranes with loadings up to $60 \%(w / w)$ [114]. In this work, silicalite was used as an alcohol-selective sieve to improve the membrane's alcohol (e.g., methanol, ethanol, propanol) separation from water, achieving $\mathrm{R}-\mathrm{OH} / \mathrm{H}_{2} \mathrm{O}$ selectivities of 38.3 with increasing silicalite loadings. The conclusion was that the zeolite particles were well coated by the polymer, and as the zeolite loading increased, the water molecules encountered a more tortuous path since they had to diffuse around the zeolites. A similar work was reported in 1988 by S. Kulprathipanja, et al. in patents for the separation of monosaccharides from polysaccharides in water solution using zeolite/cellulose acetate membranes $[115,116]$. This is one of the first reports that describes these membranes as mixed-matrix membranes. In a second patent, the utilization of this type of membrane (i.e., zeolite/polymer) was extended to fluids, either liquids or gases. The new patent also encompassed a larger variety of polymers (e.g., polysulfones, polycarbonates, polyethers, and polyamides) and additives (e.g., inorganic carbons, ion-exchange resins, silicalites, and aluminosilicates). In 1991, L. M. Robeson proposed an empirical limit on the permeability-selectivity tradeoff he observed when plotting permeability and selectivity data of several polymer membranes in a logarithmic plot [117,118]. Robeson realized that all polymer membranes lay below an imaginary bound that became known as Robeson's upper bound against which the performances of membranes are compared (Figure 9). By 2000, Mahajan, et al. addressed the problems encountered with the dispersion of zeolites in polymers [119]. Starting with the priming of zeolites through the addition of a small amount of the polymer solution to disperse the zeolites, the authors in this work suggest using polymers with selectivity-permeability properties close to the upper bound to match the transport properties of the materials and to promote polymer adsorption onto the surface of the sieve in order to achieve maximum performance. The use of zeolites in MMMs for gas separations proved to be promising but the low affinity of the polymer for the inorganic additive motivated the search for additives that were more compatible with the polymer matrix. The search for these materials lead to the dawn of the MOF-based mixed-matrix membranes.

In 2004, H. Yehia, et al. reported the first work on the use of porous hybrid materials (MOFs) in mixed-matrix membranes for gas separations using a copper-based MOF and a rubbery polymer (PAET) [120]. This MMM was loaded with up to $30 \%(w / w)$ MOF crystals and was tested for $\mathrm{CH}_{4} / \mathrm{CO}_{2}$ separations with promising results. A year later, in 2005 , $\mathrm{Li}$, et al. studied the interactions between porous additives and polymers and reported on their gas permeation experiments with zeolites 3A, 4A, 5A/PSf MMMs [121]. They concluded that polymer rigidification and partial pore blockage of the zeolite by the polymer chains occurred on the surface of the zeolite and resulted in a decrease in gas permeation with increasing zeolite loading. By 2006, A. Car, et al. prepared $\mathrm{Cu}(\mathrm{BTC})_{2}$ and $\mathrm{Mn}(\mathrm{HCOO})_{2} \mathrm{MOFs}$ that were used in conjunction with PSf and PDMS in the preparation of MMMs [122]. They reported mixed results for permeability and selectivity. The same year, E. V. Perez, et al. incorporated for the first time nanocrystals of a MOF (MOF-5) into Matrimid ${ }^{\circledR}$, a polyimide with high $\mathrm{T}_{\mathrm{g}}$ [123]. Their MMMs showed improved gas permeation with increased MOF loadings.

Three years later, in 2009, E. V. Perez, et al. reported on their extensive work on MOF-based MMMs for gas separations showing improved dispersion of MOF nanocrystals and strong interactions between the MOF and the polymer that were attributed to the presence of organic components in the MOF [124-126]. Gas transport in these MMMs improved with increased loadings, bringing the membranes to or above the upper bound. In 2010, T.-H. Bae, et al. prepared the first ZIF-based MMM incorporating ZIF-90 into Ultem ${ }^{\mathrm{TM}}$, Matrimid ${ }^{\circledR}$, and 6FDA-DAM [127]. A few years later, in 2015, E. V. Perez, et al. reported that they had successfully tested (Al) $\mathrm{NH}_{2}-\mathrm{MIL}-53 / \mathrm{VTEC}^{\text {TM }}$ MMMs at pressures up to 30 bar and $300{ }^{\circ} \mathrm{C}$, achieving $\mathrm{H}_{2} / \mathrm{CO}_{2}$ mixture selectivities of 8 [128]. The chronological progress for MMMs is shown in Figure 10. 


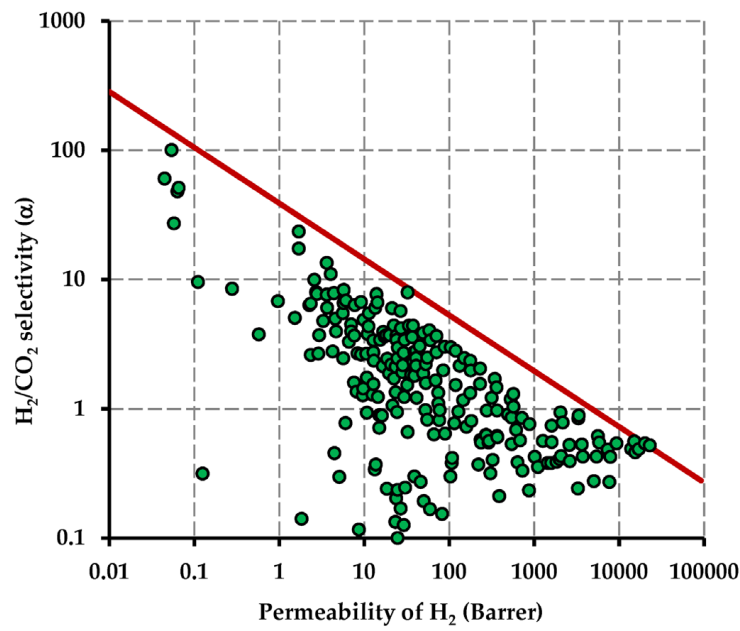

Figure 9. Updated (2008) Robeson's upper bound for $\mathrm{H}_{2} / \mathrm{CO}_{2}$. The $x$-axis corresponds to the most permeable gas. Adapted with permission from [118]. Copyright, 2008, Elsevier.

\begin{tabular}{|c|c|c|}
\hline Progress in membrane science until 1899 & Year & Contributors \\
\hline First observations of permeation phenomena with water & 1748 & M. l'Abbé Nollet [64,65] \\
\hline $\begin{array}{r}\text { Osmosis introduced to explain the diffusion of liquids across } \\
\text { permeable partitions (membranes) }\end{array}$ & 1827 & R. J. H. Dutrochet $[66,67]$ \\
\hline Solution-diffusion concept describing gas transport & 1829 & T. Graham $[23,24]$ \\
\hline Rate of permeation of gases through membranes & 1831 & J. K. Mitchell $[68,69]$ \\
\hline Graham's law of gas diffusion & 1833 & T. Graham [70-73] \\
\hline Fick's law of diffusion (diffusion of salts in water) & 1855 & A. Fick [74-76] \\
\hline Solution-diffusion model for gas transport in membranes & 1866 & T. Graham [25-27] \\
\hline Solubility of gases in rubber & 1879 & S. Wroblewski [77] \\
\hline Concept of semipermeable membranes & 1887 & J. H. van't Hoff [78-81] \\
\hline Progress $1900-1999$ & Year & Contributors \\
\hline Preparation of synthetic non-rubber membranes: cellulose nitrate & 1907 & S. L. Bigelow, et al. $[82,83]$ \\
\hline Knudsen diffusion & 1909 & M. Knudsen $[87,88]$ \\
\hline Ion exchange membranes & 1911 & F. G. Donan $[89,90]$ \\
\hline $\begin{array}{r}\mathrm{CO}_{2} \text { adsorption and permeability in mineral matter-compounded } \\
\text { rubber membrane (inorganic-based MMM) }\end{array}$ & 1912 & F. Steinitzer [91] \\
\hline Pervaporation & 1917 & P. A. Kober $[92,93]$ \\
\hline $\begin{array}{r}\text { Effects of membrane aging on gas permeation and gas flux } \\
\text { proportional to partial pressure in the mixture }\end{array}$ & 1920 & J. D. Edwards, et al. [94] \\
\hline $\begin{array}{r}\text { Time lag concept to calculate solubility and diffusivity from } \\
\text { permeability }\end{array}$ & 1920 & H. A. Daynes [104] \\
\hline $\mathrm{CO}_{2}$ adsorption in compounded rubber with $\mathrm{ZnO}$ & 1922 & C. S. Venable, et al. [105] \\
\hline Permeability to $\mathrm{H}_{2}$ of compounded rubbers & 1929 & T. Ohya, et al. [106] \\
\hline Gas permeation with fillers: additive aggregation & 1931 & V. N. Morris [107] \\
\hline Solubility and permeability in rubbers filled with minerals & 1955 & G. J. Van Amerongen [108] \\
\hline Interaction of rubber with fillers and effects on gas permeation & 1959 & N. A. Melikhova, et al. [109] \\
\hline Zeolites in polymers & 1971 & G. Christen, et al. [110] \\
\hline Time lags in zeolite/silicone measuring solubilities & 1973 & D. R. Paul, et al. [111,112] \\
\hline Extensive research on zeolite/polymer membranes & 1987 & $\begin{array}{l}\text { H. J. C. te Hennepe, et al. } \\
{[114,129-132]}\end{array}$ \\
\hline Silicalite/cellulose MMMs & 1988 & $\begin{array}{l}\text { S. Kulprathipanja, et al. } \\
{[115,116]}\end{array}$ \\
\hline $\begin{array}{r}\text { Robeson's upper bound for selectivity-permeability correlations for } \\
\text { polymer membranes }\end{array}$ & 1991 & L. M. Robeson $[117,118]$ \\
\hline Progress 2000 to present day & Year & Contributors \\
\hline Factors controlling the successful formation of MMMs & 2000 & Mahajan, et al. [119] \\
\hline Cu-MOF/PAET MMMs for gas separations & 2004 & H. Yehia, et al. [120] \\
\hline $\begin{array}{r}\text { Effects of polymer rigidification, zeolite pore size, and partial pore } \\
\text { blockage on MMMs }\end{array}$ & 2005 & Li, et al. [121] \\
\hline $\mathrm{Cu}_{3} \mathrm{BTC}_{2} / \mathrm{PDMS}$ and $\mathrm{Mn}(\mathrm{HCOO})_{2} / \mathrm{PSf} \mathrm{MOF}-\mathrm{MMMs}$ & 2006 & A. Car, et al. [122] \\
\hline $\begin{array}{r}\text { MOF-5/Matrimid }{ }^{\text {MMMs for gas separations using MOF }} \\
\text { nanocrystals and polyimide }\end{array}$ & 2006 & E. V. Perez, et al. [123] \\
\hline MOF-5, Cu-MOF, MOP-18/Matrimid ${ }^{\circledast}$ MMs & 2009 & E. V. Perez, et al. [124-126] \\
\hline ZIF-90/Ultem ${ }^{\mathrm{TM}} /$ Matrimid $\circledast$ /6FDA-DAM MMMs & 2010 & T.-H. Bae, et al. [127] \\
\hline $\begin{array}{r}\mathrm{NH}_{2}-\mathrm{MIL}_{-53} / \mathrm{VTEC}^{\mathrm{TM}} \text { (MOF-based MMM) tested at high pressure } \\
\text { and high temperature }\left(30 \mathrm{bar} \text { and } 300^{\circ} \mathrm{C}\right)\end{array}$ & 2015 & E. V. Perez, et al. [128] \\
\hline
\end{tabular}

Figure 10. Chronological progress in mixed-matrix membrane science. 


\section{Evolution of Inorganic-Based MMMs}

Researchers in the membrane-based gas separation field have done extensive research to substitute polymeric for metallic membranes due to the gas separation limitations of polymeric membranes. Metallic membranes show good gas separation properties, including high gas pair selectivities and high gas permeabilities, whereas, in contrast to metallic membranes, polymeric membranes are mechanically robust. Due to these reasons, MMMs received more attention and review articles emerged describing the advances in inorganic-based MMMs [133-136].

The history of inorganic materials as additives for MMMs goes back to 1971 in a patent published by G. Christen, et al. The authors used synthetic/natural zeolites in polysiloxane membranes to separate $\mathrm{O}_{2}$ and $\mathrm{N}_{2}$ from air [110]. After this first report of MMMs incorporating zeolites, no other reports appeared until a patent was published in 1985 by Sterzel and Sanner on the use of a poly(tetrafluoroethylene) membrane containing the cobalt-salicylaldehyde-ethylenediamine complex as the inorganic filler. The $\mathrm{MMM}$ was used to separate a $\mathrm{O}_{2} / \mathrm{N}_{2}$ mixture [137]. A year later, in 1986, R. S. Drago, et al. studied the facilitated transport of $\mathrm{O}_{2}$ in polystyrene using Co(II) Schiff base complexes as additives for MMMs increasing $\mathrm{O}_{2}$ permeability [138]. After that, a patent was published in 1988 based on MMMs containing cellulose acetate and silicate particles at ambient conditions. These membranes were used to separate $\mathrm{O}_{2} / \mathrm{N}_{2}$ and $\mathrm{H}_{2} / \mathrm{CO}_{2}$ [115]. From 1988 to 2000, there was a slight increase in the use of MMMs having inorganic fillers for gas separations. In the last two decades, an extensive number of research studies were carried out on MMMs containing inorganic additives, primarily molecular sieving zeolites and metal oxides. Interest in carbon molecular sieve-based MMMs emerged in the 2000 to 2002 period [133,134].

\subsection{Zeolites Silicates and Metal Oxides in MMMs}

After the first report of silicate-containing MMMs in 1988, MMMs consisting of different ratios of polyethersulfone (PES) and zeolites 13X and 4A were reported in 1994 [139]. Permeabilities were recorded for $\mathrm{H}_{2}, \mathrm{~N}_{2}, \mathrm{O}_{2}, \mathrm{CO}_{2}$, and Ar. With a $50 \mathrm{wt} \%$ zeolite $13 \mathrm{X}$ loading, $\mathrm{O}_{2} / \mathrm{N}_{2}, \mathrm{Ar} / \mathrm{N}_{2}, \mathrm{CO}_{2} / \mathrm{N}_{2}$, $\mathrm{H}_{2} / \mathrm{N}_{2}$, and $\mathrm{CO}_{2} / \mathrm{O}_{2}$ ideal gas selectivities were $4.18,1.68,43.1,70.8$, and 10.4, respectively. Following the work carried out in 1994, Battal and co-workers were able to incorporate higher loadings of zeolite $4 \mathrm{~A}$ into the PES matrix by using a special fabrication procedure that included the evaporation of excess solvent under a $0.2 \mathrm{~atm}$ pressure of $\mathrm{N}_{2}$ at $60^{\circ} \mathrm{C}$ followed by annealing at $80^{\circ} \mathrm{C}$. For ideal gas experiments, the $\mathrm{H}_{2}$ permeability significantly increased with the incorporation of the zeolite, while the permeability values of the other gases increased slightly when compared to pristine PES. More importantly, this study was the first report of mixed gas experiments carried out on MMMs. With increasing the percentage of $\mathrm{H}_{2}$ and $\mathrm{CO}_{2}$ in the feed gas mixture, the permeabilities of $\mathrm{H}_{2}$ and $\mathrm{CO}_{2}$ increased [140]. In a research study carried out in 2000, the effect of zeolite particle size on the performance of polymer-zeolite MMMs was investigated. Zeolite silicates having particle sizes ranging from 0.1 to $8 \mu \mathrm{m}$ were used to investigate $\mathrm{CO}_{2}, \mathrm{O}_{2}$, and $\mathrm{N}_{2}$ permeabilities at $20 \mathrm{wt} \%$ and $40 \mathrm{wt} \%$ loadings. With increasing particle size, $\mathrm{CO}_{2}, \mathrm{O}_{2}$, and $\mathrm{N}_{2}$ permeabilities increased significantly. For example, permeability increased approximately from 2000 to 4000 Barrer when the particle size increased from 0.1 to $8 \mu \mathrm{m}$ [141].

There were just a handful of publications on inorganic material-based MMMs before 2001. However, the ten-year period from 2001 to 2010 turned out to be the emerging period for incorporating inorganic materials into MMMs for gas separation applications. Many publications and patents were published showing improved results for gas separations. Although higher permeabilities could be achieved by increasing the amount of inorganic material, the mechanical stability of the membranes was reduced. During this period, several different studies were carried out to address this issue by improving polymer-additive interactions in order to improve the mechanical characteristics of the respective MMMs. In one such study, the plasticizer di-butyl phthalate was used together with zeolite $4 \mathrm{~A}$ in a Matrimid ${ }^{\circledR}$ polymer matrix [142]. In addition to incorporating plasticizers, the membranes were formed at elevated temperatures to ensure the reactivity of the plasticizer and the polymer. 
As shown in Figure 11, the lower region of the membrane shows better contact between the zeolite particles and the polymer matrix.

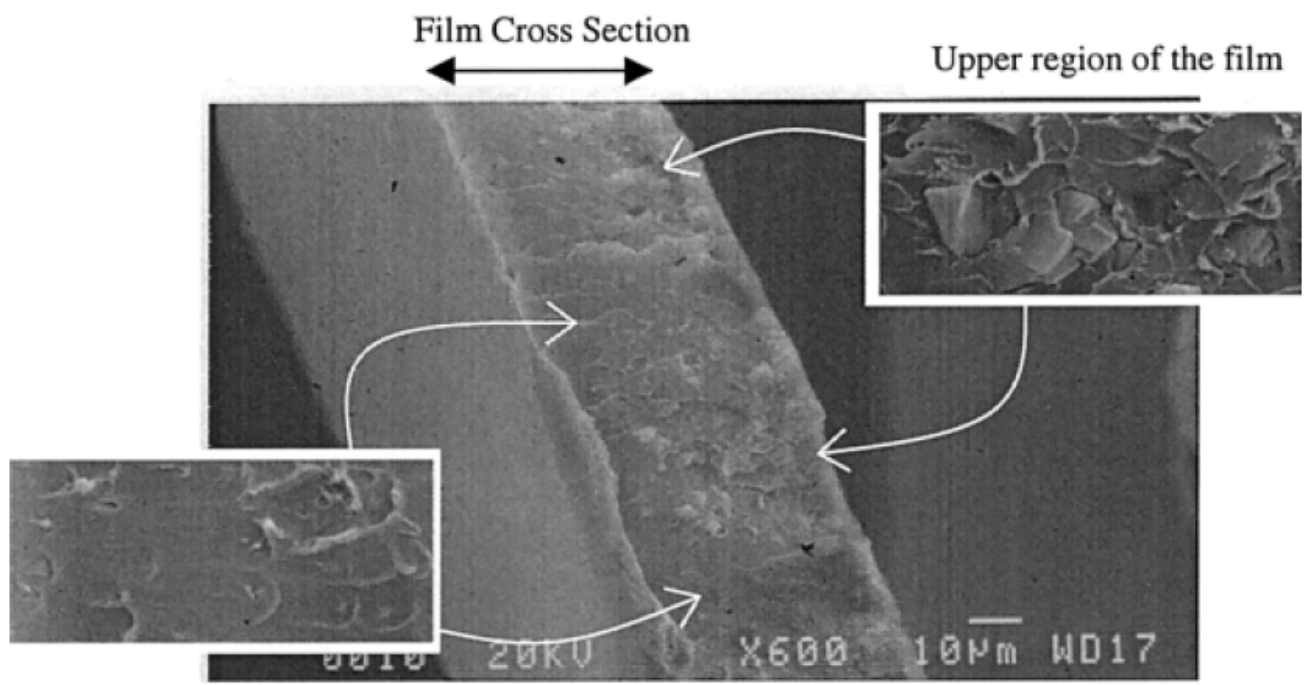

Lower region of the film

Figure 11. Scanning electron microscopy (SEM) image of the cross-section of a $75 / 25$ Matrimid $^{\circledR} /$ di-butylphthalate polymer blend with $15 \%$ zeolite 4 A. Reproduced with permission from [142]. Copyright, 2002, Wiley.

By 2002, T. C. Merkel, et al. reported the first reverse selective MMM using fumed silica as filler in PMP-2 for hydrocarbon separations [143]. The authors deduced that the fumed silica nanoparticles prevented a close packing of the chains which in turn increased the free volume of the polymer. The increase in free volume led to a decrease in diffusivity selectivity between larger and smaller molecules leaving the solubility selectivity to control gas transport in the MMM. Since larger molecules are more soluble than smaller molecules, larger hydrocarbons like $n$-butane would permeate faster than methane, as was seen in their permeability experiments. Based on the discovery made by T. C. Merkel, et al. a new theory was presented by R. J. Hill in 2006 [144]. The leading speculation in this work was based on the repulsive interactions between the non-porous additive and the polymer chains which results in free volume at the polymer-additive interface. As a result, the free volume of the entire system increases resulting in higher permeabilities for larger molecules over small molecules. These advances and the ability of additives to change drastically the gas transport properties of polymers propelled the research in the MMM field in the following years, extending into potential industrial applications for which the geometry of the MMM had to be changed from the traditional flat geometry to a hollow fiber to increase membrane area.

The use of hollow fiber membranes for gas separations emerged around 1973 [145]. Although many polymeric hollow fiber membranes were tested for gas separations, mixed-matrix hollow fiber membranes were not common mainly due to the challenges in fabrication. Mixed-matrix hollow fiber membranes were first reported in 2006 by Li, et al. who fabricated PES/BTDA-TDI/MDI co-polyimide (P84) hollow fibers with a $0.55 \mu \mathrm{m}$ PES-zeolite beta MMM dense, selective layer that showed good $\mathrm{CO}_{2} / \mathrm{CH}_{4}$ separation properties for pure gases $\left(\mathrm{CO}_{2} / \mathrm{CH}_{4}=29.2\right)$ and gas mixtures $\left(\mathrm{CO}_{2} / \mathrm{CH}_{4}=33.8\right)$. A very thin $(0.55 \mu \mathrm{m})$ PES-zeolite beta mixed-matrix dense selective layer was applied by manipulating the flow rates of the inner and outer layers during the spinning process. The interaction between the inner and the outer layer of the hollow fiber was improved through heat treatment at $235^{\circ} \mathrm{C}$ [146].

Researchers incorporated many different zeolites into polymers to produce useful MMMs for gas separation. In addition to these, some have modified the chemical structure of zeolites in order to improve gas separation properties. To further improve the characteristics of MMMs, a third component 
was sometimes added to the MMM mixture. Y. Zhang and co-workers were able to improve the permeabilities of gases, including $\mathrm{H}_{2}, \mathrm{~N}_{2}, \mathrm{O}_{2}, \mathrm{CH}_{4}$, and $\mathrm{CO}_{2}$, by $10 \%$ to $50 \%$ by combining carbon aerogel and zeolite in Matrimid ${ }^{\circledR}[147,148]$. According to the $\mathrm{N}_{2}$ adsorption data, the availability of combined micropores and mesopores improves the separation properties of these membranes. From SEM images of the cross-sections of the MMMs, the authors observed a good dispersion of the aerogel particles in the polymer which exhibited plastic deformation from the freeze fracture. Y. Zhang also performed mechanical analysis (stress-strain) of the MMMs to measure changes in Young's modulus and $\mathrm{T}_{\mathrm{g}}$, the resuls showed increased modulus from 2.4 GPa (Matrimid ${ }^{\circledR}$ ) to 2.7 GPa $\left(20 \% w / w\right.$ aerogel/Matrimid ${ }^{\circledR}$ MMM) and increased $\mathrm{T}_{\mathrm{g}}$ of the MMMs from $317{ }^{\circ} \mathrm{C}\left(\mathrm{Matrimid}^{\circledR}\right)$ to $338^{\circ} \mathrm{C}\left(20 \% w / w\right.$ aerogel/Matrimid $\left.{ }^{\circledR} \mathrm{MMM}\right)$. These mechanical properties improvements were attributed to the penetration of the polymer chains into the mesopores of the carbon aerogel particles to achieve a good contact. These results show that a strong additive/polymer interaction could be achieved in MMMs and can be detected by routine mechanical analyses. Y. Zhang, et al. also reported similar results for ZSM-5/Matrimid ${ }^{\circledR}$ MMMs in 2008 [149], the mechanical analyses showed increased modulus and $\mathrm{T}_{\mathrm{g}}$ for the MMMs with increasing ZSM-5 loadings up to $30 \% w / w$. A study carried out in 2006 reported the effect of zeolite $4 \mathrm{~A}$ nanocrystals and microcrystals on the gas separation of $\mathrm{He} / \mathrm{N}_{2}$, $\mathrm{H}_{2} / \mathrm{N}_{2}, \mathrm{He} / \mathrm{CO}_{2}$ and $\mathrm{H}_{2} / \mathrm{CO}_{2}$ [150]. Although the gas permeabilities decreased with the increased percentage of zeolite particles in the matrix, gas selectivities increased significantly, especially with nanocrystalline zeolite 4A particles. According to another publication in 2007, $\mathrm{Na}$ ions in zeolite $\mathrm{NaA}$ were successfully replaced with Ag ions to improve the gas separation characteristics of PES-based MMMs [151]. The membranes with zeolite AgA showed higher permeability for $\mathrm{CO}_{2}$ and lower $\mathrm{CH}_{4}$ permeabilities (compared to NaA zeolite-MMMs) resulting in a higher $\mathrm{CO}_{2} / \mathrm{CH}_{4}$ selectivity of 59 at a $50 \mathrm{wt} \%$ loading. This same year, W. Yave, et al. [152] reported that $40 \mathrm{wt} \% \mathrm{TiO}_{2} / \mathrm{PMP}-2 \mathrm{MMMs}$ also suffered from physical aging and probably chemical aging too atfter being stored for 4 months, the $n-\mathrm{C}_{4} \mathrm{H}_{10}$ permeability in these MMMs dropped by $40 \%$ and the $n-\mathrm{C}_{4} \mathrm{H}_{10} / \mathrm{CH}_{4}$ selectivity dropped by $10 \%$. Similar loss of permeability (up to $40 \%$ ) over a period of 154 days were also observed by S. Matteuci, et al. [153] for $20 \mathrm{vol} \% \mathrm{TiO}_{2} /$ PTMSP MMMs. An important progress in the reduction of aging in MMMs came in 2011 from the work of J. K. Ward, et al. [154]. Ward observed that molecular sieve SSZ-13/PDMC MMMs suppressed significantly physical aging of the MMMs with a loss of $5 \%-10 \%$ of permeability wereas the neat PDMC loosed $30 \%$ of permeability in the same time frame. MMMs using Matrimid ${ }^{\circledR}$ and mesoporous ZSM-5 nanoparticles to improve gas separations were reported in 2008 [149]. The results indicated a good contact between the nanoparticles and the polymer matrix since the polymer chains penetrated into the mesopores of ZSM- 5 . Meanwhile, the micropores of ZSM-5 improved the size and shape selectivity. At a $10 \%$ loading of ZSM- 5, the $\mathrm{H}_{2} / \mathrm{N}_{2}$ selectivity increased from 79.6 to 143 compared to pure Matrimid ${ }^{\circledR}$. At 20\% loading, the $\mathrm{O}_{2} / \mathrm{N}_{2}$ and $\mathrm{H}_{2} / \mathrm{CH}_{4}$ selectivities increased from 6.6 to 10.4 and 83.3 to 169 , respectively, when compared to pure Matrimid ${ }^{\circledR}$. In 2011, the amine-functionalized FAU /EMT intergrown zeolites were used as the inorganic filler in 6FDA-ODA-based MMMs to improve $\mathrm{CO}_{2} / \mathrm{CH}_{4}$ separations [155]. Defect-free MMMs were obtained with amine-functionalized zeolites and, at $25 \mathrm{wt} \%$ modified zeolite loadings, the MMMs showed encouraging $\mathrm{CO}_{2} / \mathrm{CH}_{4}$ selectivities for both pure and mixed gas experiments. The MMMs achieved $\mathrm{CO}_{2} / \mathrm{CH}_{4}$ selectivity increments from the pure polymer of $118 \%$ (ideal) and $94 \%$ (gas mixture).

Non-porous and ordered mesoporous silica based MMMs have also been significantly studied. Joly, et al. studied composite membranes made from polyimide and silica [156]. Unlike porous inorganic materials such as zeolites, addition of nonporous silica alters the polymer chain packing thus affecting the gas transport properties of the polymer. According to Gomes, et al. incorporation of silica particles in a polymer matrix could result in a higher permeability or a slight decrease in selectivity due to an increased free volume in the membrane that results from the formation of non-selective voids at the additive/polymer interface [136,157]. Ahn, et al. studied the addition of fumed silica into PIM-1 in terms of gas permeability and selectivity. By studying the density, thermal stability, and morphology of the MMMs, the authors of this work were able to describe the reasons for the 
increments of gas permeabilities. Additional voids created in the polymer backbone by the interactions of the polymer chains and the silica particles resulted in higher permeabilities. For instance, the $\mathrm{CO}_{2}$ permeability increased from 6000 Barrer (pure PIM-1) to 13400 Barrer upon the addition of $24 \%$ silica into PIM-1 [158]. Takashi, et al. also studied the effect of chemical modification of $\mathrm{SiO}_{2}$ nanoparticle dispersion in poly(ether imide). MMMs containing sylil-modified $\mathrm{SiO}_{2}$ fillers displayed reduced void volumes compared to unmodified MMMs. At $5 \mathrm{wt} \%$ loading, void volumes in MMMs containing silylated $\mathrm{SiO}_{2}$ and pristine $\mathrm{SiO}_{2}$ were $0.25 \mathrm{vol} \%$ and $1.00 \mathrm{vol} \%$, respectively $[159,160]$.

Most common molecular sieving materials such as MOFs, ZIFs, Zeolites show low aspect ratios compared to layered materials such as silicates. Therefore, the incorporation of a small volume fraction of such layered materials can improve the performance of MMMs [161,162]. Defontaine, et al. were able to improve the $\mathrm{CO}_{2} / \mathrm{CH}_{4}$ selectivity of PDMS by $145 \%$ with the incorporation of sepiolite [163]. The effect on the $\mathrm{H}_{2} / \mathrm{CO}_{2}$ separation in PBI with the addition of sheet like AMH-3 was studied by Choi, et al. in 2008. According to their observations, a $3 \mathrm{wt} \% \mathrm{AMH}-3 \mathrm{MMM}$ showed a lowering of $\mathrm{CO}_{2}$ permeability which resulted in an increase in selectivity from 15 to 40 with respect to the polymer [164].

Modifications to the chemical structure of the polymer matrix were important to the mechanical properties of MMMs. In 2007, SPES was used as the precursor for MMMs with zeolite 4A [165]. Compared to PES membranes, SPES-based membranes displayed improved properties at the polymer-zeolite interface as visualized by SEM. In SPES MMMs, particle aggregation is minimal, which is considered an important characteristic for industrial gas separation MMMs. Figure 12 shows the morphological differences of PES-zeolite 4A membranes and SPES-zeolite 4A membranes from SEM micrographs of their cross-sections.

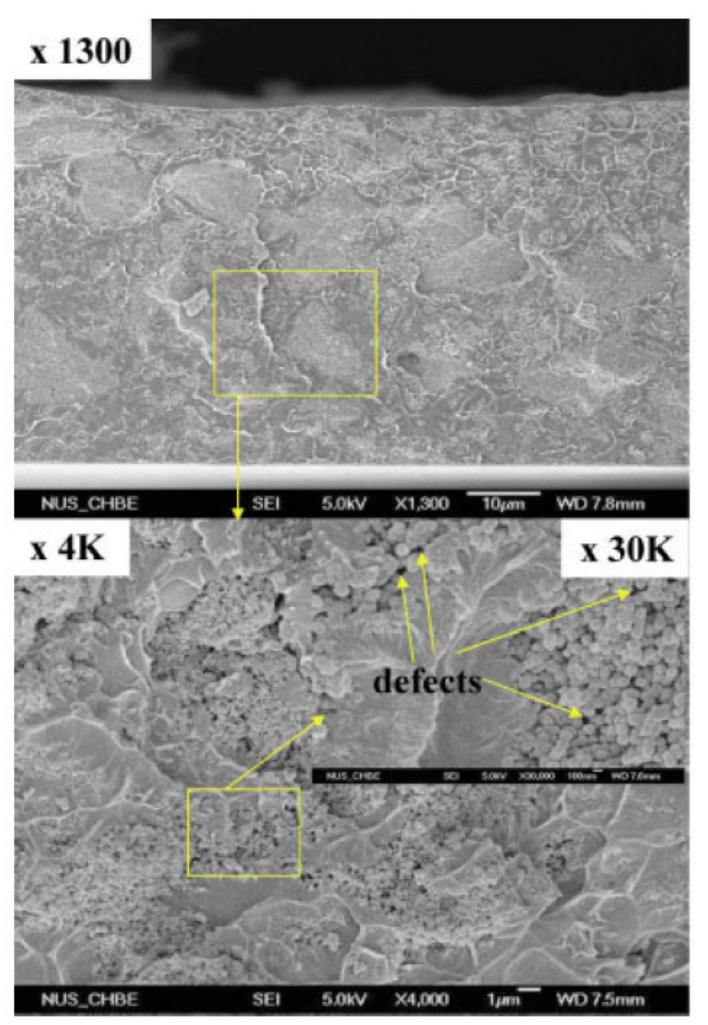

(a)

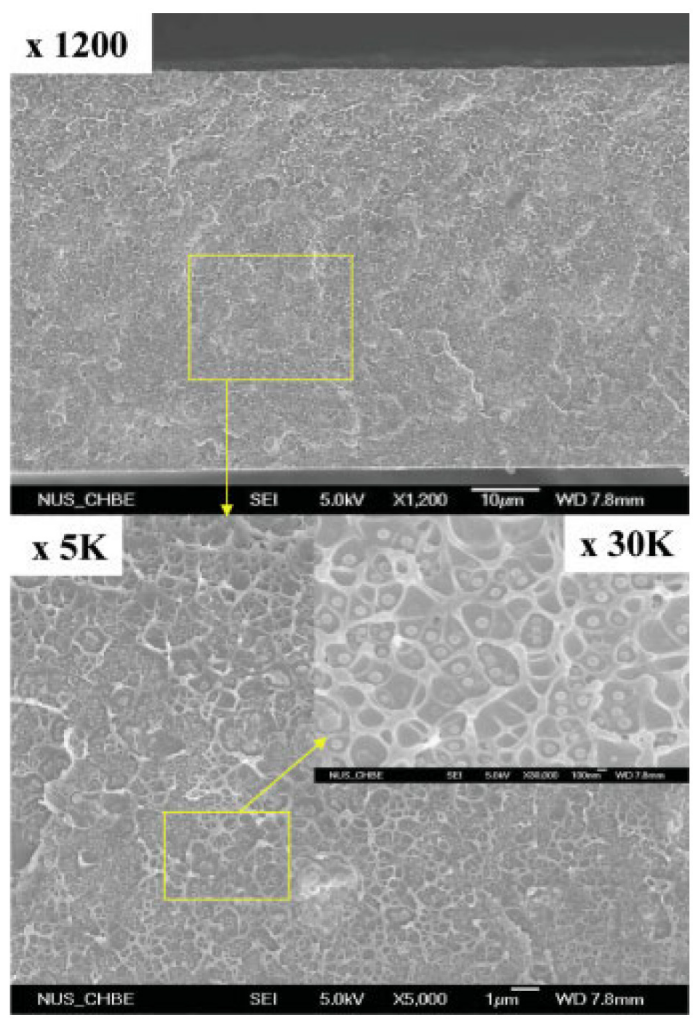

(b)

Figure 12. SEM images of the cross-sections of (a) polyethersulfone (PES)-zeolite 4A MMM; (b) sulfonated polyethersulfone (SPES)-zeolite 4A MMM. Reproduced with permission from [165]. Copyright, 2007, Wiley. 
In another study, Jha and co-workers were able to obtain an increased $\mathrm{CO}_{2} / \mathrm{N}_{2}$ selectivity, from 43 to 54, by preparing MMMs with methoxy ethoxy ethanol (MME)-substituted PPZ and SAPO-34 [166]. PPZ's rubbery nature allows better interfacial contact with the additive. By converting to MME-substituted PPZ, the $\mathrm{CO}_{2}$ selectivity of the MMMs was increased. Their MMMs showed gas separation properties that surpassed the Robeson upper bound for $\mathrm{CO}_{2} / \mathrm{N}_{2}$ separations. Another study carried out in 2010 was based on acrylate-derivatized polysulfone (PSf-acrylate) and zeolite $3 \mathrm{~A}$ for the separation of $\mathrm{H}_{2}$ from $\mathrm{CO}_{2}$ [167]. Unmodified PSf has a $\mathrm{H}_{2} / \mathrm{CO}_{2}$ separation factor of 1.53 , but the $40 \%$ zeolite 3A-PSF-acrylate MMM exhibited an improved selectivity of 3.57 . With further increase in zeolite loading, however, the $\mathrm{H}_{2}$ permeability increased and the selectivity ratio decreased.

In addition to chemically modifying the polymer structure or incorporating additives into the polymer matrix, the polymer and additive were chemically reacted together in a few occasions to obtain MMMs. In one study, the cross-linkable polymer PDMC was cross-linked with the dispersed inorganic additive SSZ-13 to prepare MMMs [154]. In this work, the non-crosslinked $25 \mathrm{wt} \%$ SSZ-13/PDMC MMM showed a $\mathrm{CO}_{2}$ permeability of 153 Barrer and a $\mathrm{CO}_{2} / \mathrm{CH}_{4}$ ideal selectivity of 34.7, whereas the cross-linked MMM exhibited good separation properties for the $\mathrm{CO}_{2} / \mathrm{CH}_{4}$ gas pair with selectivity and permeability increments of $6.9 \%$ and $121 \%$, respectively. In mixed gas experiments $\left(10 \% \mathrm{CO}_{2}+90 \% \mathrm{CH}_{4}\right)$ at 700 psia and $35{ }^{\circ} \mathrm{C}$, the $\mathrm{CO}_{2} / \mathrm{CH}_{4}$ selectivity and $\mathrm{CO}_{2}$ permeability were increased by $13 \%$ and $47 \%$, respectively. In this work, cross-linking the polymer with the inorganic particles ensured good contact between the continuous phase and the dispersed phase. In 2012, MMMs for $\mathrm{CO}_{2}$ separations were fabricated based on SPEEK and $-\mathrm{SO}_{3}$ functionalized mesoporous MCM-41 [168,169]. Covalent interactions between the inorganic filler and the polymer were visualized using SEM. Experiments were carried out at temperatures ranging from 25 to $65{ }^{\circ} \mathrm{C}$ and at pressures of 10 bar to test the membranes for industrial applications. $\mathrm{CO}_{2} / \mathrm{N}_{2}$ and $\mathrm{CO}_{2} / \mathrm{CH}_{4}$ selectivities of 40.5 and 22.9, respectively, were reported at a $\mathrm{CO}_{2}$ permeability of 21 Barrer.

\subsection{Carbon Materials in MMMs}

A variety of carbon based materials, including CNTs, graphene, fullerenes, and CMSs, prepared by the pyrolysis of polymer precursors at high temperatures under controlled environments were used as fillers in MMM preparation [170,171]. CNTs and CMSs are known to have several orders of magnitude higher permeabilities than molecular sieves. In contrast, a graphitic material could be categorized as a selective material. Like other inorganic molecular sieving materials, such as zeolites and metal oxides, CMSs show better selectivity and good permeabilities at the same time. The main advantage of CMSs is the variety of pore sizes and structures that can be obtained by varying the precursor material and the pyrolysis temperature. Generally, CMSs can be used to improve gas flux through a polymeric membrane. A patent on mixed-matrix nanoporous carbon membranes published in 2001 by Corbin, et al. is the first report of carbon material-based mixed-matrix membranes [172]. Following this study, Koros and co-workers in 2002 made mixed-matrix membranes having carbon-based molecular sieving particles prepared by pyrolyzing a precursor polymer [173]. Successful preparation of MMMs using carbon molecular sieves was again reported in 2003 [174]. During this particular study, Matrimid ${ }^{\circledR} 5218$ polyimide films were pyrolyzed at $800{ }^{\circ} \mathrm{C}$ following a published procedure and then ball-milled to get fine carbon molecular sieve (CMS) particles. These particles were then dispersed in Matrimid ${ }^{\circledR} 5218$ and Ultem ${ }^{\mathrm{TM}} 1000$ precursors to form MMMs. SEM images showed poor polymer-sieve contact in Ultem ${ }^{\mathrm{TM}} 1000$ and good contact in Matrimid ${ }^{\circledR} 5218 . \mathrm{CO}_{2} / \mathrm{CH}_{4}$ selectivities of 50 and $\mathrm{O}_{2} / \mathrm{N}_{2}$ selectivities of 7 were obtained for these membranes. Matrimid ${ }^{\circledR} 5218 \mathrm{MMMs}$ having 36\% CMS displayed gas separation properties that surpassed the Robeson's upper bound for $\mathrm{O}_{2} / \mathrm{N}_{2}$ separation.

Gas separation properties for KY-zeolite/Matrimid ${ }^{\circledR}$ MMMs pyrolyzed at $800{ }^{\circ} \mathrm{C}$ were studied focusing on $\mathrm{CO}_{2} / \mathrm{CH}_{4}$ separations [175]. This is the first report of MMMs containig both zeolitic and 
carbon materials. For the pyrolyzed membranes having $\mathrm{KY}$ zeolites, the measured $\mathrm{CO}_{2}$ and $\mathrm{CH}_{4}$ permeabilities were 266 Barrer and 2.2 Barrer, respectively and the $\mathrm{CO}_{2} / \mathrm{CH}_{4}$ selectivity was 124 .

To improve the interaction between the polymer matrix and CMS particles, the addition of a third component was tested in a study carried out in 2015 [176]. Interactions between PES and CMS were enhanced by the addition of DEA as the third component in the MMMs. Their MMM, having 15 wt \% DEA, showed more than a three-fold increment in $\mathrm{CO}_{2}$ permeance (from 30 to 123.5 GPU) from the PES membrane. Results show that the MMMs reported in this work had good separation properties for $\mathrm{CO}_{2} / \mathrm{CH}_{4}$ that surpassed the Robeson's upper bound.

There are not many reports of bucky balls and other fullerenes being used as inorganic fillers. However according to a few studies, $\mathrm{C}_{60}$ fullerenes could increase the selectivities for the gases considered. MMMs based on benzylamine modified $\mathrm{C}_{60}$ as the filler in Matrimid ${ }^{\circledR} 5218$ were reported in 2003 [177]. Although the permeabilities for all the gases tested $\left(\mathrm{He}, \mathrm{O}_{2}, \mathrm{~N}_{2}, \mathrm{CH}_{4}\right.$ and $\left.\mathrm{CO}_{2}\right)$ decreased with the increasing amount of benzylamine modified $\mathrm{C}_{60}$, the selectivity for $\mathrm{He} / \mathrm{N}_{2}$ increased while the others remained constant. In their work carried out on MMMs of ethyl cellulose (EC) and $\mathrm{C}_{60}$ particles, Sun, et al. reported improved permselectivity for $\mathrm{C}_{3} \mathrm{H}_{6} / \mathrm{C}_{3} \mathrm{H}_{8}$ separations with a 16 wt $\%$ $\mathrm{C}_{60} / \mathrm{EC}$ MMM [178]. $\mathrm{C}_{3} \mathrm{H}_{6}$ favors the $\pi$-electron cloud in $\mathrm{C}_{60}$ due to $\pi-\pi$ interactions, which improves the solubility and permeability of $\mathrm{C}_{3} \mathrm{H}_{6}$. Permeability and selectivity values increased 7.1 and 1.6 times, respectively, when compared to those of the pure EC membrane. To further emphasize their theory, the membrane was treated with UV radiation, which destroys the $\pi$-electron cloud in $\mathrm{C}_{60}$. Afterwards, the permeability of $\mathrm{C}_{3} \mathrm{H}_{6}$ and the $\mathrm{C}_{3} \mathrm{H}_{6} / \mathrm{C}_{3} \mathrm{H}_{8}$ selectivity decreased compared to the initial values.

Unlike fullerenes and carbon molecular sieves, both CNTs and FCNTs were commonly used to fabricate MMMs [171,179]. CNTs can act either as a pathway for gas molecules to go through or as a sieve. More importantly, CNTs are known to be stiff particles having dimensions ranging from 1 to $100 \mathrm{~nm}$. As a result, they can be used as rigidifying agents in membranes. The first report of CNT-based MMMs for gas separations, in 2006, used poly(imide-siloxane) polymer and SWCNTs with closed ends [180]. The gas permeation results showed a decrease in permeability for He and an increase in permeability for $\mathrm{O}_{2}, \mathrm{~N}_{2}$, and $\mathrm{CH}_{4}$. The drop in He permeability was attributed to the affinity of SWCNTs with the polymer matrix. All types of CNTs are electrically conducting materials, therefore, by applying an external electric field, CNTs can be aligned in one direction, which is important for gas transport and membrane rigidity. Based on this property, in 2012, Kumar, et al. prepared MMMs using PS and MWCNTs to enhance $\mathrm{H}_{2}$ permeability [181]. MWCNTs were dispersed in the PS matrix either by mechanical sonication and stirring or by applying a high transverse DC electric field to orient the MWCNTs. According to their gas permeability data, MMMs made with oriented MWCNTs showed a high $\mathrm{H}_{2}$ gas permeability of 275 Barrer.

The next noticeable improvement in CNT-based MMMs incorporated functionalized CNTs. FCNTs were used either to improve the interactions between the polymer and the CNTs or to improve the separation properties of the membranes. Ismail and co-workers fabricated MMMs comprised of PES and FMWCNT that showed improved gas separation for $\mathrm{CO}_{2}$ over $\mathrm{CH}_{4}$ [182]. Before the MWCNTs were functionalized, they were purified by treating with strong acids. Then, 3-aminopropyltriethoxysilane was used to functionalize the surface of the MWCNTs, which improved their dispersion within the polymer matrix. MMMs containing $0.5 \mathrm{wt} \%$ functionalized MWCNTs showed a 388\% increase in permselectivity for $\mathrm{CO}_{2} / \mathrm{CH}_{4}$ compared to pure PES. In 2014, A. L. Ahmad, et al. explored the effects of the addition of $\beta$-cyclodextrin-modified MWCNTs into a cellulose acetate (CA) matrix to prepare MMMs focusing on $\mathrm{CO}_{2} / \mathrm{N}_{2}$ separation [183]. Good gas permeance values were obtained for $\mathrm{CO}_{2}$ during the single gas experiments, which were greater than the permeabilities of either MMMs containing pristine MWCNTs or the bare CA membranes. The MMMs with a $0.1 \mathrm{wt} \%$ modified MWCNT loading exhibited a $\mathrm{CO}_{2}$ permeance of $741 \mathrm{GPU}$ at 3 bar.

In most cases, the incorporation of CNTs improved gas permeabilities. However, graphene oxide showed better sieving properties when oriented perpendicularly to the direction of gas flow [184,185]. Based on these observations, Li, et al. studied the synergistic effect of GO and CNTs on the permeability 
and selectivity of gases in MMMs made with both additives. MMMs based only on GO and Matrimid ${ }^{\circledR}$ demonstrated high gas selectivities for $\mathrm{CO}_{2} / \mathrm{N}_{2}$ and $\mathrm{CO}_{2} / \mathrm{CH}_{4}$ but low gas permeabilities. The CNT-containing MMMs, however, showed higher permeabilities but lower selectivities. When the authors tested the MMMs containing both GO and CNT in Matrimid ${ }^{\circledR}$, they observed that both, permselectivity and permeability, increased. Numerically, compared to pure Matrimid ${ }^{\circledR}$, the MMM with $5 \mathrm{wt} \% \mathrm{GO}$ and $5 \mathrm{wt} \% \mathrm{CNT}$ showed increments of $331 \%, 149 \%$ and $147 \%$ in $\mathrm{CO}_{2}$ permeability, $\mathrm{CO}_{2} / \mathrm{CH}_{4}$ selectivity, and $\mathrm{CO}_{2} / \mathrm{N}_{2}$ selectivity, respectively [171]. The chronological progress for the inorganic-based MMMs is shown in Figure 13.

\begin{tabular}{|c|c|c|}
\hline Inorganic-based MMMs Progress & Year & Contributors \\
\hline Heterogenous membrane for separating fluid mixtures & 1971 & G. Christen, et al. [110] \\
\hline Polymer membranes containing crystalline compounds & 1985 & Sterzel, et al. [137] \\
\hline Facilitated transport of $\mathrm{O}_{2}$ in $\mathrm{Co}(\mathrm{II}) /$ polystyrene MMMs & 1986 & R.S. Drago, et al. [138] \\
\hline Gas separation by means of mixed-matrix membranes & 1988 & S. Kulprathipanja, et al. \\
\hline Gas permeation characteristics of polymer-zeolite MMMs & 1994 & Sueer, et al. [139] \\
\hline Effect of feed composition on the performance of polymer-zeolite MMMs & 1995 & Battal, et al. [140] \\
\hline Factors controlling the successful formation of MMMs & 2000 & Mahajan, et al. [119] \\
\hline Effect of zeolite particle size on the performance of MMMs & 2000 & Tantekin, et al. [141] \\
\hline n-Pentane/i-pentane separation with zeolite-PDMS MMMs & 2001 & Tantekin, et al. [186] \\
\hline First reverse-selective fumed silica/PMP-2 MMMs & 2002 & T. C. Merkel, et al. [143] \\
\hline $\begin{array}{r}\text { Preparation and characterization of a glassy fluorinated polyimide/zeolite } \\
\text { MMMs }\end{array}$ & 2002 & Pechar, et al. [187] \\
\hline $\begin{array}{r}\text { The effects of polymer chain rigidification, zeolite pore size, and pore } \\
\text { blockage PES-zeolite A MMMs }\end{array}$ & 2005 & Li, et al. [121] \\
\hline Gas separation of nanostructured PES-zeolite 4A MMMs & 2006 & Huang, et al. [150] \\
\hline Diffusive permeability and selectivity of nanocomposite membranes & 2006 & R. J. Hill [144] \\
\hline Mechanical analysis of MMMs & 2006 & Y. Zhang, et al. $[147,148]$ \\
\hline Removal of thiophenes from n-octane with PDMS-AgY zeolite MMMs & 2007 & Qi, et al. [188] \\
\hline $\begin{array}{r}\text { Poly(4-methyl-2-pentyne)/ } \mathrm{TiO}_{2} \text { hybrid nanocomposite membrane for } \\
\text { butane/methane separation }\end{array}$ & 2007 & Yave, et al. [152] \\
\hline $\mathrm{Ag}^{+}$-zeolite/polymer MMMs with a high $\mathrm{CO}_{2} / \mathrm{CH}_{4}$ selectivity & 2007 & Li, et al. [151] \\
\hline Primer to prevent nanoparticle agglomeration in MMMs & 2007 & Li, et al. [165] \\
\hline $\begin{array}{r}\mathrm{CO}_{2} \text { selective MMMs formulation and characterization using rubbery } \\
\text { substituted PPZ }\end{array}$ & 2008 & Jha, et al.[166] \\
\hline $\mathrm{H}_{2}$ separation using PSf acrylate-zeolite MMMs & 2010 & Khan, et al. [167] \\
\hline Thin Pd-silica MMMs with nano-dispersion for improved $\mathrm{H}_{2}$ permeability & 2010 & Kanezashi, et al. [189] \\
\hline $\begin{array}{r}\text { Cross-linkable MMMs with surface modified molecular sieves and aging } \\
\text { reduction }\end{array}$ & 2011 & Ward, et al. [154] \\
\hline $\begin{array}{r}\text { MMMs based on polymerizable room-temperature ionic liquids and } \\
\text { SAPO-34 particles to improve } \mathrm{CO}_{2} \text { separation }\end{array}$ & 2011 & Hudiono, et al. [190] \\
\hline $\begin{array}{r}\text { Cross-linked polyvinylalcohol-polysiloxane/fumed silica MMMs } \\
\text { containing amines for } \mathrm{CO}_{2} / \mathrm{H}_{2} \text { separation }\end{array}$ & 2011 & Xing, et al. [191] \\
\hline $\begin{array}{r}\text { Amine-functionalized zeolite FAU/EMT-polyimide MMMs for } \mathrm{CO}_{2} / \mathrm{CH}_{4} \\
\text { separation }\end{array}$ & 2011 & Nik, et al. [155] \\
\hline $\begin{array}{r}\text { SPEEK and functionalized mesoporous MCM-41 MMMs for } \mathrm{CO}_{2} \\
\text { separations }\end{array}$ & 2012 & Khan, et al. [169] \\
\hline $\begin{array}{r}\text { Amine-functionalized SBA-15 in poly(styrene-b-butadiene-b-styrene) } \\
\text { nanostructured MMMs }\end{array}$ & 2013 & Buonomenna, et al. [192] \\
\hline $\begin{array}{r}\text { PSf MMMs incorporating Pd nanoparticles dispersed in PVPy for } \mathrm{H}_{2} \\
\text { separation }\end{array}$ & 2014 & Suhaimi, et al. [193] \\
\hline
\end{tabular}

Figure 13. Chronological progress for inorganic-based MMMs. 


\section{Evolution of MOF-Based MMMs}

\subsection{Metal-Organic Frameworks}

There is still an ambiguity regarding the distinction between coordination polymers $(\mathrm{CP})$ and MOFs that muddies the classification of hybrid organic-inorganic materials [194]. For simplicity and following IUPAC recommendations [195], we will use the term MOFs to refer to the organic-inorganic compounds that form 1D, 2D, or 3D frameworks. MOFs offer great potential for gas separations owing to their large surface areas, gas sorption capacities, pore apertures suitable for molecular sieving, and high temperature stability. These materials can also undergo chemical functionalization of their organic components before or after their synthesis to tune their gas affinity, pore size, pore aperture, and affinity to polymers. MOFs, ZIFs, MILs, MOPs, MOCs, and their variations are materials that can form crystalline frameworks or single molecular cages (MOPs and MOCs) that result from combining metal ions (SBUs) with organic linkers (Figure 14a,b). It is important to note that MOPs (Figure 14b) and MOCs are single porous molecular cages that offer the potential to be dissolved in organic solvents while retaining their porosity and 3D structure in solution. MOFs, on the other hand, grow into particles of sizes that range from the nanometer scale to the micrometer scale, depending on the synthesis conditions, and cannot be dissolved into single unit cells without destroying the framework. MOFs can be dispersed in organic solvents (Figure 14a).

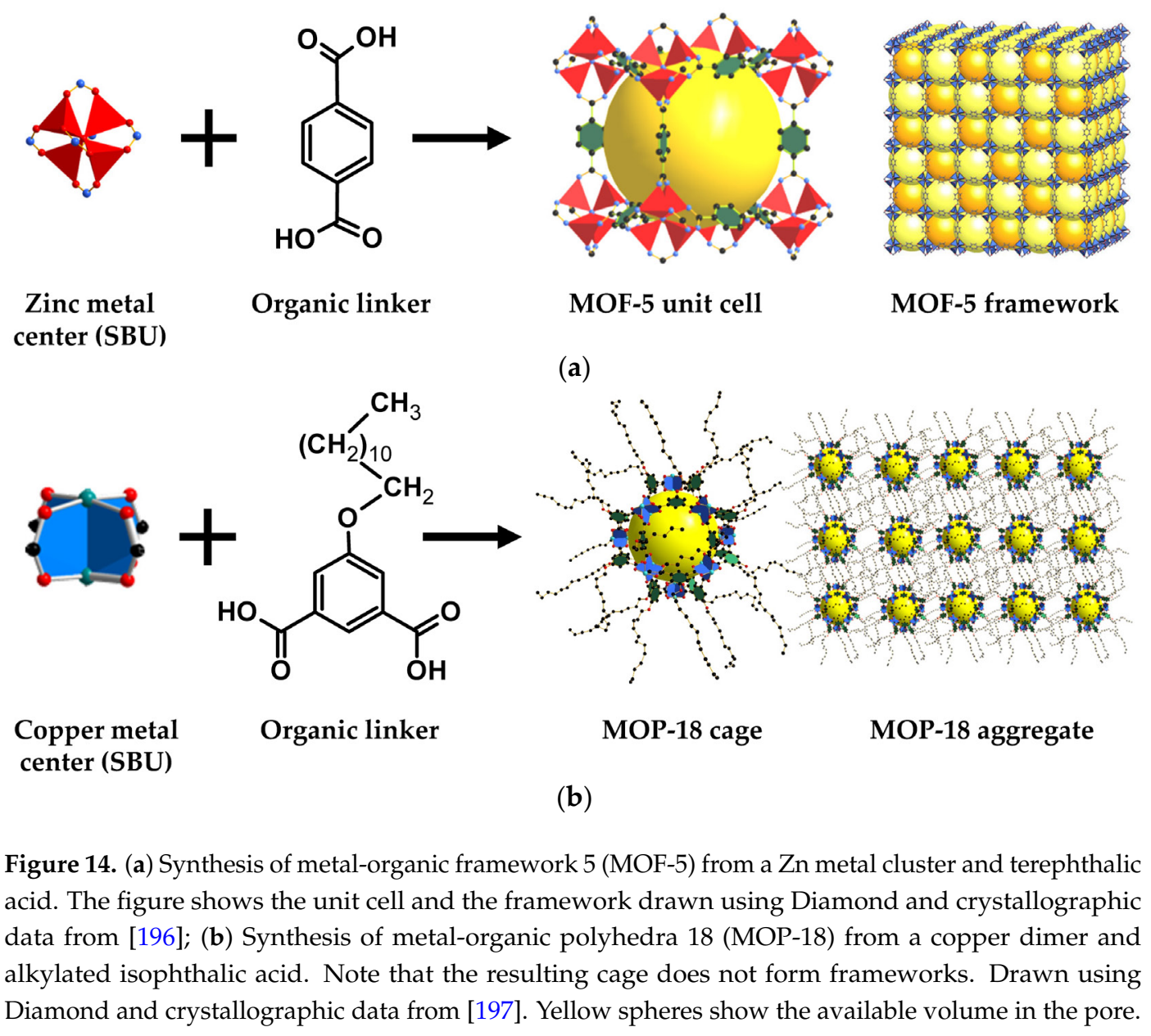

ZIFs are a subfamily of MOFs that are characterized by the similitude of their $\mathrm{Zn}-\mathrm{N}-\mathrm{Zn}$ angle $\left(145^{\circ}\right)$ to that of sodalite's Si-O-Si bonds. The $\mathrm{Zn}-\mathrm{N}$ bond in ZIFs is resistant to high temperatures and to water, making them attractive for MMM preparation. Due to the variety of available imidazolate 
linkers, a large number of ZIFs with different chemical functionalities and pore apertures have been synthesized and tested for gas adsorption and gas separation in MMMs (Figure 15) [198].

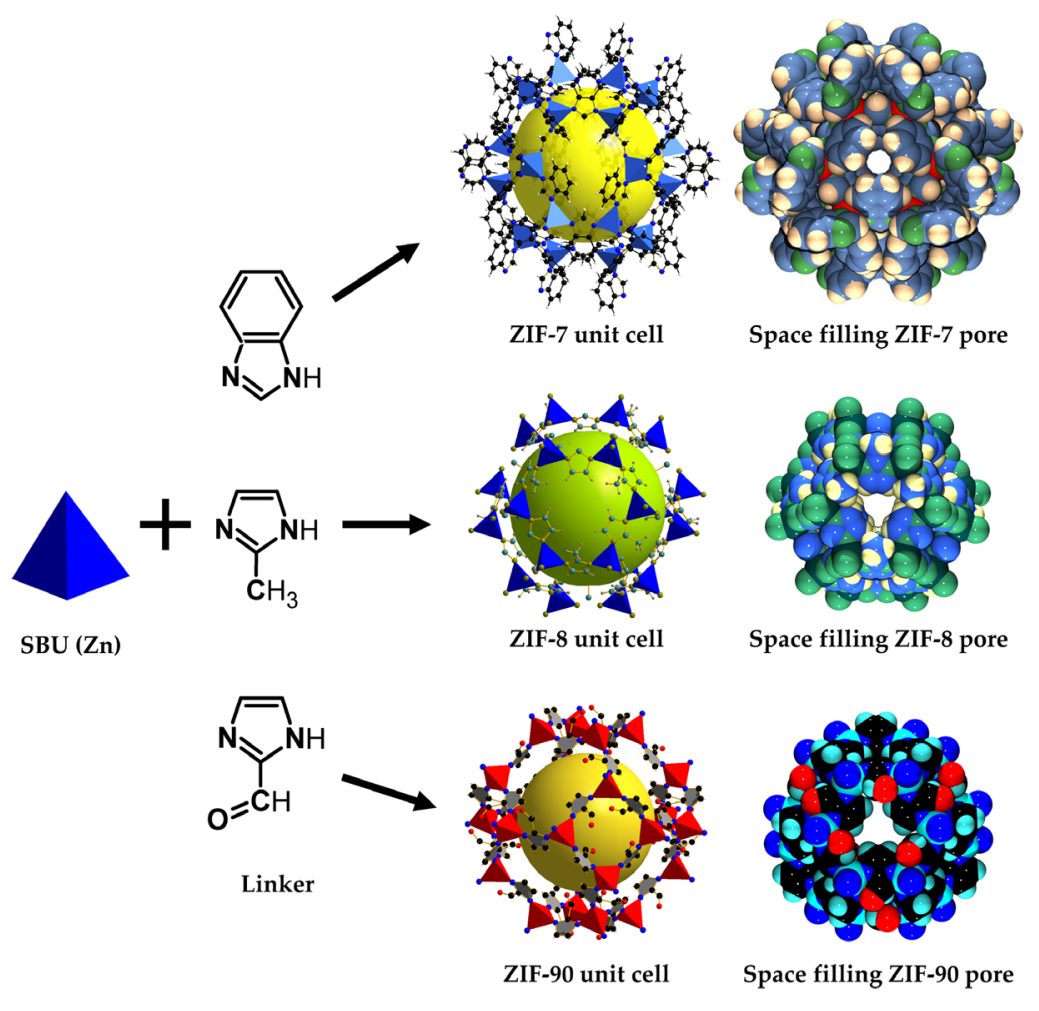

Figure 15. Synthesis of zeolitic imidazolate 7 (ZIF-7), ZIF-8, and ZIF-90 from a Zn ion and imidazolates. Unit cells and space filling models drawn using Diamond with crystallographic data for ZIF-7 [199], ZIF-8 [200], and ZIF-90 [201]. Note that depending on the linker, different pore aperture shapes can be obtained.

\subsection{MOFs in MMMs}

One of the first reports on the use of MOFs for the preparation of MMMs for gas separations emerged from the work of H. Yehia, et al. in 2004 [120]. In this work, a copper-based MOF (Cu-MOF) was synthesized from copper acetate, 4,4'-biphenyl dicarboxylate, and triethylenediamine [202]. The obtained crystals were then mixed with the rubbery polymer PAET to form MMMs with loadings up to $30 \%(w / w)$. The MMMs were tested for $\mathrm{CH}_{4} / \mathrm{CO}_{2}$ separations at $35^{\circ} \mathrm{C}$ and 2.0 bar and resulted in an increase in $\mathrm{CH}_{4}$ permeation and a decrease in $\mathrm{CO}_{2}$ permeation that were attributed to the hydrophobicity and pore size $(0.12 \mathrm{~nm})$ of the MOF. Two years later, in 2006, A. Car, et al. synthesized $\mathrm{Cu}(\mathrm{BTC})_{2}$ and $\mathrm{Mn}(\mathrm{HCOO})_{2} \mathrm{MOFs}$ that were used at loadings up to $40 \%(w / w)$ in conjunction with PSf and PDMS for the preparation of MMMs [122]. The membranes were tested for $\mathrm{H}_{2}, \mathrm{~N}_{2}, \mathrm{O}_{2}, \mathrm{CH}_{4}$, and $\mathrm{CO}_{2}$ permeability. The authors reported mixed results for permeability and selectivity, but no further characterization of the MOFs or the MMMs was attempted. The same year, E. V. Perez, et al. incorporated for the first time nanocrystals of MOF-5 (Figures 14a and 16) into Matrimid ${ }^{\circledR}$, a polyimide with high $\mathrm{T}_{\mathrm{g}}$ [123]. Their preliminary results showed that, at 30\% $(w / w)$ loadings, MOF-5 improved the gas permeability of the MMMs by $120 \%$ over the pure polymer without significant variation in gas selectivity. 


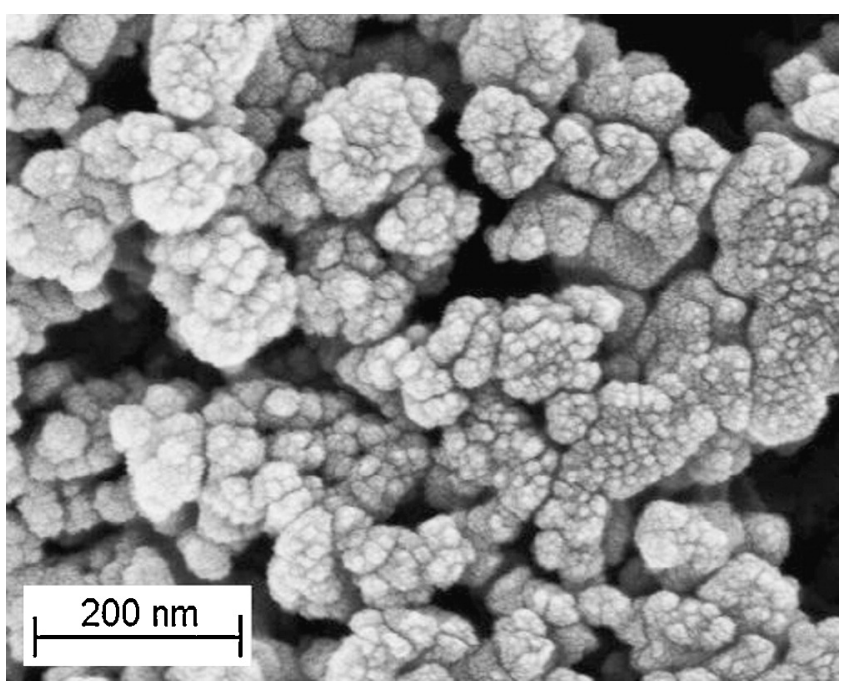

Figure 16. SEM image of nanocrystals of MOF-5. Reproduced with permission from [124]. Copyright, 2009, Elsevier.

Also in 2006, C. Barcena prepared PAET, POT, and PDMS MMMs of Cu-MOF with loadings up to $30 \%(w / w)$ [203]. Gas permeation $\left(\mathrm{H}_{2}, \mathrm{~N}_{2}, \mathrm{O}_{2}, \mathrm{CH}_{4}\right.$, and $\left.\mathrm{CO}_{2}\right)$ results for these membranes resulted in no significant changes in permeability or selectivity compared to the pure polymers. In 2008, working on the progress made by Yehia, et al., Car, et al., and Perez, et al., in 2008 Y. Zhang, et al. reported on the preparation of Matrimid ${ }^{\circledR}$-based MMMs that contained a submicron, water stable Cu-MOF (Cu-BPY-HFS) [204]. The MOF exhibited a thermal stability up to $100{ }^{\circ} \mathrm{C}$ that limited the drying temperature of the membranes to $50{ }^{\circ} \mathrm{C}$. An increase in $\mathrm{CH}_{4}$ permeability up to $180 \%$ was observed at $35{ }^{\circ} \mathrm{C}$ for a $40 \mathrm{wt} \% \mathrm{MOF}$ loading. Ideal selectivities also decreased as the MOF content increased, but did so more markedly for those gas pairs containing $\mathrm{CH}_{4}$ and $\mathrm{N}_{2}$. The authors attributed the declines to the increased affinity of the $\mathrm{MMM}$ for $\mathrm{CH}_{4}$ due to the presence of the MOF. Y. Zhang, et al. also reported the mechanical properties of their MOF-based MMMs by performing stress-strain tests at room temperature. The results indicated an increased modulus from $2.41 \mathrm{GPa}\left(\mathrm{Matrimid}^{\circledR}\right.$ ) to $2.67 \mathrm{GPa}$ (MMM with $20 \mathrm{wt} \%$ MOF loading). At $30 \mathrm{wt} \%$, the authors observed a decrease in modulus from 2.67 GPa to $2.54 \mathrm{GPa}$. These improvements in modulus were attributed to a good contact and affinity between the polymer and the MOF. $\mathrm{T}_{\mathrm{g}}$ measurements were not performed in this work due to the lower thermal stability of the MOF (up to $200{ }^{\circ} \mathrm{C}$ ) and high $\mathrm{T}_{\mathrm{g}}$ of the plymer $\left(316^{\circ} \mathrm{C}\right.$ ). Similar measurements of mechanical properties of MOF-based MMMs were also performed by E. V. Perez, et al. in 2009 [125,126] (increased modulus of MOP-18/Matrimid ${ }^{\circledR}$ MMMs), by T. Yang, et al. in 2011 [205] (increased $\mathrm{T}_{\mathrm{g}}$ of ZIF-7/PBI MMMs), by E. V. Perez, et al. in 2015 [128] (mechanical stability of $\mathrm{NH}_{2}$-MIL-53/VTEC MMMs at $300{ }^{\circ} \mathrm{C}$ by thermomechanical analyses), and in MOF-based MMM reviews [206,207]. Recently, in 2016, S. J. D. Smith, et al. [208] and E. M. Mahdi, et al. [209] reported more detailed works on mechanical analyses of MMMs which are discussed at the end of this section, following the chronological progress.

Continuing their work on MOF-based MMMs, E. V. Perez, et al. reported complete studies of MOF-5/Matrimid ${ }^{\circledR}$ and Cu-MOF/Matrimid ${ }^{\circledR}$ MMMs in 2009 [124,125]. The same year, they also reported their initial work on MOP-18/Matrimid ${ }^{\circledR}$ MMMs that later was reported in more detail [126]. E. V. Perez, et al. found that plastic deformation of the polymer (e.g., polymer veins) occurred around the MOF-5 particles due to the strong interaction between the MOF and the polymer (Figure 17) [124]. Their detailed observations of gas permeation at $35^{\circ} \mathrm{C}$ and 2 bar showed that up to a $120 \%$ increase in permeability with no significant variation in ideal selectivity could be achieved at a $30 \%(w / w)$ MOF-5 loading without introducing nonselective voids in the membrane. They also concluded that diffusivity was significantly enhanced due to the porosity introduced by the uniform channels of 
MOF-5. With their work on Cu-MOF/Matrimid ${ }^{\circledR}$ MMMs, E. V. Perez, et al. provided support for the case that the uniformity of the MOF channels and the pore size may play a significant role in gas permeation in MMMs [125]. In their work, the highly porous and thermally stable Cu-MOF [202] (BET surface area of $3000 \mathrm{~m}^{2} / \mathrm{g}$ and pore size of about $1 \mathrm{~nm}$ ) was loaded into Matrimid ${ }^{\circledR}$ up to

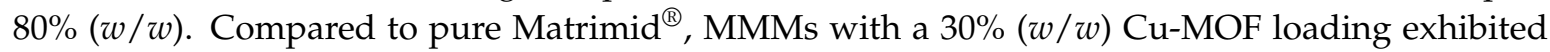
permeabilities enhanced by $1000 \%\left(\mathrm{O}_{2}\right)$ or $1400 \%\left(\mathrm{~N}_{2}\right)$, while suffering only a $17 \%$ decrease in $\mathrm{O}_{2} / \mathrm{N}_{2}$ selectivity $\left(\mathrm{O}_{2} / \mathrm{N}_{2}=6.14\right.$ for Matrimid ${ }^{\circledR} ; 5.07$ for MMM; Permeability of Matrimid ${ }^{\circledR}$ to $\mathrm{O}_{2}=1.5$ Barrer, $\mathrm{MMM}=17.2$ Barrer).

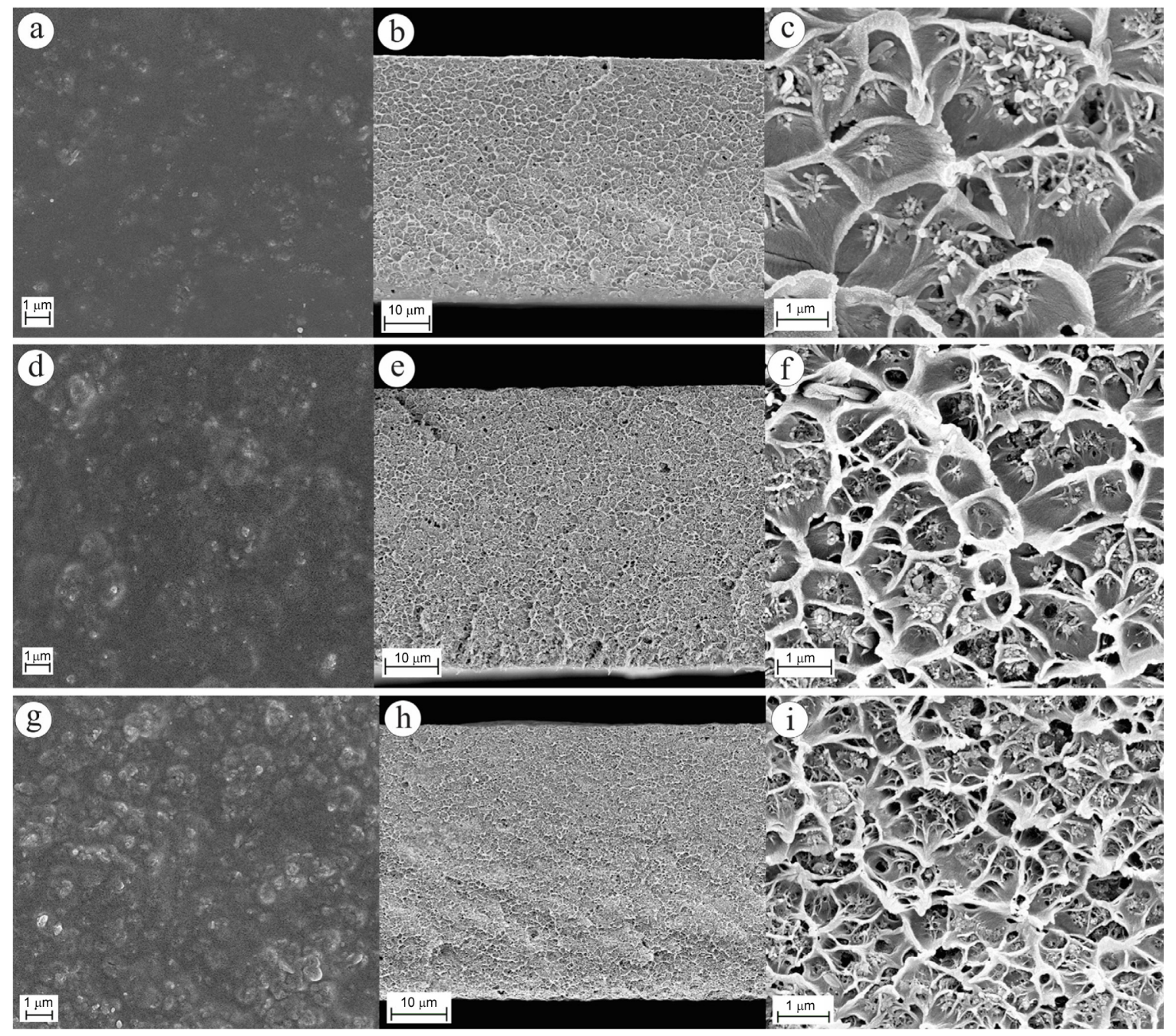

Figure 17. SEM images of the surface $(\mathbf{a}, \mathbf{d}, \mathbf{g})$ and the cross-sections at low $(\mathbf{b}, \mathbf{e}, \mathbf{h})$ and at high $(\mathbf{c}, \mathbf{f}, \mathbf{i})$ magnifications of $10 \%(w / w), 20 \%(w / w)$, and 30\% $(w / w)$ MOF-5/Matrimid ${ }^{\circledR}$ MMMs, respectively. Cross-sections showing plastic deformation of the polymer matrix due to the presence of MOF-5 nanoparticles. Reproduced with permission from [124]. Copyright, 2009, Elsevier.

Although the use of MOFs for MMM preparation significantly mitigated interfacial rejections and resulted in membranes free of defects, E. V. Perez, et al. recognized that the limiting factor in achieving a perfect dispersion was the aggregation of the nanocrystals. Aiming to solve this problem, they introduced MOP-18 molecular cages (Figure 14b) into Matrimid ${ }^{\circledR}$ to study the effect this type of hybrid material would have on the gas separation properties of MMMs [125]. Their work showed that MOP-18 was dispersed at the molecular level in the polymer matrix since it both dissolved in 
the casting solvent and exhibited affinity for the polymer. Gas permeability, however, did not change significantly possibly due to pore blockage by the alkyl chains of the MOP.

Following on the success of previous works of Perez, et al. [124] and Zhang, et al. [204], R. Adams, et al., in 2010, prepared defect-free MMMs of CuTPA (a Cu-MOF) and PVAc with a 15\% MOF loading [210]. Their permeability experiments showed that the $\mathrm{CO}_{2} / \mathrm{CH}_{4}$ selectivity of the MMM increased by as much as $15 \%$ over the pure polymer owing to the presence of the MOF in the membrane. By comparing the apparent diffusivities of the gases in the MMM with those in the pure polymer, the authors concluded that the gases were diffusing through the MOF and not through voids or defects at the MOF-polymer interface, and that a true mixed-matrix effect was achieved. This same year, T.-H. Bae, et al. reported on the first ZIF-based MMM incorporating ZIF-90 crystals (Figure 15) into Ultem ${ }^{\mathrm{TM}}$, Matrimid ${ }^{\circledR}$, and 6FDA-DAM polyimides [127]. Submicrometer-sized ZIF-90 crystals synthesized using methanol and deionized water as nonsolvents (Figure 18) were incorporated in these polyimides (Figure 19) a $15 \mathrm{wt} \%$ ZIF loadings. The SEM images of the cross-sections showed good adhesion of the polymer to the ZIF and no gross defects at the interface. The SEM images also showed different degrees of polymer plasticization around the crystals, with Ultem ${ }^{\mathrm{TM}}$ showing the least plasticization and 6FDA-DAM showing the most. Gas permeation studies showed that ZIF-90/Ultem ${ }^{\mathrm{TM}}$ and ZIF-90/Matrimid ${ }^{\circledR}$ MMMs only increased permeability and retained $\mathrm{CO}_{2} / \mathrm{CH}_{4}$ selectivities. This result, according to the authors, was due to a mismatch between the high gas permeability in the pores of ZIF-90 (estimated to be thousands of Barrers) and the low permeability in the polymers (Ultem $^{\mathrm{TM}}$ and Matrimid ${ }^{\circledR}, 1$ to 10 Barrer). In the case of ZIF-90/6FDA-DAM, the mismatch was less because 6FDA-DAM exhibits higher permeabilities $\left(\mathrm{CO}_{2}=390\right.$ Barrer) than Ultem ${ }^{\mathrm{TM}}$ and Matrimid ${ }^{\circledR}$, resulting in an MMM with improvement in both permeability and selectivity. The ZIF-90/6FDA-DAM MMM showed an increase in $\mathrm{CO}_{2}$ permeability of 720 Barrer and a higher $\mathrm{CO}_{2} / \mathrm{CH}_{4}$ selectivity of 37 compared to 24 for 6FDA-DAM.
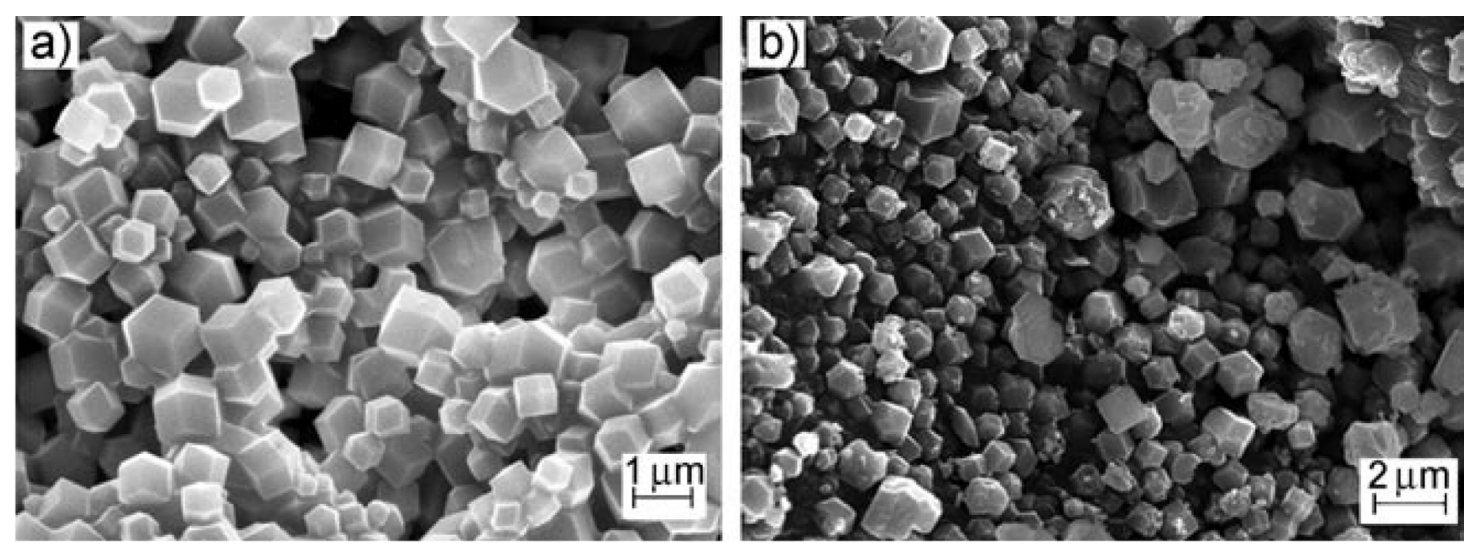

Figure 18. SEM images of submicrometer-sized ZIF-90 particles synthesized using nonsolvents: (a) methanol (ZIF-90A); (b) deionized water (ZIF-90B) [127]. Reproduced with permission from [127]. Copyright, 2010, Wiley. 

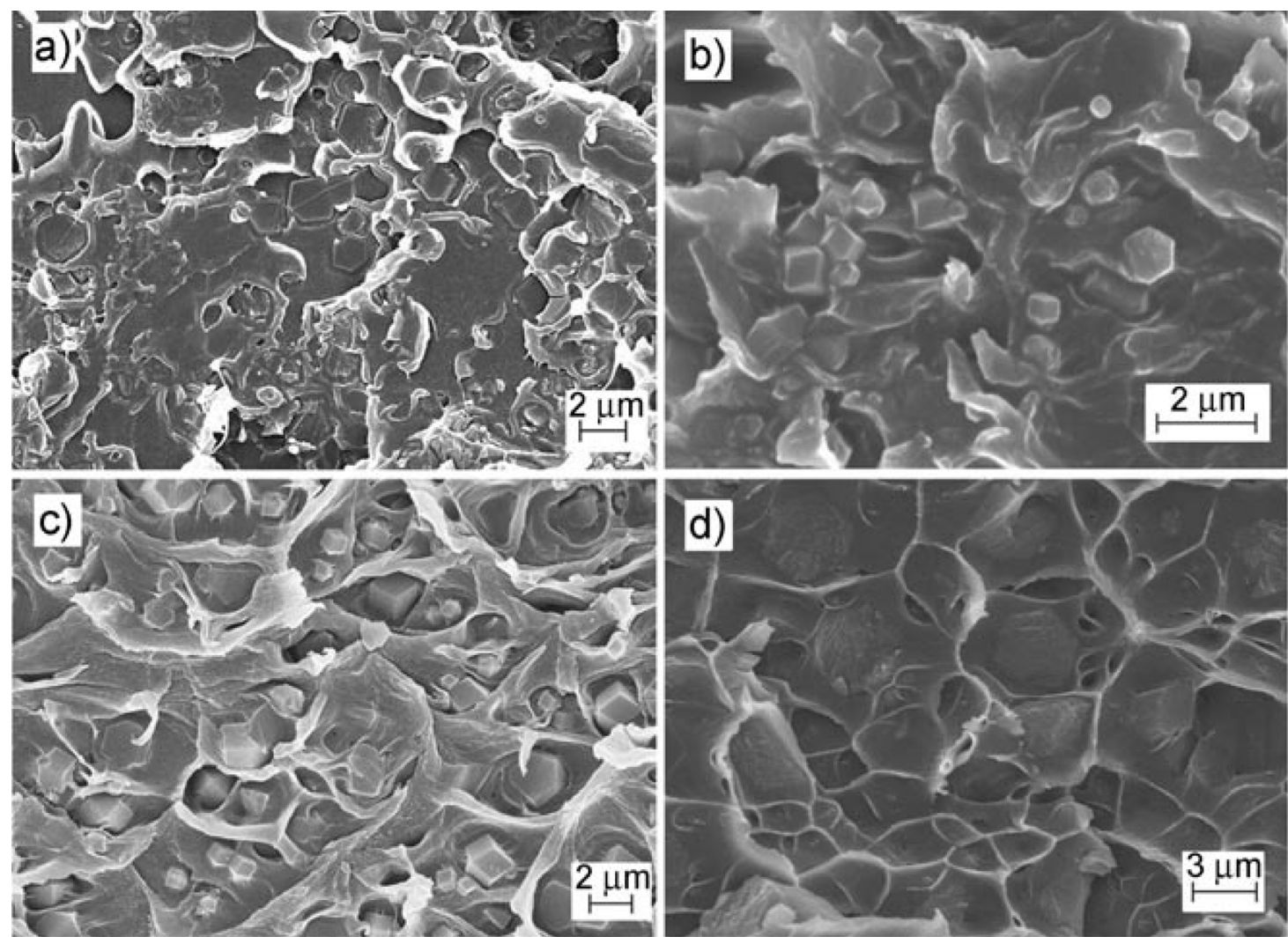

Figure 19. SEM images of cross-sections of 15 wt \% ZIF-90/polyimide MMMs: (a) ZIF-90A/Ultem ${ }^{\text {TM}}$; (b) ZIF-90A/Matrimid ${ }^{\circledR}$; (c) ZIF-90A/6FDA-DAM; and (d) ZIF-90B/6FDA-DAM. Reproduced with permission from [127]. Copyright, 2010, Wiley.

By 2010, K. Diaz, et al. studied $\left[{ }^{13} \mathrm{C}\right] \mathrm{O}_{2}$ gas diffusion in ZIF-8/PPEES MMMs containing up to $30 \mathrm{wt} \%$ ZIF-8 [211]. The authors used macroscopic (e.g., gas adsorption, time lag method) and microscopic techniques (e.g., PFG-NMR) to study gas transport in the membranes. Gas solubility experiments were carried out using the dual chamber method and the dual-mode solubility model to identify Langmuir (partially immobilized gas) and Henry sorption. Permeability experiments were also performed to obtain solubility and diffusivity data using the time lag method. From these studies, the authors concluded that ZIF-8 crystals provided Langmuir sorption sites for $\mathrm{CO}_{2}$ that resulted in an increase in gas adsorption in the MMMs when the ZIF content was increased. From PFG NMR, the authors also observed chemical shifts, corresponding to ${ }^{13} \mathrm{C}$, for both free (124.2 ppm) and sorbed (120.7 ppm) $\left[{ }^{13} \mathrm{C}_{2} \mathrm{O}_{2}\right.$ molecules in the membranes. The authors also found that the self-diffusion coefficient of $\mathrm{CO}_{2}$ in the MMMs was about 2 times larger than the effective diffusion. This same year, J. Hu, et al. reported on the preparation of $\mathrm{Cu}_{3}(\mathrm{BTC})_{2} / \mathrm{PI}$ (ODA-PMDA) hollow fiber MMMs [212]. In this work, the MOF was first synthesized and then its size reduced to submicrometer size using a ball mill. Though this method for reducing the crystal size is rather crude and prone to destroy the crystals, the authors loaded $6 \mathrm{wt} \%$ of the MOF into the polyamic acid form of the ODA-PMDA polymer, and then, using the dry/wet spinning method, prepared the hollow fiber MMMs. The fibers were solvent exchanged in water for $1 \mathrm{~d}$, washed with methanol and hexanes 3 times, and dried to induce imidization using a temperature program up to $300{ }^{\circ} \mathrm{C}$. Although most $\mathrm{Cu}-\mathrm{MOFs}$ are thermally labile and sensitive to water, the authors obtained X-ray diffraction patterns for the hollow fiber MMMs. Gas permeation at 10 bar and $25{ }^{\circ} \mathrm{C}$ showed improved flux, from 876 (PI) to 1270 (MMM) GPUs, and improved $\mathrm{H}_{2} / \mathrm{CO}_{2}$ selectivity, from 10.0 (PI) to 27.8 (MMM). Another significant contribution to this field in 2010 came from the theoretical work of S. Keskin, et al. on the application of MOFs in MMMs for gas separations [213,214]. S. Keskin used 
atomistic and continuum modeling to select the best MOF for a particular separation [213]. The authors first validated their models using gas permeation data for MOF-5/Matrimid ${ }^{\circledR}$ MMMs reported by E. V. Perez, et al. [124] and then predicted the $\mathrm{CO}_{2} / \mathrm{CH}_{4}$ separation performance for $6 \mathrm{MOF} / \mathrm{Matrimid}{ }^{\circledR}$ MMMs. From the series of Matrimid ${ }^{\circledR}$-based MMMs containing IR-MOFs (e.g., IRMOF-1, IRMOF-8, IRMOF-10, IRMOF-14) and copper MOFs (CuBTC and $\mathrm{Cu}$ (hfipbb) $\left(\mathrm{H}_{2}\right.$ hfipbb) 0.5 ), the authors found that $\mathrm{Cu}$ (hfipbb) $\left(\mathrm{H}_{2} \text { hfipbb }\right)_{0.5} /$ Matrimid ${ }^{\circledR} \mathrm{MMMs}$ possessed the best $\mathrm{CO}_{2} / \mathrm{CH}_{4}$ separation performance with selectivity and permeability that improved with increasing MOF loading. In another work reported the same year, S. Keskin, et al. performed Grand Canonical Monte Carlo and equilibrium molecular dynamics simulations to calculate adsorption isotherms and self-diffusivities of $\mathrm{H}_{2} / \mathrm{CH}_{4}$ mixtures in a $\mathrm{Zn}(\mathrm{bdc})(\text { ted })_{0.5} \mathrm{MOF}$ [214]. The results revealed that the MOF strongly adsorbed $\mathrm{CH}_{4}$ and reduced hydrogen's diffusivity. It was also concluded that when the MOF was exposed to a $\mathrm{H}_{2} / \mathrm{CH}_{4}$ mixture, $\mathrm{H}_{2}$ dragged the slowly diffusing $\mathrm{CH}_{4}$ molecules through the pore. The authors also performed atomistic and continuum modeling of the $\mathrm{Zn}(\mathrm{bdc})(\text { ted })_{0.5} /$ polymer $\left(\mathrm{Hyflon}^{\circledR}\right.$, sulfonated and 6FDA-based polyimides, Teflon ${ }^{\mathrm{TM}}$, and polytrimethylsilylpropyne) MMMs for this separation and concluded that the MMMs greatly enhanced the permeability of $\mathrm{H}_{2}$ without lowering the selectivity. More recently, in 2016, I. Erucar and S. Keskin [215] reviewed the progress made in this field and observed that there is still significant amount of work to be done to understand the effects of the incorporation of MOFs in MMMs for gas separations. The authors determined that the effects of the physical and chemical properties of MOFs (e.g., pore size, pore volume, surface area, type of organic linker, and compatibility between the MOF and the polymer) on MMM properties need to be studied in order to develop a structure-performance relationship to predict MMM performance from its constituents (MOFs and polymers). Size, dispersion, orientation of MOF particles in the MMM and their interaction with the polymer (e.g., pore blockage, polymer rigidification around $\mathrm{MOF}$ ) are also areas that need more development to improve performance. In 2010, M. J. C. Ordoñez, et al. [216] and I. H. Musselman, et al. [217] report on the use of ZIF-8 (Figure 15) for the preparation of ZIF-8/Matrimid ${ }^{\circledR}$ MMMs for gas separations. The authors found that, as the ZIF loading increased up to $60 \%(w / w)$, the MMMs became more rigid and difficult to handle. From SEM images of the MMMs with $30 \%$ and 50\% $(w / w)$ ZIF-8 loadings (Figure 20), it was concluded that there was a strong interfacial contact between the ZIF-8 crystals and the polymer. However, as the loading increased to $80 \%(w / w)$, reduced interfacial contact lead to aggregation of the ZIF. For all the gases tested $\left(\mathrm{H}_{2}, \mathrm{CO}_{2}, \mathrm{CH}_{4}, \mathrm{~N}_{2}, \mathrm{O}_{2}\right.$, and $\left.\mathrm{C}_{3} \mathrm{H}_{8}\right)$, the permeabilities increased with increasing ZIF loading up to $40 \%(w / w)$. At this loading, the permeabilities increased by $53 \%$ for $\mathrm{C}_{3} \mathrm{H}_{8}, 147 \%$ for $\mathrm{H}_{2}$, $158 \%$ for $\mathrm{CO}_{2}, 170 \%$ for $\mathrm{O}_{2}, 239 \%$ for $\mathrm{N}_{2}$, and $271 \%$ for $\mathrm{CH}_{4}$ with no significant changes in selectivity, which was attributed to the increase in free volume in the membrane due to the increase in distance between the polymer chains. Above $40 \%(w / w)$ loading, the permeabilities decreased significantly, up to $94 \%$ relative to the $40 \%$ loading, due to the increase in tortuosity and increased polymer density that forced the smaller molecules to diffuse around the ZIF crystals.

Progress in the preparation of MOF-based MMMs continued in 2011, when S. Basu, et al. prepared dense and asymmetric MMMs of $\mathrm{Cu}_{3}(\mathrm{BTC})_{2}, \mathrm{ZIF}-8$, and (Al) MIL-53 in Matrimid ${ }^{\circledR}$ [218]. This was the first time that a MOF (MIL-53) with a breathing or gating effect was used for the preparation of MMMs. At $30 \mathrm{wt} \%$ loading, the dense MMMs exhibited permeability increments of $196 \%$ for $\mathrm{Cu}_{3}(\mathrm{BTC})_{2}$, $209 \%$ for ZIF-8, and $218 \%$ for (Al) MIL-53 with a $15 \%$ increase in $\mathrm{CO}_{2} / \mathrm{CH}_{4}$ separations. The authors also noted that, although the structure varied significantly from MOF to MOF, the gas permeation properties of their MMMs were quite similar at any loading. The PDMS-coated asymmetric MMMs of $\mathrm{Cu}_{3}(\mathrm{BTC})_{2}$ and (Al) MIL-53 showed increased $\mathrm{CO}_{2} / \mathrm{CH}_{4}$ mixture selectivities with increasing MOF loadings at any given $\mathrm{CO}_{2} / \mathrm{CH}_{4}$ feed composition. The ZIF-8 MMMs, however, did not show changes in selectivity with respect to the Matrimid ${ }^{\circledR}$. The increased selectivities were attributed to strong interactions of $\mathrm{CO}_{2}$ with the MOF frameworks. 

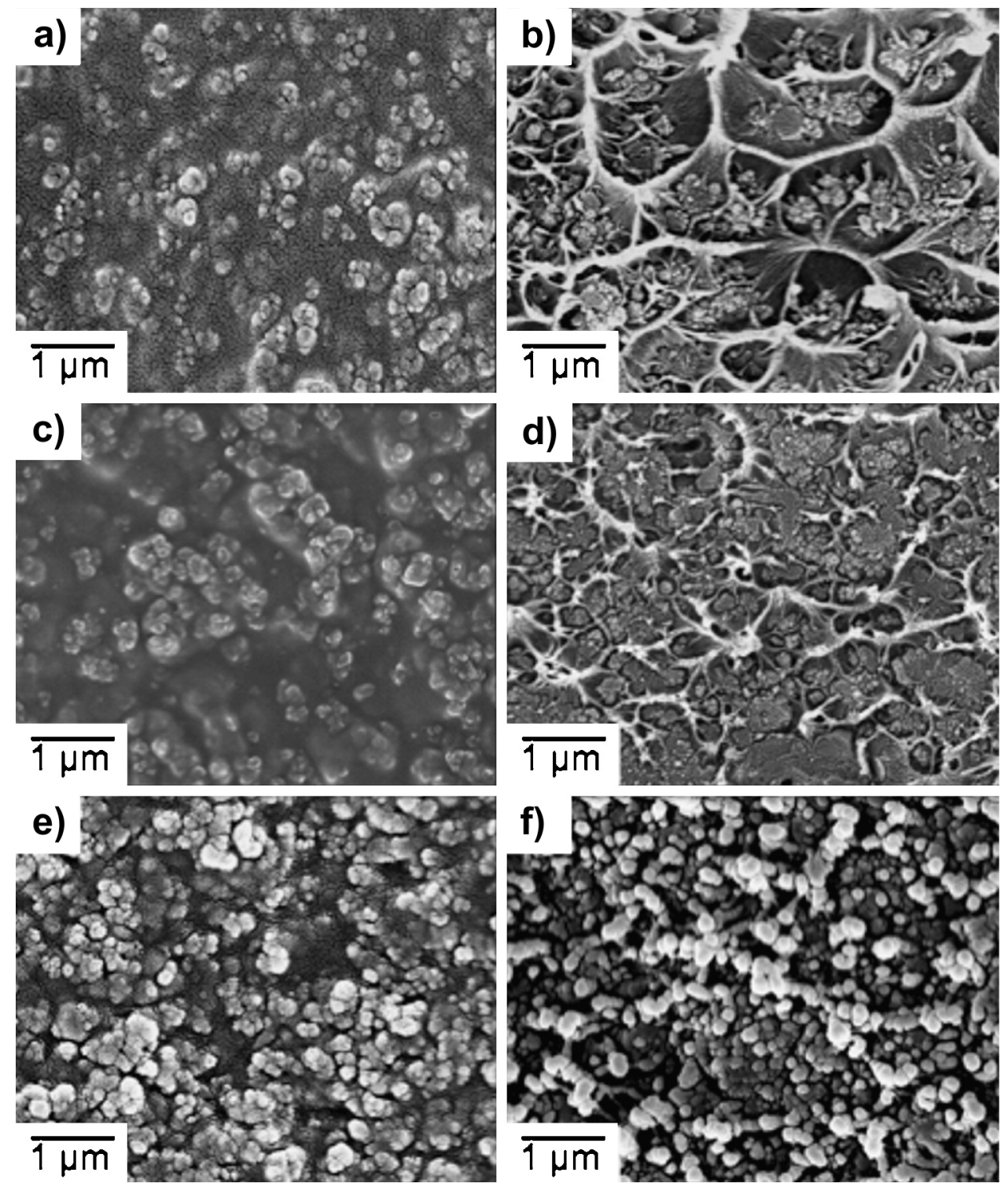

Figure 20. SEM images of surfaces $(\mathbf{a}, \mathbf{c}, \mathbf{e})$ and cross-sections $(\mathbf{b}, \mathbf{d}, \mathbf{f})$ of ZIF-8/Matrimid ${ }^{\circledR}$ MMMs: $(\mathbf{a}, \mathbf{b}) 30 \%$; (c,d) 50\%; and (e,f) 80\% (w/w). Adapted with permission from [216]. Copyright, 2010, Elsevier.

Another significant development in MOF-based MMMs came also in 2011, where X. L. Liu, et al. extended the application of MOF-based MMMs to the recovery of $C_{2}-C_{5}$ alcohols from water by organophilic pervaporation [38]. The incorporation of the superhydrophobic and flexible framework of ZIF-8 into PMPS, a silicone rubber polymer, resulted in thin, defect-free ZIF-8/PMPS MMMs (Figure 21a) that were supported on alumina capillaries and showed a isobutanol/water selectivity of 40.1 and an isobutanol permeance of 7000 GPU. The authors also concluded that the energy required for pervaporation per unit of isobutanol was only half that of distillation, making the membrane-based separation more efficient. Membrane separation performance as a function of increased ZIF-8 loading was also explored and showed that the MMMs increased both selectivity and flux as the ZIF-8 loading increased. ZIF-8/PMPS MMMs also showed improved separation and flux properties for ethanol, $n$-propanol, $n$-butanol, and $n$-pentanol separations from water (Figure 21b). The authors also used ZIF-7 (Figure 15) to prepare ZIF-7/PMPS MMMs for the separation of isobutanol from water, but their results showed membranes with lower separation factors and lower isobutanol permeances. The reduced 
performance of the ZIF-7/PMPS MMMs was attributed to the reduced pore aperture of ZIF-7 (0.30 nm) and to its more rigid framework.

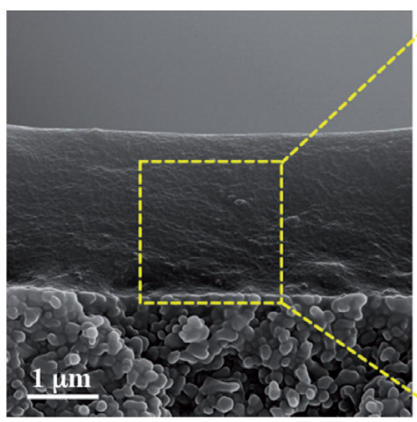

(a)

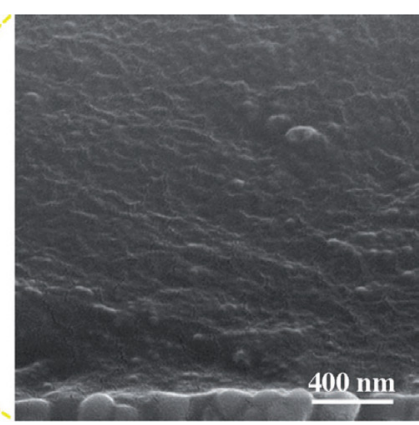

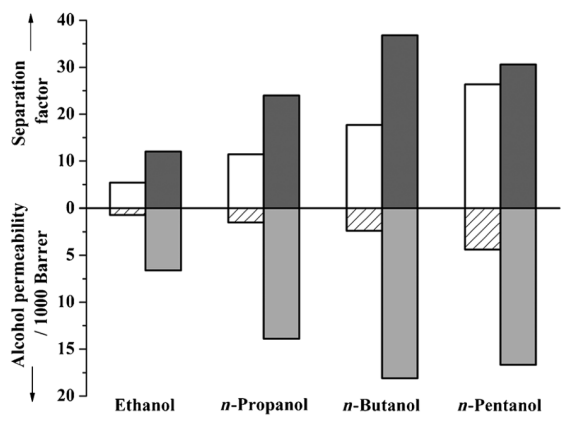

(b)

Figure 21. (a) SEM image of the cross-section of a 10\% (w/w) ZIF-8/polymethylphenylsiloxane (PMPS) MMM on an alumina capillary support; (b) Alcohol/water separation factors and alcohol permeability of PMPS (open and line filled) and ZIF-8/PMPS MMMs (gray). Adapted with permission from [38].

Copyright, 2011, Wiley.

A new procedure to incorporate ZIFs into polymers came from the work of T. Yang, et al. in 2011 with the dispersion of colloidal ZIF-7 in PBI [205]. By keeping the ZIF-7 nanocrystals in a DMF solution, the authors avoided the aggregation of crystals when dried and eliminated the lengthy MOF dispersion steps that usually include sonication and stirring. With this strategy, MMMs with up to $50 \mathrm{wt} \%$ loadings were prepared and tested for gas mixture permeation from 35 to $180{ }^{\circ} \mathrm{C}$ at 7 bar. TEM and SEM images of a 50/50 (w/w) ZIF-7/PBI MMM (Figure 22a) showed a uniform dispersion of ZIF-7 nanocrystals with no significant agglomeration due to their coating by PBI that acts as a coating agent.

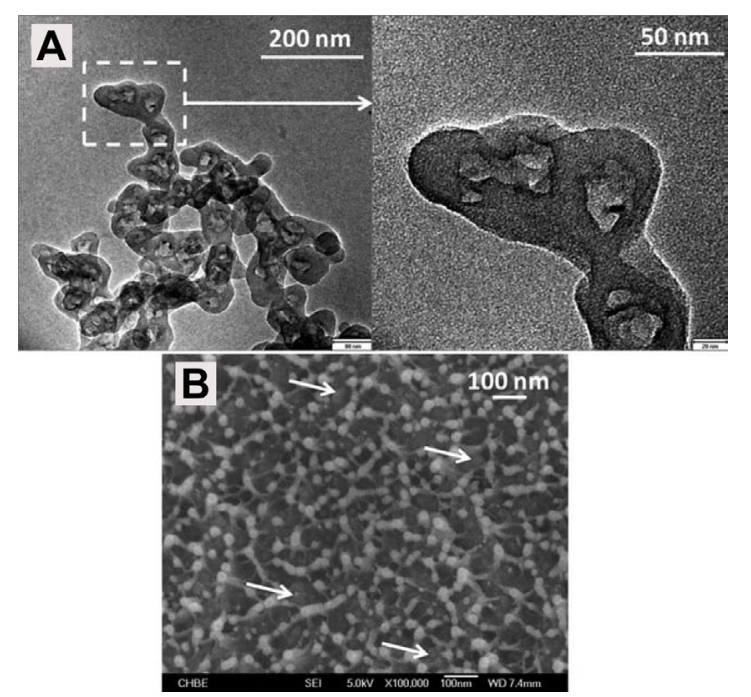

(a)

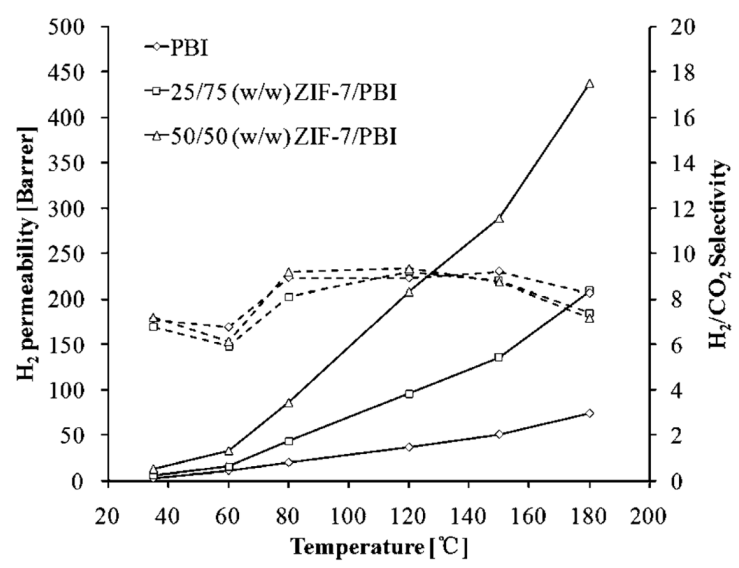

(b)

Figure 22. (a) Transmission electron microscopy (TEM) images (A) of the MMM suspension precipitated in methanol and SEM images (B) of the cross-section of a 50/50 (w/w) ZIF-7/Polybenzimidazole (PBI) MMM; (b) $\mathrm{H}_{2} / \mathrm{CO}_{2}$ mixture permeability and selectivity of PBI and ZIF-7/PBI MMMs with increasing temperatures. Reproduced with permission from [205]. Copyright, 2011, The Royal Society of Chemistry. 
Gas permeation with $\mathrm{H}_{2} / \mathrm{CO}_{2}$ mixtures (Figure 22b) showed that the MMMs retained $\mathrm{H}_{2} / \mathrm{CO}_{2}$ selectivity and increased $\mathrm{H}_{2}$ permeability significantly with both ZIF loading and temperature increments. This same year, 2011, B. Zornoza, et al. reported on the preparation of a MMM using PSf (Udel ${ }^{\circledR}$ ) and a functionalized MOF, (Al) $\mathrm{NH}_{2}-\mathrm{MIL}-53$ [219]. The aminated MOF was the first attempt to control the separation properties of the MOF-based MMM by decorating the channels of the MOF with amine functional groups $\left(-\mathrm{NH}_{2}\right)$ covalently bonded to the organic linker. SEM images of the cross-sections of MMMs containing 8, 16, 25, and $40 \mathrm{wt} \% \mathrm{NH}_{2}-\mathrm{MIL}-53$ revealed that the polymer effectively wetted the micrometer-sized crystals (Figure 23a). Gas mixture $\left(\mathrm{CO}_{2} / \mathrm{CH}_{4}\right)$ permeation experiments at 3 bar and $35^{\circ} \mathrm{C}$ showed that the membranes had moderate $\mathrm{CO}_{2}$ permeation increments and a small $\mathrm{CH}_{4}$ permeability decrease that resulted in an increase in $\mathrm{CO}_{2} / \mathrm{CH}_{4}$ selectivity. At 10 bar, the MMM selectivity to $\mathrm{CO}_{2} / \mathrm{CH}_{4}$ (Figure 23b) improved significantly from 55 (PSf) to 110 (MMM) due to the opening of the MOF pores in the MMM (gating effect) that allows for more $\mathrm{CO}_{2}$ to be adsorbed in the pores. A similar work comparing the $\mathrm{CO}_{2} / \mathrm{CH}_{4}$ separation properties of $-\mathrm{NH}_{2}$ functionalized UiO-66 and MOF-199/6FDA-ODA MMMs to that of the corresponding neat MOF/6FDA-ODA MMMs was reported by O. G. Nik, et al. in 2012 [220]. The authors observed $\mathrm{CO}_{2} / \mathrm{CH}_{4}$ selectivity increments of $35 \%$ for the $25 \mathrm{wt} \% \mathrm{NH}_{2}$-MOF-199/6FDA-ODA MMM and 17\% for the $25 \mathrm{wt} \% \mathrm{NH}_{2}$-UiO/6FDA-ODA $\mathrm{MMM}$ over the pure polymer. The increase in selectivity was attributed to polymer rigidification induced by the amine moiety in the MOFs.
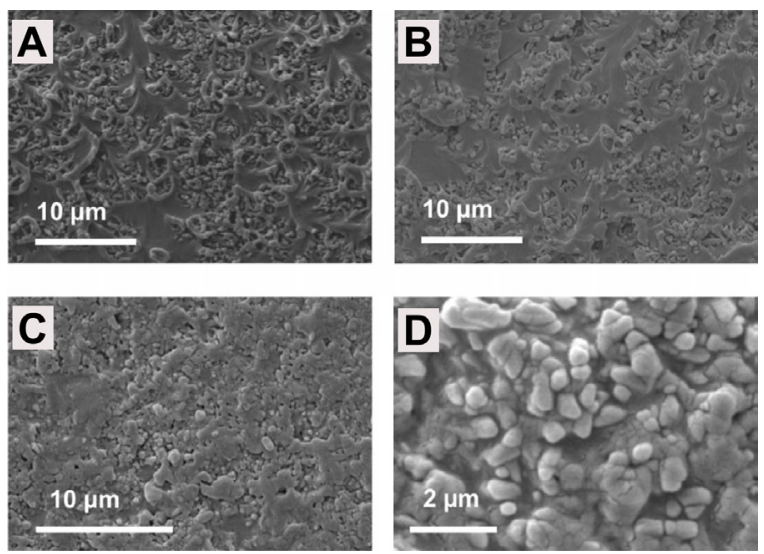

(a)

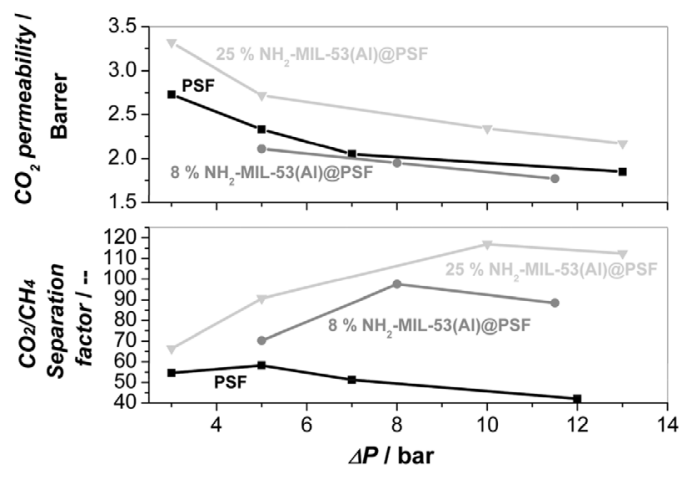

(b)

Figure 23. (a) SEM images of the cross-sections of 8 (A); 16 (B); 25 (C); and 40 (D) wt \% $\mathrm{NH}_{2}$-MIL-53/polysulfone (PSf) MMMs; (b) $\mathrm{CO}_{2} / \mathrm{CH}_{4}$ mixture separation performance of $\mathrm{NH}_{2}$-MIL-53/PSf MMMs at $-10{ }^{\circ} \mathrm{C}$ with increasing pressures from 3 to 13 bar. Reproduced with permission from [219]. Copyright, 2011, The Royal Society of Chemistry.

In this same year, B. Zornoza, et al. [221] tested MMMs comprised of PSf, silicalite-1 (S1C), and HKUST-1 or ZIF-8. The SEM images of the cross-sections of the MMMs (Figure 24) showed an even dispersion for the ZIF-8/PSf MMM and some polymer veins for the HKUST-1/PSf MMM. The addition of the S1C zeolite to both systems introduced regions with a slightly different morphology but not a significant S1C/PSf affinity in the form of polymer veins or plastic deformation was observed. Permeability experiments showed mixed results depending on the type of MOF used and the gas separation performed (Figure 25). For the ZIF-8/S1C/PSf MMM, the combination of the ZIF and S1C improved the MMM performance for separations based on gas diffusivity differences. For the HKST-1/S1C/PSf MMM, the performance of the MMM improved for $\mathrm{CO}_{2}$ separations probably due to the affinity of the MOF for $\mathrm{CO}_{2}$. The authors conclude that the incorporation of the zeolite in the MMMs may have a synergistic effect on the MMM that leads to improved separation properties. Although the mechanism of this effect is not clear, the results suggest S1C has an effect on the properties of the MMM. 

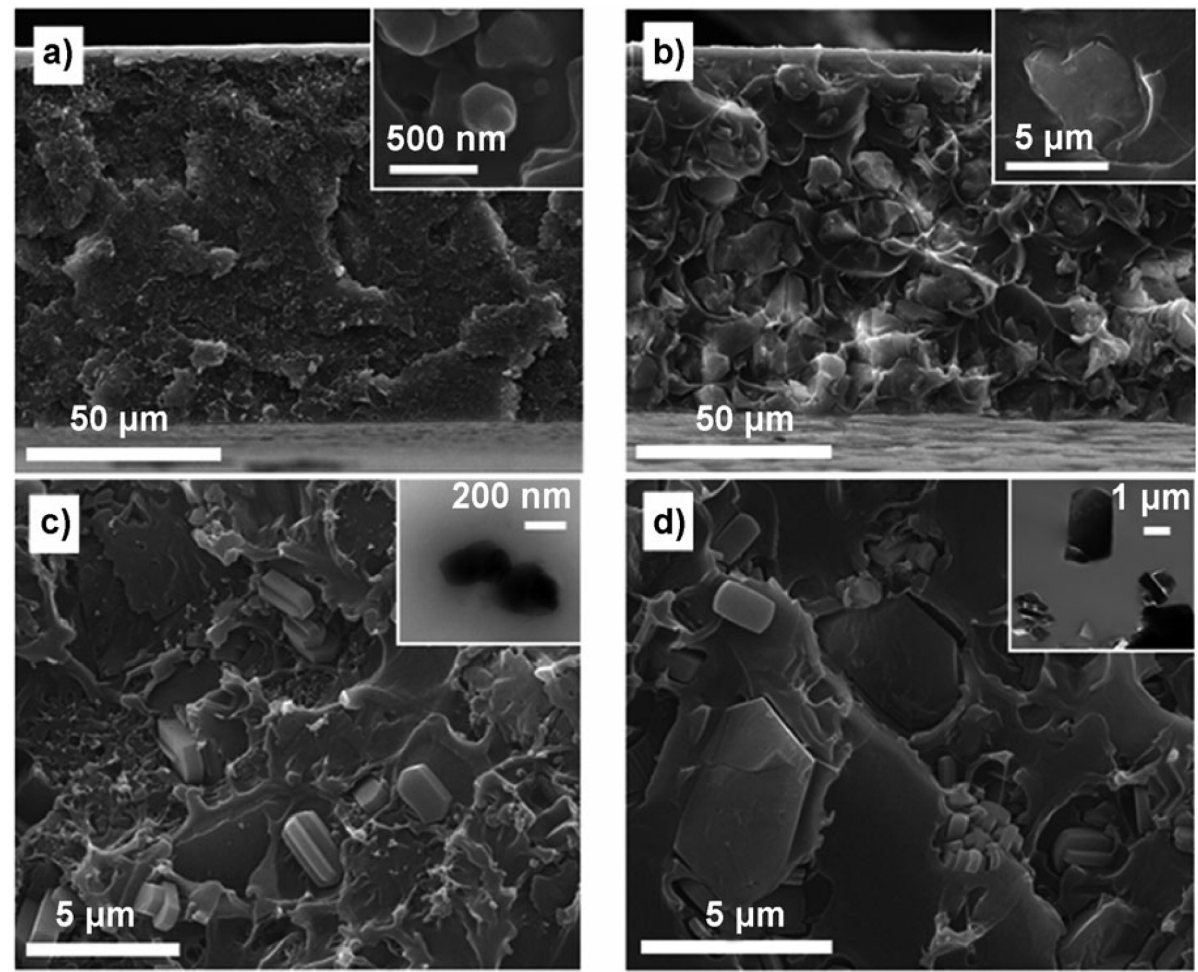

Figure 24. SEM images of the cross-sections of MMMs: (a) 16 wt \% ZIF-8/PSf; (b) 16 wt \% HKUST-1/PSf; (c) 8 wt \% ZIF-8 +8 wt \% S1C/PSf; and (d) 8 wt \% HKUST-1 + 8 wt \% S1C/PSf. Reproduced with permission from [221], Copyright, 2011, Wiley.

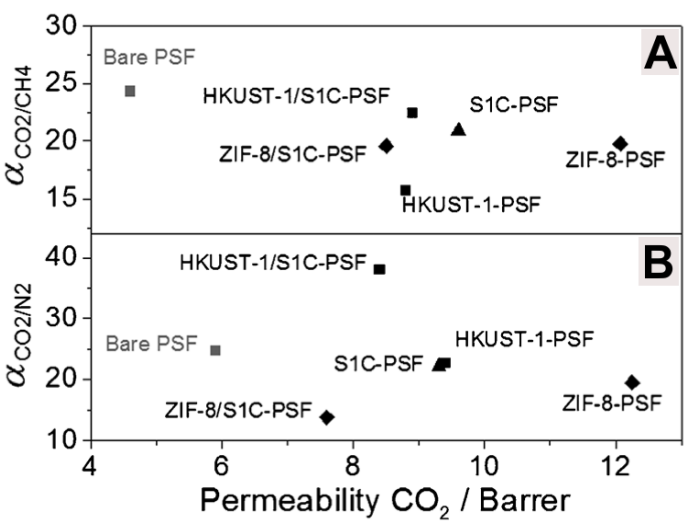

(a)
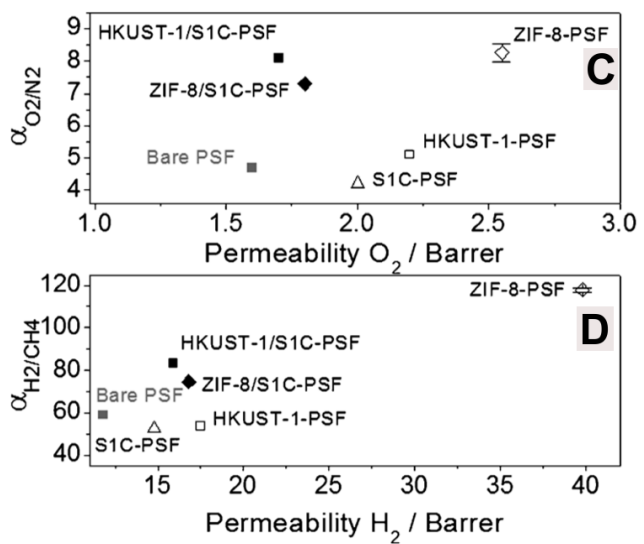

(b)

Figure 25. (a) $\mathrm{CO}_{2} / \mathrm{CH}_{4}$ (A) and $\mathrm{CO}_{2} / \mathrm{N}_{2}$ (B) selectivities and $\mathrm{CO}_{2}$ permeabilities for PSf and the MMMs; (b) $\mathrm{O}_{2} / \mathrm{N}_{2}$ (C) and $\mathrm{H}_{2} / \mathrm{CH}_{4}$ (D) selectivities and $\mathrm{H}_{2}$ permeabilities for PSf and the MMMs. Reproduced with permission from [221]. Copyright, 2011, Wiley.

The development of MOF-based MMMs was boosted in 2012 when, H. B. T. Jeazet, et al. reported on their work with MIL-101, a hydrolytically stable MOF, used in conjunction with PSf in the preparation of MMMs for $\mathrm{O}_{2} / \mathrm{N}_{2}$ separations [222]. The low hydrothermal stability of MOFs (e.g., MOF-5, IRMOF series, HKUST-1) was recognized to be a potential problem for industrial gas separations and was addressed by the authors with the use of a water stable MOF (MIL-101). MMMs with 8, 16, and 24 wt \% MIL-101 exhibited increased permeability with increasing MOF loading, while retaining the $\mathrm{O}_{2} / \mathrm{N}_{2}$ selectivity of the membrane. Oxygen permeabilities increased from 1.5 Barrer (PSf) to 6 Barrer (24 wt \% MIL-101/PSf MMM), while the $\mathrm{O}_{2} / \mathrm{N}_{2}$ selectivity remained 
between 5 and 6. Another important development in 2012 towards the potential industrial utilization of MOF-based MMMs came from the work of Y. Dai, et al. with the preparation of the first MOF-based hollow fiber MMMs [223]. The 13 wt \% ZIF-8/Ultem ${ }^{\mathrm{TM}}$ hollow fiber MMMs were coated with PDMS to seal surface defects and then tested for $\mathrm{CO}_{2} / \mathrm{N}_{2}$ separations (flue gas) over a range of temperatures and pressures. The hollow fiber MMMs exhibited an increase in the $\mathrm{CO}_{2} / \mathrm{N}_{2}$ separation performance at $25^{\circ} \mathrm{C}$ and 7 bar over that for pure gases (MMM: $\mathrm{CO}_{2} / \mathrm{N}_{2}=44, \mathrm{CO}_{2}=18 \mathrm{GPUs}$; PSf: $\mathrm{CO}_{2} / \mathrm{N}_{2}=36$, $\mathrm{CO}_{2}=11$ GPUs) and a decrease in $\mathrm{CO}_{2} / \mathrm{N}_{2}$ selectivity for mixed $\left(20 \% \mathrm{CO}_{2}\right.$ in $\left.\mathrm{N}_{2}\right)$ gases (MMM: ideal $\mathrm{CO}_{2} / \mathrm{N}_{2}=44, \mathrm{CO}_{2}=18$ GPU; MMM: gas mixture $\left.\mathrm{CO}_{2} / \mathrm{N}_{2}=32, \mathrm{CO}_{2}=26 \mathrm{GPU}\right)$. Nevertheless, the preparation of MOF-containing hollow fiber MMMs was a significant milestone towards the implementation of MMMs in large-scale gas separations. Another important development in 2012 came from the work of T. Yang, et al. with the testing of hollow fiber ZIF-8/PBI MMMs with ZIF-8 loadings up to $33 \mathrm{wt} \%$ for the separation of $\mathrm{H}_{2} / \mathrm{CO}_{2}(50 / 50)$ gas mixtures at 7 bar and temperatures up to $180{ }^{\circ} \mathrm{C}$ [224]. The SEM images of the cross-sections of the hollow fiber MMMs (Figure 26a) showed a thin ZIF-8/PBI selective layer on the shell side of the fiber bearing a macroporous support. Gas permeation data with $\mathrm{H}_{2} / \mathrm{CO}_{2}$ mixtures at temperatures from 25 to $180{ }^{\circ} \mathrm{C}$ (Figure 26b) showed a continuous increase in $\mathrm{H}_{2}$ permeance with increasing ZIF-8 loading, from $60 \mathrm{GPU}$ (10 wt \% ZIF-8 loading) to $200 \mathrm{GPU}$ (33 wt \% ZIF-8 loading). Selectivities for $\mathrm{H}_{2} / \mathrm{CO}_{2}$ at $180{ }^{\circ} \mathrm{C}$ ranged from 8 (33 wt \% ZIF-8 loading) to 12 (10 wt \% ZIF-8 loading). The decrease in selectivity was attributed to the larger pore aperture of ZIF-8.

Although most of the work performed until 2012 concentrated on the separation of permanent gases, the separation of volatile organic compounds with MOF-based MMMs was explored this year by C. Zhang, et al. with the preparation of $16.4 \mathrm{wt} \%$ to $48.0 \mathrm{wt} \%$ ZIF-8/6FDA-DAM MMMs and the testing of these MMMs in propylene/propane separations with pure gases and gas mixtures $\left(1: 1 \mathrm{C}_{3} \mathrm{H}_{6}: \mathrm{C}_{3} \mathrm{H}_{8}\right)$ [11]. To test the MMMs, the temperature was set to $35^{\circ} \mathrm{C}$ and the pressure was increased from 0.7 to 2.8 bar. The membrane stage cut $(\theta)$ was kept to $<1 \%$ to minimize concentration polarization of the less permeable gas (i.e., the retentate) when gas mixtures were tested. The omission of removing the retentate results in a non-constant feed composition enriched with the retentate that reduces the selectivity of the membrane. For this reason, a portion of the feed close to exposed membrane area is removed at a rate that is determined by the flux of the gases across the membrane. The MMMs showed a significant improvement in gas separation over the pure polymer for both pure and gas mixtures that put the MMMs above the Robeson [118] upper bound for $\mathrm{C}_{3} \mathrm{H}_{6} / \mathrm{C}_{3} \mathrm{H}_{8}$ separations. A gas mixture selectivity of about 18 for $\mathrm{C}_{3} \mathrm{H}_{6} / \mathrm{C}_{3} \mathrm{H}_{8}$ and a $\mathrm{C}_{3} \mathrm{H}_{6}$ permeability of 42 Barrer were obtained for the $48.0 \mathrm{wt} \%$ ZIF-8/6FDA-DAM MMMs, whereas a $\mathrm{C}_{3} \mathrm{H}_{6} / \mathrm{C}_{3} \mathrm{H}_{8}$ selectivity of about 8 and $\mathrm{a} \mathrm{C}_{3} \mathrm{H}_{6}$ permeability of about 11 Barrer was obtained for the 6FDA-DAM membrane.
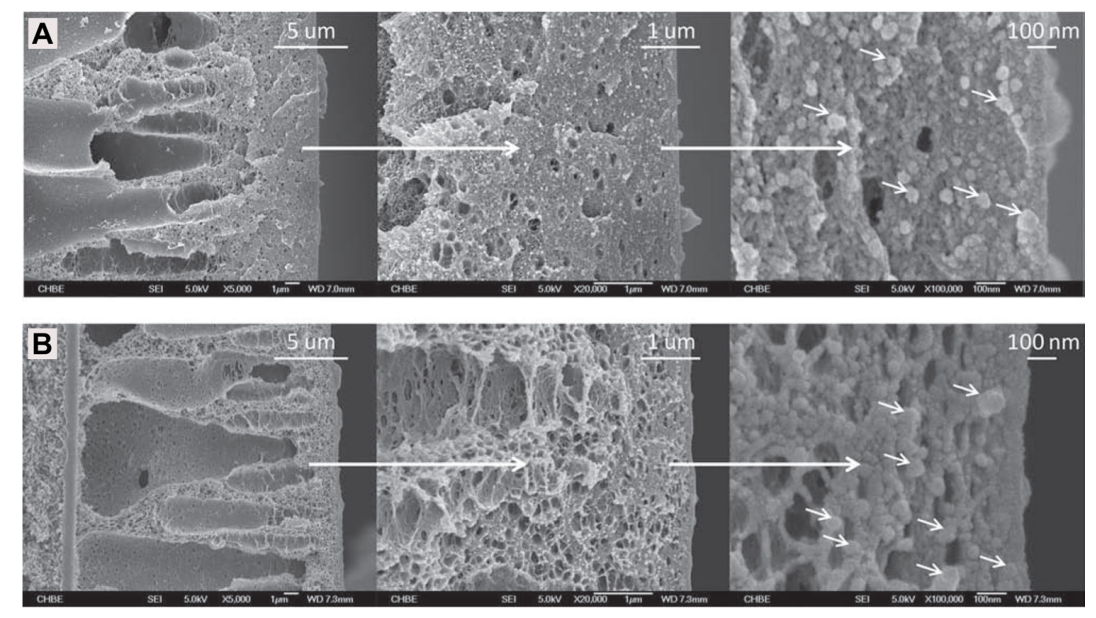

(a)

Figure 26. Cont. 

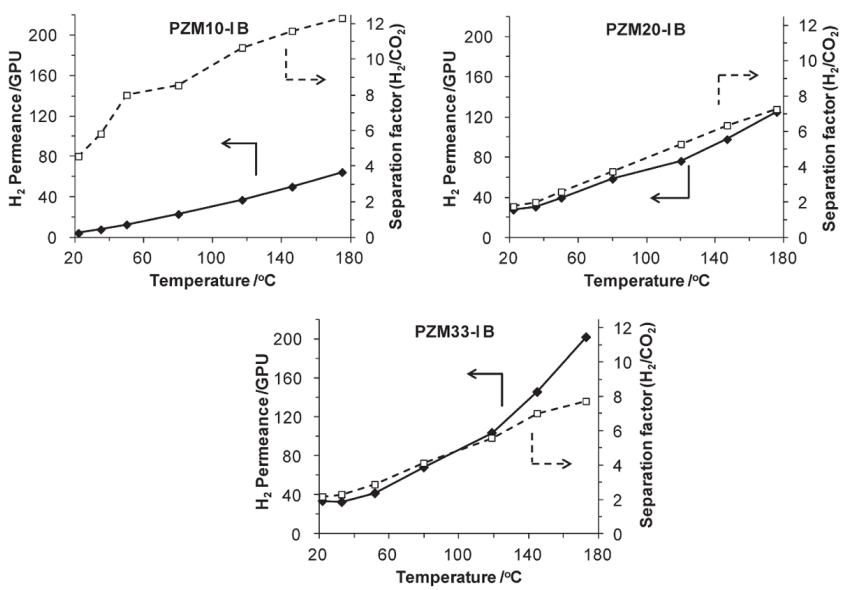

(b)

Figure 26. (a) SEM images of the cross-sections of 10 (A) and 33 (B) wt \% ZIF-8/PBI hollow fiber MMMs (arrows point to ZIF-8 nanoparticles); (b) $\mathrm{H}_{2} / \mathrm{CO}_{2}(50 / 50)$ gas mixture separation of 10 wt $\%$ (PZM10-IB), $20 \mathrm{wt} \%$ (PZM20-IB), and $33 \mathrm{wt} \%$ (PZM33-IB) hollow fiber MMMs at 7 bar with temperature increasing from 25 to $180{ }^{\circ} \mathrm{C}$. Reproduced with permission from [224]. Copyright, 2012, Wiley.

Until 2013, most polymers used for MOF-based MMMs were dense, with limited porosity. This approach changed when A. F. Bushell, et al. prepared $11 \mathrm{vol} \%, 28 \mathrm{vol} \%, 36 \mathrm{vol} \%$, and $43 \mathrm{vol} \%$ ZIF-8/PIM-1 MMMs [225]. PIM-1 (Figure 27) [226,227] is a polymer with intrinsic microporosity that results from the combination of a spirobisindane [228] as co-monomer with tetrafluorophthalonitrile.<smiles>CC1(C)CC2(CC(C)(C)c3cc(O)c(O)cc32)c2cc(O)c(O)cc21</smiles>

(a)<smiles>N#Cc1c(F)c(F)c(C#N)c(F)c1F</smiles>

(b)<smiles>COc1cc2c(cc1OC)C1(CC2(C)C)CC(C)(C)c2cc3oc4c(O)c(C#N)c(oc3cc21)c1ccccc41</smiles>

(PIM-1)

Figure 27. Synthesis of the polymer of intrinsic microporosity 1 (PIM-1) from 3,3,3' $3^{\prime}$,-tetramethyl-1, $1^{\prime \prime}$ spirobisindane-5,5' ,6,6'-tetrol (a) and 2,3,5,6-tetrafluorophthalonitrile (b).

The polymer is soluble in common organic solvents and possesses permeabilities on the order of thousands of Barrer for $\mathrm{H}_{2}$ (1300 Barrer) and $\mathrm{CO}_{2}$ (2300 Barrer) that surpass the upper bound. The polymer also exhibits good $\mathrm{H}_{2} / \mathrm{N}_{2}$ and $\mathrm{CO}_{2} / \mathrm{N}_{2}$ selectivities of 14 and 25 , respectively, that make it attractive for membrane-based gas separations [227]. Permeability experiments with the MMMs at 1 bar and $22{ }^{\circ} \mathrm{C}$ showed that the MMMs improved the permeability and selectivity of smaller gases (e.g., $\mathrm{H}_{2}, \mathrm{He}, \mathrm{O}_{2}$ ) much more than larger gases like $\mathrm{N}_{2}, \mathrm{CO}_{2}$, and $\mathrm{CH}_{4}$ (Table 2). Overall, the superior performance of ZIF-8/PIM-1 MMMs put them above the upper bound. From PALS studies, the authors concluded that the introduction of ZIF-8 in the polymer increases the free volume and the interconnectivity of the free volume of the membrane, which may result in faster diffusivities. 
Table 2. Permeabilities and selectivities of $0,11,28,36$, and 43 vol \% ZIF-8/PIM-1 MMMs. Adapted with permission from [225]. Copyright, 2013, Elsevier.

\begin{tabular}{|c|c|c|c|c|c|c|c|c|c|c|c|}
\hline \multirow{2}{*}{$\begin{array}{c}\text { ZIF-8 } \\
\text { (vol \%) }\end{array}$} & \multicolumn{6}{|c|}{ Permeability (Barrer) } & \multicolumn{5}{|c|}{ Selectivity } \\
\hline & $\mathbf{H}_{2}$ & $\mathrm{He}$ & $\mathrm{O}_{2}$ & $\mathbf{N}_{2}$ & $\mathrm{CO}_{2}$ & $\mathrm{CH}_{4}$ & $\mathrm{H}_{2} / \mathrm{N}_{2}$ & $\mathrm{H}_{2} / \mathrm{CH}_{4}$ & $\mathrm{He} / \mathrm{N}_{2}$ & $\mathrm{O}_{2} / \mathrm{N}_{2}$ & $\mathrm{CO}_{2} / \mathrm{CH}_{4}$ \\
\hline 0 & 1630 & 760 & 580 & 180 & 4390 & 310 & 9.1 & 5.3 & 4.2 & 3.2 & 14.2 \\
\hline 11 & 2560 & 1310 & 820 & 250 & 4815 & 320 & 10.2 & 8.0 & 5.2 & 3.3 & 15.0 \\
\hline 28 & 2980 & 1430 & 870 & 195 & 4270 & 230 & 15.2 & 13.0 & 7.3 & 4.5 & 18.6 \\
\hline 36 & 5745 & 2930 & 1640 & 380 & 6820 & 510 & 15.1 & 11.3 & 7.7 & 4.3 & 13.4 \\
\hline 43 & 6680 & 3180 & 1680 & 350 & 6300 & 430 & 19.1 & 15.5 & 9.1 & 4.8 & 14.7 \\
\hline
\end{tabular}

A second PALS study on the correlation of gas permeability with free volume came also in 2013 from H. B. T. Jeazet, et al. using 7.5, 14, 19, and $24 \mathrm{wt} \%$ (Cr) MIL-101/PSf $M M M s$ for $\mathrm{O}_{2}, \mathrm{~N}_{2}, \mathrm{CO}_{2}$, and $\mathrm{CH}_{4}$ separations [229]. SEM images (Figure 28a) of the MMMs showed even MOF distributions and good wetting of the particles by the polymer. As with other MOF-based MMMs, permeabilities at $30^{\circ} \mathrm{C}$ and 3 bar increased with increasing MOF loading, but selectivities remained constant.

Using PALS studies and the Tao and Eldrup standard model that correlates the pick-off lifetime of ortho-positronium to the free volume hole size in polymers, the authors attributed the increase in permeability to the free volume in the polymer and the added large free volume in the MIL-101 particles (Figure 28b). PALS also indicated that the polymer chains did not penetrate into the pores and that both the polymer and the MOF structures were not affected. The results also suggested that neither defects nor additional free volume in the polymer and at the MOF/polymer interface was introduced. This same year (2013), T. Singh, et al. [230] performed a finite element analysis on single component permeation in MMMs that resulted in contradictions in the fundamental assumptions of the Maxwell, Bruggeman, Pal, Lewis-Nielsen, and other models [231,232] that describe or predict gas transport (permeability and selectivity) in MMMs. The hypothesis for their work was that the effects of the interfacial adsorption equilibrium constant $(K)$ on permeability were not taken into account in the models by implicitly considering $K \approx 1$, when in reality most filler/polymer interfaces may not have interfacial equilibrium constants of $1(K \neq 1)$. The assumption that $K \approx 1$ ultimately leads to an erroneous interpretation that deviations of experimental results from the models are due to "non-idealities", polymer rigidification, or defects at the filler/polymer interface. These observations about the models are even more important for MOF-based MMMs because MOFs have better compatibility with the polymer, which greatly reduces defects in the membrane. Singh, et al. concluded that there was a need to perform a "rigorous" prediction of permeation in ideal MMMs to separate the true dependence of the permeability on the diffusivities in the matrix and filler phases, the filler/polymer interface adsorption equilibrium, and the volume fraction of the filler. With these predictions, it would then be possible to reliably interpret MMM data and separate the effects of the filler properties from non-idealities or defects. Singh, et al. developed an "exact model" that takes into account the effects of interfacial equilibrium between the filler and the matrix and the differences in diffusivity between the filler and the polymer. The solution to their model was performed by finite element analysis using COMSOL Multiphysics. From their model, they conclude that the individual values of $K$ and the diffusivity ratio $D_{f} / D_{m}$ determine the MMM permeability and not the combined permeability ratio $P_{f} / P_{m}=K D_{f} / D_{m}$. In this work, the authors also back-calculated the permeability of $\mathrm{CO}_{2}$ in ZIF-8 from the experimental data of 6 different ZIF-8/ polymer (Torlon ${ }^{\circledR}$, Ultem ${ }^{\mathrm{TM}}$, Matrimid ${ }^{\circledR}$, 6FDA-DAM:DABA 4:1, 6FDA-DAM, and PDMS) MMMs using the Maxwell and Lewis-Nielsen models. The results show that the models fail to predict the permeability of $\mathrm{CO}_{2}$ in ZIF-8 at different loadings (Figure 29). 


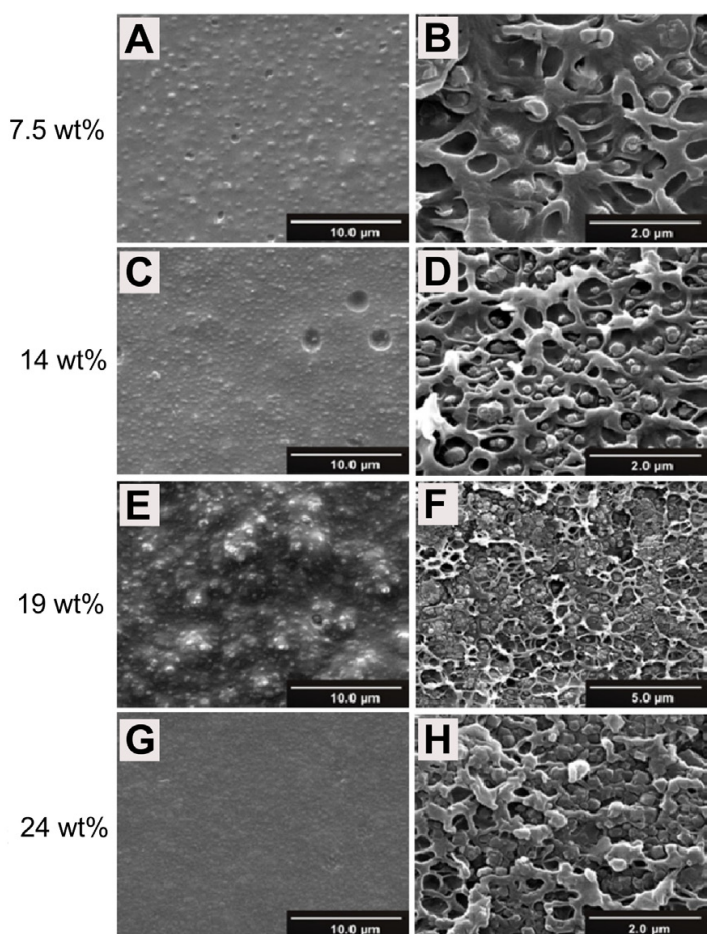

(a)

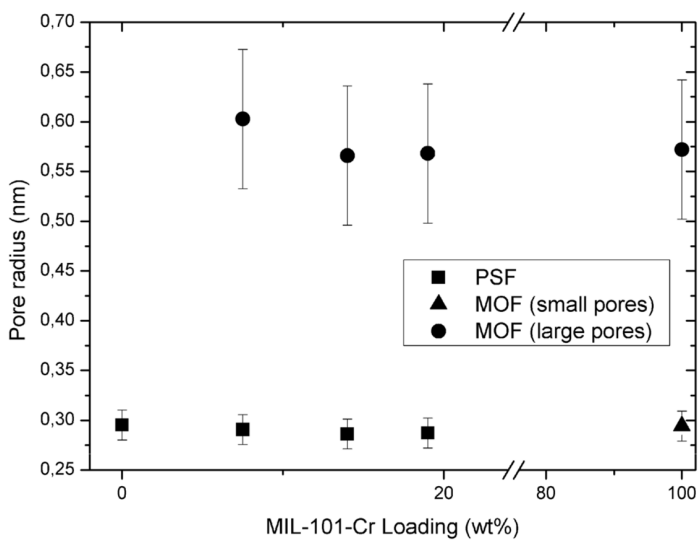

(b)

Figure 28. (a) SEM images of the surfaces (A,C,E,G) and cross-sections (B,D,F,H) of MIL-101/PSf MMMs; (b) Pore radii of the free volume with increasing MIL-101 loading in PSf. Adapted with permission from [229]. Copyright, 2013, MDPI under the Creative Commons Attribution License (CCBY).

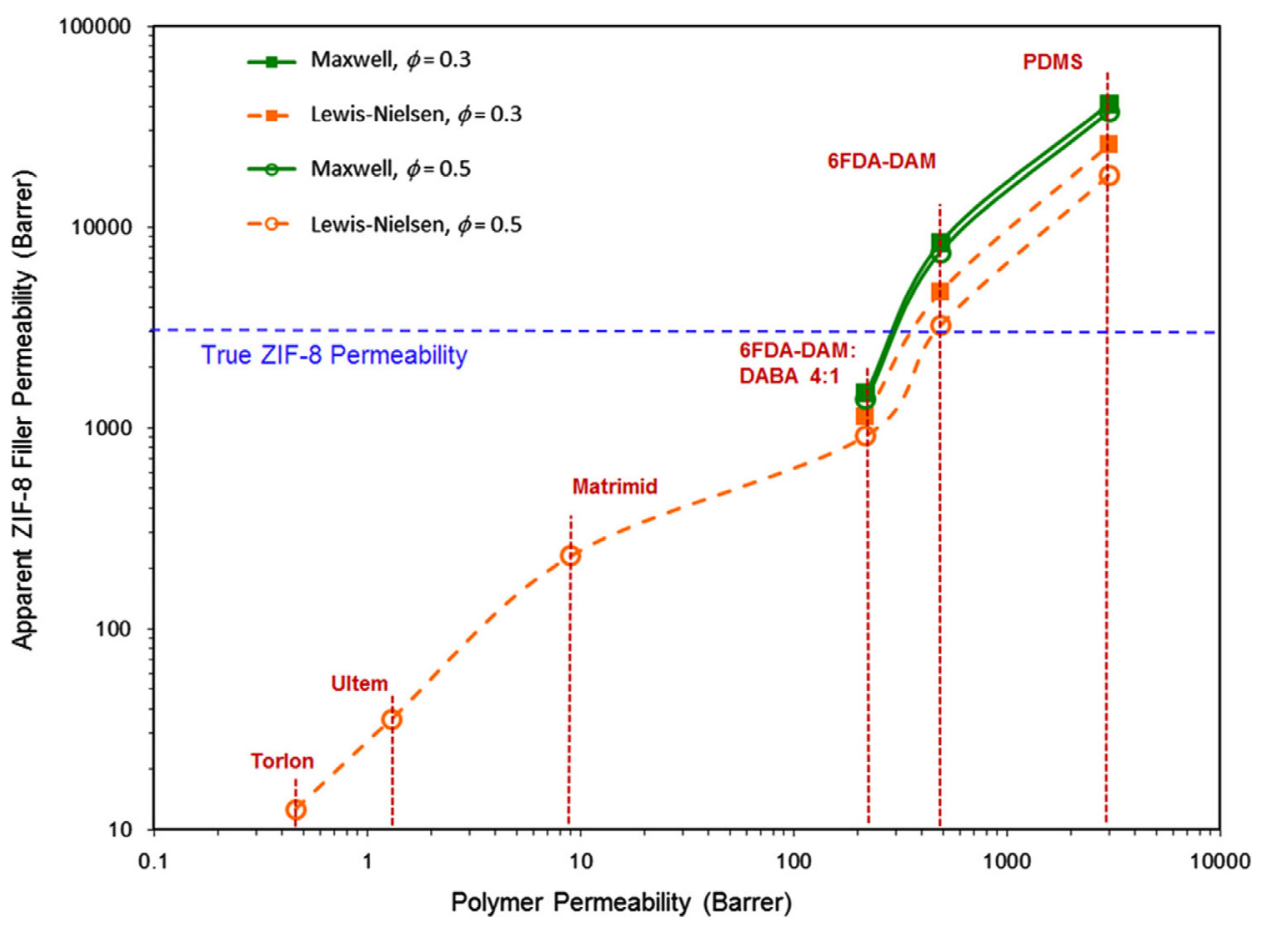

Figure 29. Back-calculated apparent $\mathrm{CO}_{2}$ permeabilities of ZIF-8 according to polymer permeability and ZIF loading $(\phi)$. True ZIF-8 permeability obtained from experimental data. Reproduced with permission from [230]. Copyright, 2013, Elsevier. 
A new approach into the preparation of MOF-based MMMs was also introduced in 2013 by L. Hao, et al. [233] with the preparation of RTILs/ZIF-8/polyRTILs MMMs aiming to improve the performance of RTILs/polyRTILs membranes with the addition of ZIF-8. RTILs have been shown to have a good $\mathrm{CO}_{2}$ affinity making them attractive for $\mathrm{CO}_{2} / \mathrm{N}_{2}$ and $\mathrm{CO}_{2} / \mathrm{CH}_{4}$ separations, but for their application in gas separations they needed to be immobilized. An approach to immobilize RTILs is the preparation of UV-polymerizable RTILs to prepare polyRTILs membranes. Although polyRTILs retain much of the selectivity of RTILs, the resulting membranes exhibit lower $\mathrm{CO}_{2}$ permeabilities than the RTILs, for this reason polyRTILs are doped with RTILs, but further permeability improvements could be achieved with the incorporation of porous fillers (e.g., SAPO-34, ZIF-8). The authors prepared ZIF-8/polyRTILs MMMs and RTILs/ZIF-8/polyRTILs MMMs with 0, 10, 20, and 25 wt \% ZIF-8 loadings keeping the RTILs/polyRTILs ratio to 1:2 for all the RTILs/ZIF-8/polyRTILs MMMs. The free RTILs in the MMMs were [emim] $\left[\mathrm{NTf}_{2}\right]$, $[\mathrm{emim}]\left[\mathrm{BF}_{4}\right]$, and $[\mathrm{emim}]\left[\mathrm{B}(\mathrm{CN})_{4}\right]$ and the UV-polymerizable RTIL was [vbim] $\left[\mathrm{NTF}_{2}\right]$. Gas permeation experiments were performed at $35{ }^{\circ} \mathrm{C}$ and 3.5 bar with $\mathrm{CO}_{2}$, $\mathrm{N}_{2}, \mathrm{CH}_{4}$, and $\mathrm{CO}_{2} / \mathrm{N}_{2}$ and $\mathrm{CO}_{2} / \mathrm{CH}_{4}$ mixtures at 50/50 mol \%. The results showed a retention of $\mathrm{CO}_{2} / \mathrm{N}_{2}$ and $\mathrm{CO}_{2} / \mathrm{CH}_{4}$ selectivities for the ZIF-8/polyRTILs at 20 and 12, respectively, with ZIF-8 loadings up to $18.9 \mathrm{wt} \%$. For these MMMs, $\mathrm{CO}_{2}$ permeabilities increased from $101(0 \mathrm{wt} \% \mathrm{ZIF}-8)$ to 199 Barrer (18.9 wt \% ZIF-8), a 100\% increase in $\mathrm{CO}_{2}$ permeability. The incorporation of the free RTILs in the ZIF-8/polyRTILs MMMs (RTILs/ZIF-8/polyRTILs) increased $\mathrm{CO}_{2}$ permeability in all cases with a retention or small decrease in selectivity. The maximum $\mathrm{CO}_{2}$ permeability achieved was with the addition of free [emim] $\left[\mathrm{B}(\mathrm{CN})_{4}\right]$ to the $25 \mathrm{wt} \%$ ZIF-8/polyRTILs MMM, this membrane provided a $\mathrm{CO}_{2}$ permeability increase of $190 \%$ from the RTILs/polyRTILs MMM (at 0 wt \% ZIF-8 loading: $\mathrm{CO}_{2}=365$ Barrer, $\mathrm{CO}_{2} / \mathrm{N}_{2}=29.9, \mathrm{CO}_{2} / \mathrm{CH}_{4}=15.8$; at 25 wt \% ZIF-8 loading: $\mathrm{CO}_{2}=1062$ Barrer, $\left.\mathrm{CO}_{2} / \mathrm{N}_{2}=24.2, \mathrm{CO}_{2} / \mathrm{CH}_{4}=12.3\right)$. Gas mixture separations for this membrane showed a slight decrease in selectivities $\left(\mathrm{CO}_{2} / \mathrm{N}_{2}=20.1, \mathrm{CO}_{2} / \mathrm{CH}_{4}=11.6\right)$, as is the case with most polymer membranes. The results of this work matched very well with the predictions of the Maxwell model and proved that the combination of free RTILs and ZIF-8 improve the separation properties of the polyRTILs in the form of RTILs /ZIF-8/polyRTILs MMMs.

Although the most common mode of operation for a polymer membrane is to permeate the smaller gas molecule rather than the larger one, some types of membranes allow larger molecules to permeate faster than smaller molecules, reversing the selectivity of the membrane. In 2014, R. Abedini, et al. reported on the use of MIL-53 and PMP in the preparation of MIL-53/PMP MMMs for reverse $\mathrm{CO}_{2} / \mathrm{H}_{2}$ separations [234]. The MMMs showed increased $\mathrm{CO}_{2}$ solubility with increasing MOF loading up to $40 \mathrm{wt} \%$, which led to an increase in $\mathrm{CO}_{2} / \mathrm{H}_{2}$ separation and $\mathrm{CO}_{2}$ permeability. The $\mathrm{CO}_{2} / \mathrm{H}_{2}$ selectivity increased from 8.86 for PMP to 16.92 for $35 \mathrm{wt} \% \mathrm{MIL}-53 / \mathrm{PMP}$, and the $\mathrm{CO}_{2}$ permeability increased from 98.74 for PMP to 225.21 for 35 wt \% MIL-53/PMP. Diffusivities, however, experienced a small decreased with MOF loading. Also in 2014, L. Diestel, et al. performed $\mathrm{CO}_{2} / \mathrm{CH}_{4}, \mathrm{CO}_{2} / \mathrm{N}_{2}, \mathrm{H}_{2} / \mathrm{CO}_{2}$, and $\mathrm{O}_{2} / \mathrm{N}_{2}$ pure and gas mixture separation studies on pure ZIF-8, pure polymer (PMPS), and the 8.3 wt \% ZIF-8/PMPS MMM prepared on $\alpha$-alumina supports [235]. In all cases, the alumina support (70 nm particles) was immersed in the synthesis (ZIF-8 membrane from seeding and secondary growth) or casting solutions (PMPS and MMM) to coat the surface. SEM images (Figure 30) show that thin membranes $(<20 \mu \mathrm{m})$ were deposited onto the substrate. 

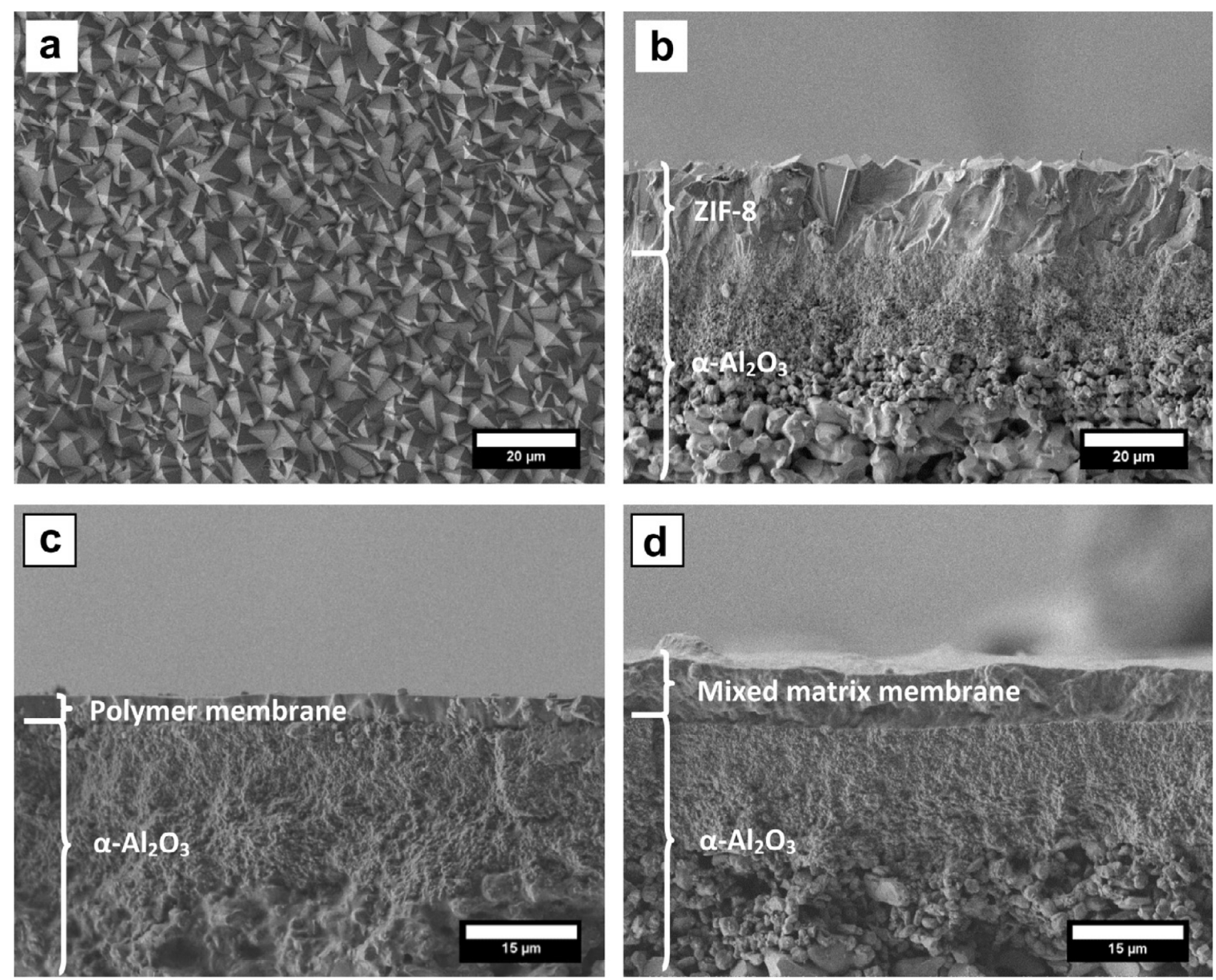

Figure 30. SEM images of the surface (a) and cross-section (b) of a ZIF- 8 membrane on an $\alpha-\mathrm{Al}_{2} \mathrm{O}_{3}$ support. The cross-sections of the PMPS and the $8.3 \mathrm{wt} \%$ ZIF-8/PMPS MMM are shown in (c) and (d), respectively. Reproduced with permission from [235]. Copyright, 2014, Elsevier.

The membranes were tested at $\Delta \mathrm{P}=0.2 \mathrm{bar}$, and the permeates were analyzed using a GC. Gas permeation results indicated that the ZIF-8 membrane performed molecular sieving, but without a sharp cut off due to the flexibility of the ZIF. The authors also observed that gas separations for the PMPS membrane and the MMM were driven mainly by a solubility process. The observed gas permeabilities (in Barrer) were: $\mathrm{ZIF}-8\left(\mathrm{H}_{2}=2598, \mathrm{CH}_{4}=234, \mathrm{CO}_{2}=623, \mathrm{~N}_{2}=260, \mathrm{O}_{2}=468\right)$, PMPS $\left(\mathrm{H}_{2}=34, \mathrm{CH}_{4}=37, \mathrm{CO}_{2}=305, \mathrm{~N}_{2}=35, \mathrm{O}_{2}=58\right)$, and $\mathrm{MMM}\left(\mathrm{H}_{2}=103, \mathrm{CH}_{4}=114, \mathrm{CO}_{2}=827, \mathrm{~N}_{2}=118\right.$, $\mathrm{O}_{2}=190$ ). From the three membranes tested, the authors found that the MMM had identical selectivity to the polymer, but with higher fluxes, which was attributed to the increased free volume in the MMM by the presence of the MOF. The authors also did not observe significant variations in ideal and gas mixture selectivities among the membranes tested. In another work carried out by L. Diestel, et al. in 2015 [236] the authors performed a comparison study using experimental data of $\mathrm{H}_{2}$ and $\mathrm{CH}_{4}$ gas permeation properties and the Maxwell model predictions. The authors prepared membranes of ZIF-8, ZIF-90, Matrimid ${ }^{\circledR}$, and the 10, 20, and 30 vol \% ZIF-8/Matrimid ${ }^{\circledR}$ and ZIF-90/Matrimid ${ }^{\circledR}$ MMMs on porous $\alpha$ alumina supports with a pore size of $70 \mathrm{~nm}$. Permeability data for both ZIF-8 and ZIF-90 MMMs showed that at 10 and $20 \mathrm{vol} \%$ ZIF loadings the MMMs exhibited lower permeabilities and higher $\mathrm{H}_{2} / \mathrm{CH}_{4}$ selectivities than the polymer and the respective $\mathrm{ZIF}$ membrane and were significantly different to what the Maxwell model would predict. At 30 vol \% loadings the MMMs showed less selectivity and reduced permeability than the polymer and still deviated significantly from the Maxwell model. The authors attributed the improved selectivity and reduced permeability of the MMMs to the 
limited flexibility of the ZIF framework resulting from the blockage of linker distortions in the ZIFs caused by the polymer/ZIF interactions.

More progress was made when, in 2014, C. Duan, et al. reported on the effect of thermal treatment on gas permeation [237]. The authors prepared $\mathrm{Cu}_{3}(\mathrm{BTC})_{2}$ MMMs (0 to $50 \mathrm{wt} \%$ loadings) from DMAc using Matrimid ${ }^{\circledR}$ and ODPA-TMPDA polymers as well as ZIF-8 MMMs with ODPA-TMPDA. The membranes were dried for 1 day at temperatures ranging from $150{ }^{\circ} \mathrm{C}$ to $220{ }^{\circ} \mathrm{C}$ before gas permeation tests were performed. The authors observed that, for both the polymer and the MMMs, an increase in permeability was achieved when the membranes were dried above the boiling point of the solvent (DMAc) and that above this temperature no significant increase in gas permeability was observed. It was concluded that incomplete removal of solvent from the membranes and from the MOFs reduced gas permeability in MMMs. Another contribution in the MOF-based MMM field came from N. A. Nordin, et al. in 2014 [238]. The authors prepared asymmetric $5 \mathrm{wt} \%$ ZIF-8/PSf membranes from NMP/THF using ZIF-8 crystals that they synthesized with sizes of 100,300 , and $500 \mathrm{~nm}$. Testing the membranes at $27^{\circ} \mathrm{C}$ and 4 bar with $\mathrm{CH}_{4}$ and $\mathrm{CO}_{2}$ revealed that the MOF particle size played an important role in the performance of the MMMs. ZIF-8 particles of $100 \mathrm{~nm}$ suffered from partial pore blockage, increased tortuosity due to the large number of small particles, and polymer rigidification that resulted in increased $\mathrm{CO}_{2} / \mathrm{CH}_{4}$ selectivity, compared to the MMMs with 300 and $500 \mathrm{~nm}$ ZIF-8 particles, and a reduction in $\mathrm{CO}_{2}$ permeability. The performance of this membrane, however, was still inferior to that of PSf, with $58 \%$ reduction in permeability and $38 \%$ reduction in selectivity with respect to PSf. Larger ZIF-8 particles (300 and $500 \mathrm{~nm}$ ) introduced non-selective voids at the interface that increased the permeability of the gases and reduced the selectivity of the MMM.

Another contribution came in 2014 from the work of E. V. Perez, et al. with MOP-18/Matrimid ${ }^{\circledR}$ MMMs [126]. This was the first time MOP-18 nanocages (Figure 14b) were incorporated into a polymer matrix and tested for gas separation at high pressures and elevated temperatures. Since the crystal or particle size is the limiting factor for the degree of dispersion of MOFs and ZIFs in polymers, independent of the procedure taken for its dispersion, the use of molecular cages in MMMs was the next logical step to follow. MOPs and MOCs are molecular cages that can be dissolved in organic solvents and, therefore, dispersed in polymer matrices at the molecular level, achieving greater particle (molecule)/polymer contact than with ZIFs and MOFs. Perez, et al. synthesized MOP-18 and prepared $0,23,33,44$, and $80 \mathrm{wt} \% \mathrm{MOP}-18 /$ Matrimid $^{\circledR}$ MMMs that did not show aggregation or gross defects. SEM images of the membranes showed smooth and even morphologies on both the surface and cross-sections of the MMMs (Figure 31) without signs of aggregation or gross defects, even at the extremely high MOP-18 loading of $80 \mathrm{wt} \%$. Compared to MOF-based MMMs, the MOP-18-based MMMs did not show macroscopic plastic deformation or rigidification at the MOP/polymer interface. The membranes were tested with $\mathrm{H}_{2}$ and $\mathrm{CO}_{2}$ at 35 and $70{ }^{\circ} \mathrm{C}$ and from 3 to 50 bar. Other gases, like $\mathrm{N}_{2}$, $\mathrm{O}_{2}, \mathrm{CH}_{4}, \mathrm{C}_{3} \mathrm{H}_{6}$, and $\mathrm{C}_{3} \mathrm{H}_{8}$, were also tested but at lower pressures (2.6 bar). Gas permeation results (Figure 32a) showed that the $44 \mathrm{wt} \% \mathrm{MOP}-18 /$ Matrimid $^{\circledR}$ MMM increased the permeability for small molecules, such as $\mathrm{H}_{2}, \mathrm{CO}_{2}, \mathrm{O}_{2}$, and $\mathrm{N}_{2}$, by up to $100 \%$. Larger molecules, however, experienced higher increases in permeability, with $\mathrm{CH}_{4}, \mathrm{C}_{3} \mathrm{H}_{8}$, and $\mathrm{C}_{3} \mathrm{H}_{6}$ increasing by $330 \%, 433 \%$, and $770 \%$, respectively, indicating the MOP's affinity for hydrocarbons that was attributed to the presence of new sorption sites associated with the MOP-18 molecules like the pore, the surface of the core, and the alkyl chains that extend from the organic linker. Selectivities (Figure 32b) decreased for most gas pairs except for $\mathrm{C}_{3} \mathrm{H}_{8} / \mathrm{N}_{2}$ and $\mathrm{C}_{3} \mathrm{H}_{6} / \mathrm{N}_{2}$, which experienced significant increase in selectivity relative to the polymer. High pressure experiments with $\mathrm{H}_{2}$ up to 30 bar and $\mathrm{CO}_{2}$ up to 50 bar at 35 and $70{ }^{\circ} \mathrm{C}$ also demonstrated that the MMMs were mechanically robust and that no defects were present at the MOP-18/Matrimid ${ }^{\circledR}$ interface that would reduce the selectivity since $\mathrm{H}_{2} / \mathrm{CO}_{2}$ selectivites at 30 bar and $70{ }^{\circ} \mathrm{C}$ decreased only slightly from 2.42 (Matrimid ${ }^{\circledR}$ ) to 2.04 (23 wt \% MOP-18/Matrimid ${ }^{\circledR}$ MMM). High pressure $\mathrm{CO}_{2}$-induced plasticization studies performed with the polymer and the MMMs also showed that 
the degree of plasticization depends largely on temperature and that, at higher temperatures, the plasticization pressure increases for both the polymer and the MMM (Figure 33).

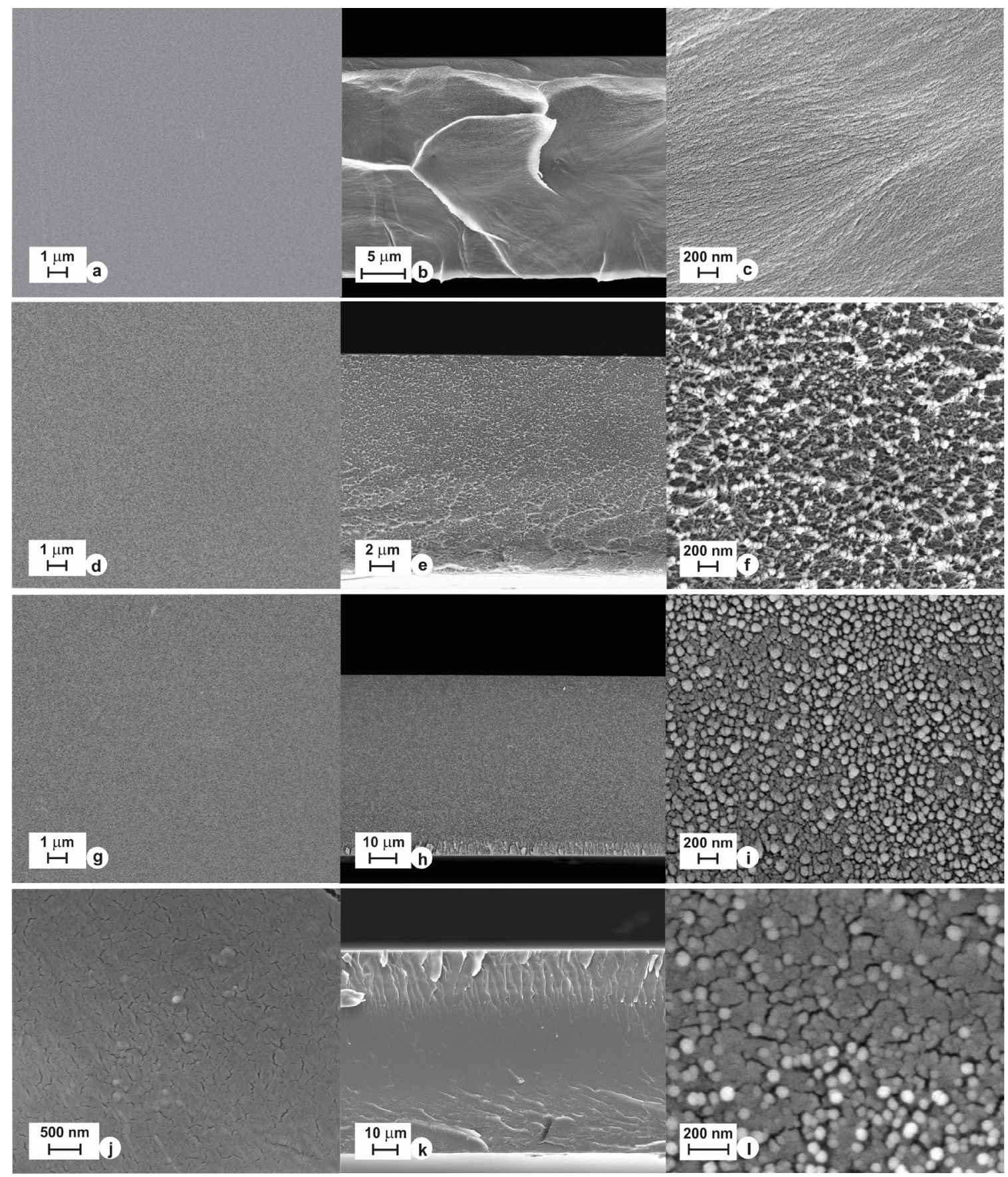

Figure 31. SEM images of the surfaces $(\mathbf{a}, \mathbf{d}, \mathbf{g}, \mathbf{j})$, cross-sections at low magnification $(\mathbf{b}, \mathbf{e}, \mathbf{h}, \mathbf{k})$, and cross-sections at high magnification $(\mathbf{c}, \mathbf{f}, \mathbf{i}, \mathbf{l})$ of $0(\mathbf{a}-\mathbf{c}) ; 23(\mathbf{d}-\mathbf{f}) ; 44(\mathbf{g}-\mathbf{i}) ;$ and $80(\mathbf{j}-\mathbf{l})$ wt \% MOP-18/Matrimid ${ }^{\circledR}$ MMMs. Reproduced with permission from [126]. Copyright, 2014, Elsevier. 


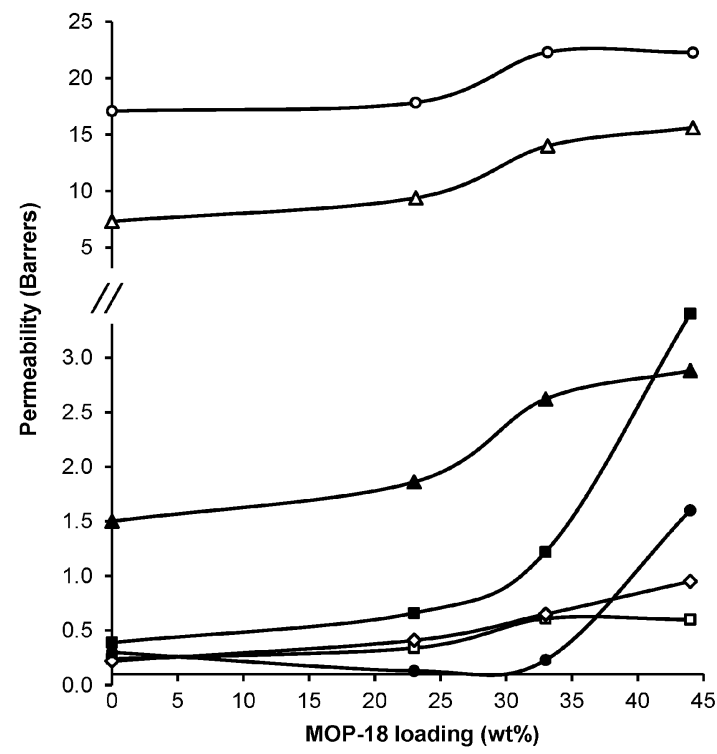

(a)

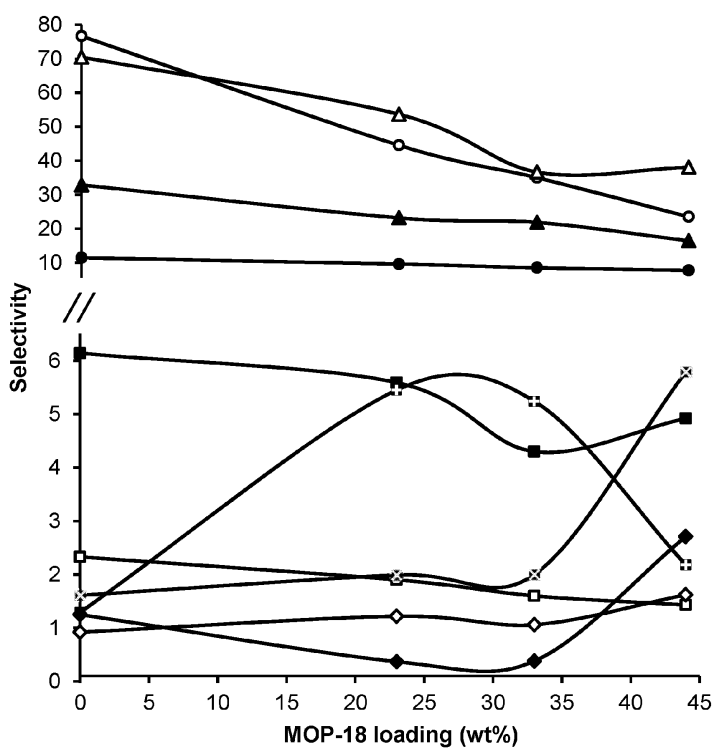

(b)

Figure 32. (a) Permeabilities of MOP-18/Matrimid ${ }^{\circledR} \mathrm{MMMs}$ at $35{ }^{\circ} \mathrm{C}$ and 2.6 bar: $\mathrm{H}_{2}(\bigcirc), \mathrm{CO}_{2}(\Delta)$, $\mathrm{O}_{2}(\boldsymbol{\Delta}), \mathrm{C}_{3} \mathrm{H}_{6}(\boldsymbol{\square}), \mathrm{N}_{2}(\square), \mathrm{CH}_{4}(\diamond)$, and $\mathrm{C}_{3} \mathrm{H}_{8}(\bullet)$; (b) Ideal selectivities of MOP-18/Matrimid ${ }^{\circledR}$ MMMs: $\mathrm{O}_{2} / \mathrm{N}_{2}(\boldsymbol{\square}), \mathrm{H}_{2} / \mathrm{CO}_{2}(\square), \mathrm{CH}_{4} / \mathrm{N}_{2}(\diamond), \mathrm{C}_{3} \mathrm{H}_{8} / \mathrm{N}_{2}(\diamond), \mathrm{C}_{3} \mathrm{H}_{6} / \mathrm{N}_{2}(\mathrm{x}), \mathrm{C}_{3} \mathrm{H}_{6} / \mathrm{C}_{3} \mathrm{H}_{8}(+), \mathrm{H}_{2} / \mathrm{CH}_{4}(\bigcirc)$, $\mathrm{H}_{2} / \mathrm{N}_{2}(\Delta), \mathrm{CO}_{2} / \mathrm{CH}_{4}(\boldsymbol{\Delta})$, and $\mathrm{H}_{2} / \mathrm{O}_{2}(\bullet)$. Reproduced with permission from [126]. Copyright, 2014, Elsevier.

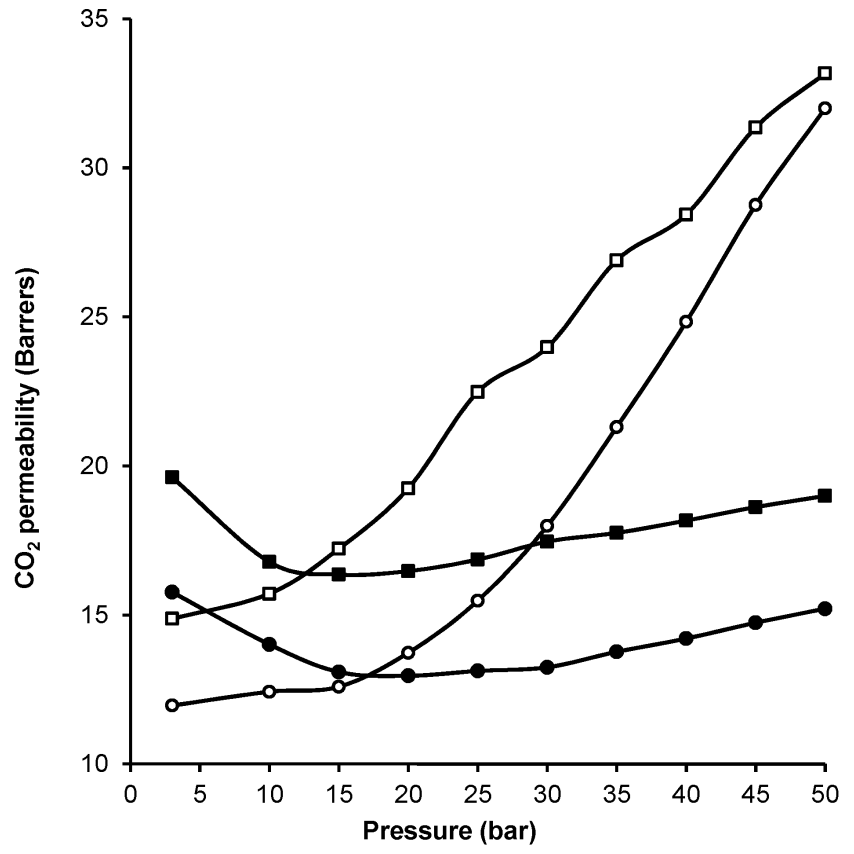

Figure 33. Permeability-pressure isotherms of $\mathrm{CO}_{2}$ in $\mathrm{Matrimid}^{\circledR}(\bigcirc$ and $\bullet$ ) and the $23 \mathrm{wt} \%$ MOP-18/Matrimid ${ }^{\circledR}$ MMM ( $\square$ and $\square$ ). Open symbols for $35{ }^{\circ} \mathrm{C}$ and solid symbols for $70{ }^{\circ} \mathrm{C}$. Reproduced with permission from [126]. Copyright, 2014, Elsevier.

The authors also performed high pressure and high temperature gas adsorption studies on MOP-18 crystals, Matrimid ${ }^{\circledR}$, and the 23 wt \% MOP-18/Matrimid ${ }^{\circledR}$ MMM. The results showed an impressive $\mathrm{CO}_{2}$ uptake at high pressure (30 bar) and elevated temperatures (Figure 34) that was comparable to that of MOFs and activated carbons. The sudden uptake of $\mathrm{CO}_{2}$ was attributed to 
the opening of the pores of the MOF that allowed the penetration of $\mathrm{CO}_{2}$ molecules into the pore. The results also showed that MOP-18 in the MMM was able to adsorb more $\mathrm{CO}_{2}$ than in its crystalline state. This behavior was attributed to the blockage of the pores by the long alkyl chains when MOP-18 is the crystalline form, whereas incorporation of the MOP into the polymer extends the chains from the surface of the MOP into the matrix, thereby exposing the pores.

a

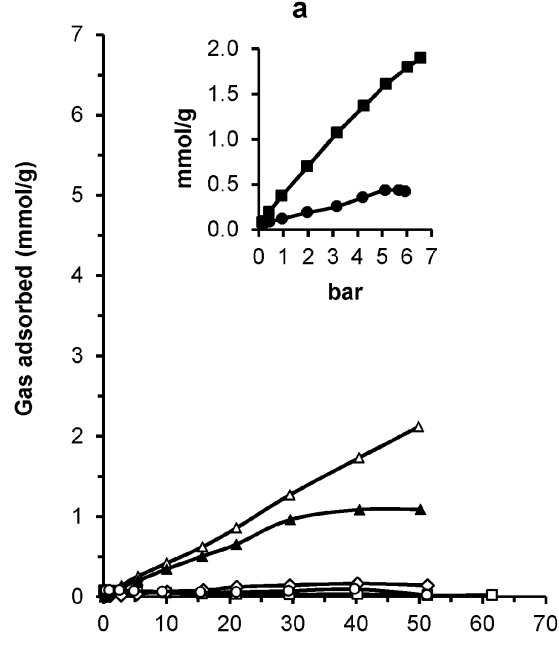

b

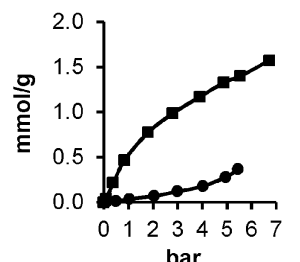

bar

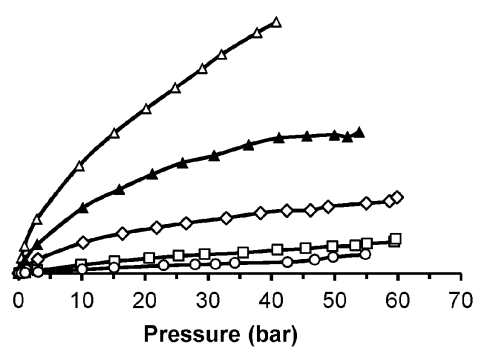

C

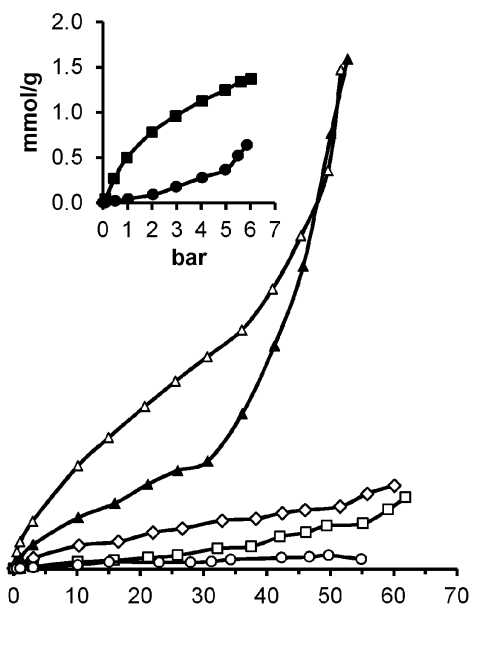

Figure 34. Gas adsorption isotherms of $\mathrm{N}_{2}(\square), \mathrm{CH}_{4}(\diamond), \mathrm{H}_{2}(\bigcirc), \mathrm{CO}_{2}(\Delta), \mathrm{C}_{3} \mathrm{H}_{6}(\boldsymbol{\square}$, insert) and $\mathrm{C}_{3} \mathrm{H}_{8}\left(\bullet\right.$, insert) at $35^{\circ} \mathrm{C}$ and $\mathrm{CO}_{2}(\boldsymbol{\Delta})$ at $70{ }^{\circ} \mathrm{C}$ in: (a) MOP-18 crystals; (b) Matrimid ${ }^{\circledR}$ membranes; and (c) 23 wt \% MOP-18/Matrimid ${ }^{\circledR}$ MMMs. Reproduced with permission from [126]. Copyright, 2014, Elsevier.

Another step in the development of MOF-based- MMMs for industrial applications came also in 2014, when S. Shahid, et al. reported on the testing of MOF-based MMMs at low and high pressures (40 bar) with pure and $\mathrm{CO}_{2} / \mathrm{CH}_{4}$ gas mixtures at $35^{\circ} \mathrm{C}[239,240]$. The testing of MMMs at high pressures is important since it puts to the test the strength of the MOF/polymer interface. S. Shahid, et al. prepared flat MMMs of MIL-53, ZIF-8, and $\mathrm{Cu}_{3} \mathrm{BTC}_{2}$ with Matrimid ${ }^{\circledR}$ with loadings up to $30 \mathrm{wt} \%$ and dried them at $200{ }^{\circ} \mathrm{C}$, the MMMs showed an increased $\mathrm{CO}_{2} / \mathrm{CH}_{4}$ selectivity due to the interactions of $\mathrm{CO}_{2}$ with the MOFs that increased its permeability in the membranes and to the sieving properties of the MMMs for $\mathrm{CH}_{4}$ that decreased its permeability. Mixed gas separation, however, showed a significant decrease in the $\mathrm{CO}_{2} / \mathrm{CH}_{4}$ selectivity for the polymer with increasing pressure due to plasticization. The effects of the $\mathrm{CO}_{2}$-induced plasticization on the polymer were reduced with MOF loading increments that, in turn, increased the MMM's $\mathrm{CO}_{2} / \mathrm{CH}_{4}$ selectivity from 15 to 40 .

Although SEM images provide a good representation of the distribution of the MOF in the membrane, the spatial distribution of the MOF particles in MMMs was not performed until 2014 when T. Rodenas, et al. performed tomographic SEM imaging of the MMM cross-sections milled with $\mathrm{Ga}^{+}$ ions (FIB-SEM) [241]. The aim of the work was to assess the distribution of the filler and its contact with the polymer by ion milling the MMMs, imaging the exposed cross-sections, and reconstructing a 3D image from a set of 2D SEM images. Ion milling (FIB) effectively avoids the introduction of artifacts and rough surfaces that generally result from freeze-fracture, allowing visualization of the spatial distribution of the MOF in the polymer as well as large defects (i.e., voids), if present, that may originate from the casting process. The authors synthesized (Al) $\mathrm{NH}_{2}-\mathrm{MIL}-53$ crystals and then prepared 25 wt \% $\mathrm{NH}_{2}$-MIL-53/Matrimid ${ }^{\circledR}$ MMMs that were FIB milled for SEM imaging in the BSE mode (Figure 35). In the BSE mode, the intensity scales with the atomic number of the elements present in the sample, making it suitable for imaging areas with different chemical compositions (e.g., the MOF and the polymer). Another advantage of this mode is that it provides a more uniform contrast than the 
in-lens mode. The images show a random and even distribution of the MOF in the matrix (Figure 35b) with the presence of voids at the MOF agglomerates (Figure 35c). Upon alignment of the stack of 2D SEM images, the 3D structure of the analyzed volume was reconstructed (Figure 36a,c,d) and segmentation of each phase (polymer, MOF, voids) by image thresholding generated the volumes corresponding to the MOF (Figure 36b) and voids (Figure 36e).
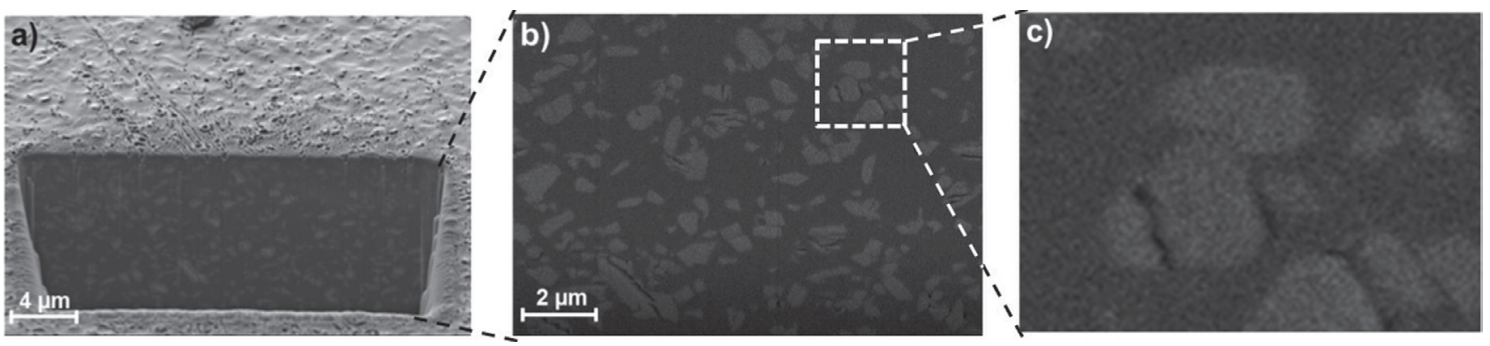

Figure 35. SEM images of a 25 wt \% $\mathrm{NH}_{2}-\mathrm{MIL}-53 /$ Matrimid $^{\circledR}$ MMM cross-section: (a) low magnification image of the hole milled with focused ion beam (FIB); (b) representative image of the cross-section obtained in backscattered electron (BSE) mode; (c) enlarged view showing the contrast between the polymer, MOF, and voids. Reproduced with permission from [241]. Copyright, 2014, Wiley.

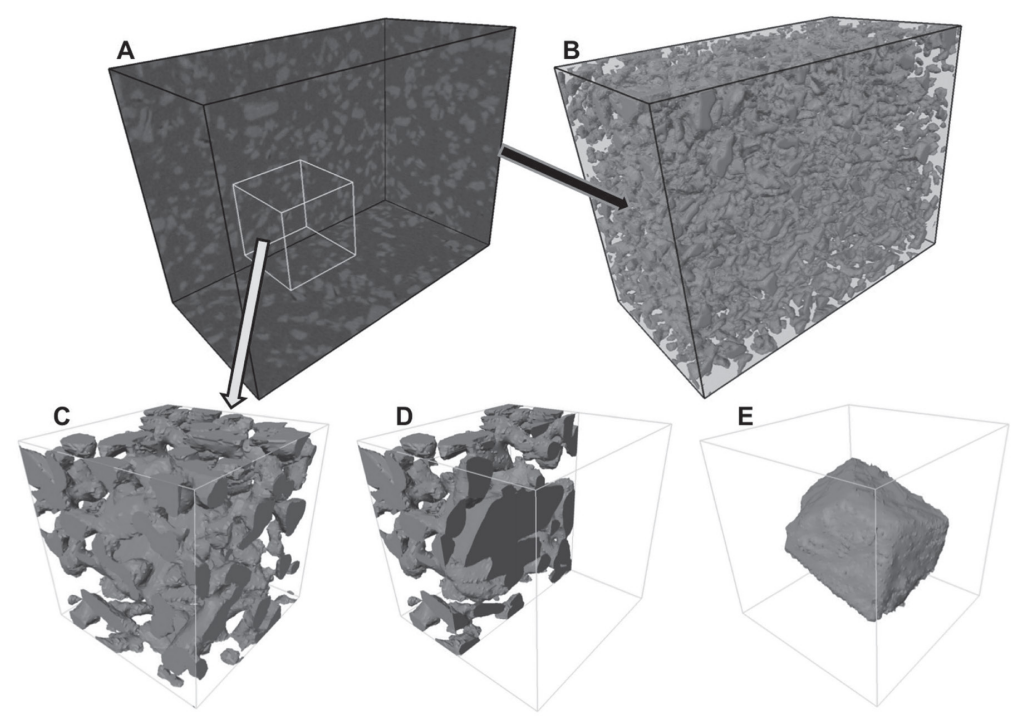

Figure 36. A $25 \mathrm{wt} \% \mathrm{NH}_{2}$-MIL-53/Matrimid ${ }^{\circledR}$ MMM imaged with FIB-SEM: (A) 3D reconstructed volume of the studied portion; (B) volume corresponding to MOF crystals; (C) magnification of selected volume in (A); (D) half volume of (C); (E) surface-rendered view of volume corresponding to voids. Reproduced with permission from [241]. Copyright, 2014, Wiley.

In 2014, the application of MOF-based MMMs was expanded by the work of Z. Y. Yeo, et al. with the utilization of ZIF-8/PES MMMs as supports for the growth of ZIF-8 membranes on the surface of the MMM via secondary growth [242]. Due to the limited affinity of a MOF for an inorganic support (e.g., $\mathrm{Al}_{2} \mathrm{O}_{3}$ or $\mathrm{TiO}_{2}$ ), the use of a $\mathrm{MMM}$ as an intermediary support facilitates the adhesion of the selective layer (e.g., ZIF-8) due to the favorable interactions between the organic ligands of the MOF and the polymer. The authors prepared 5 and $10 \mathrm{wt} \%$ ZIF-8/PES MMMs as supports and performed rub seeding and dip coating in a $1 \%$ ZIF-8 solution to provide nucleation sites. The ZIF-8 membrane was then grown by solvothermal synthesis in a methanol solution containing $\mathrm{ZnCl}_{2}$, 2-methylimidazole, and sodium formate. SEM images of the cross-sections of the ZIF-8 membranes (Figure 37a) showed no noticeable interfaces between the ZIF-8 layer and the MMM, indicating that good adhesion of the ZIF to the MMM was achieved. Flexible, continuous, and homogeneous ZIF-8 layers about 6-8 $\mu \mathrm{m}$ 
in thickness were obtained after $6 \mathrm{~h}$. SEM of the surface of the ZIF-8 layer (Figure 37b) showed a continuous, dense, well inter-grown, and compact layer with no gross defects. Gas permeation for $\mathrm{CO}_{2}$ and $\mathrm{CH}_{4}$ obtained for the 5 and $10 \mathrm{wt} \%$ ZIF-8/PES MMMs showed an increase in gas flux with constant ideal $\mathrm{CO}_{2} / \mathrm{CH}_{4}$ selectivity. These properties were greatly modified when the ZIF-8 layer was grown onto the polymer and the MMM. For these membranes, the $\mathrm{CH}_{4}$ flux decreased 50\%, and the ideal $\mathrm{CO}_{2} / \mathrm{CH}_{4}$ selectivity increased by $60 \%$, from 9 for PES to 15 for the ZIF-8 layer on PES and the MMM. Gas mixture $\left(50 / 50 \mathrm{CO}_{2} / \mathrm{CH}_{4}\right)$ separation showed a slight increase in $\mathrm{CO}_{2} / \mathrm{CH}_{4}$ separation for the ZIF-8 layer grown on the MMM with respect to the layer grown on the polymer (ZIF-8 on PES, $\mathrm{CO}_{2} / \mathrm{CH}_{4}=13.8 ; \mathrm{ZIF}-8$ on $\left.\mathrm{MMM}, \mathrm{CO}_{2} / \mathrm{CH}_{4}=14.6\right)$.

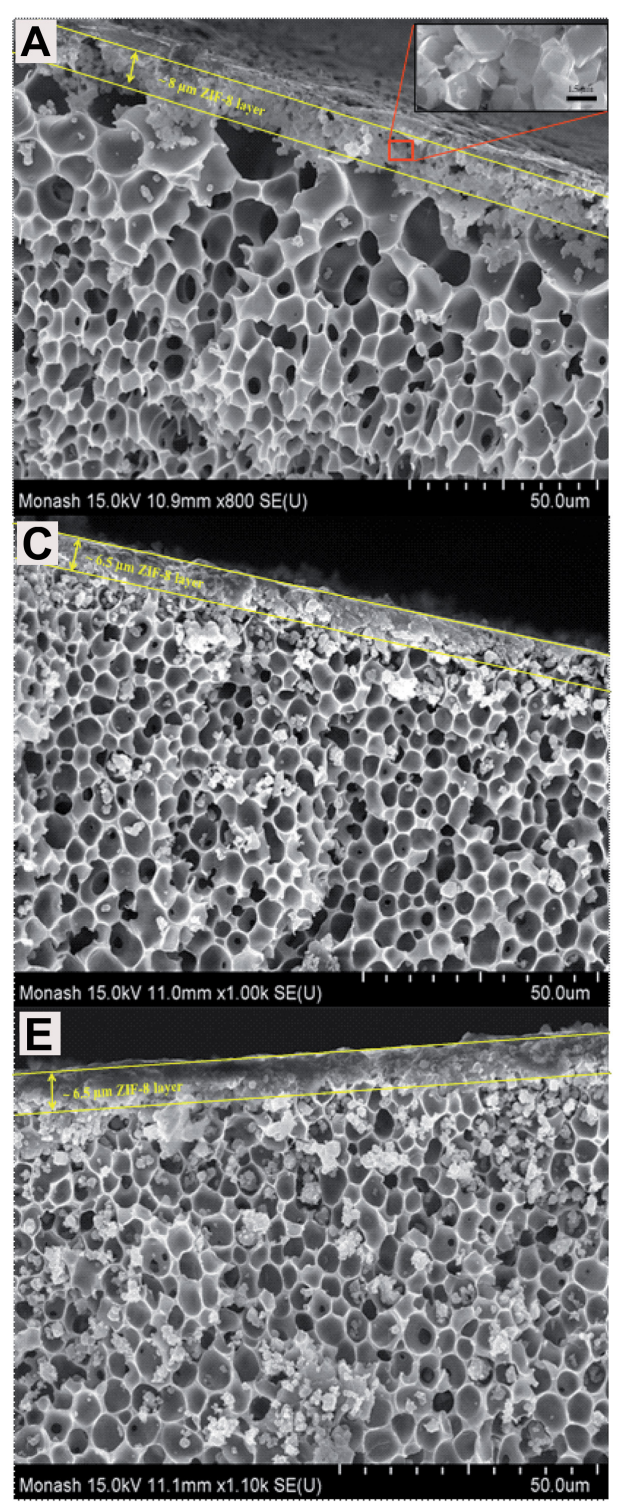

(a)

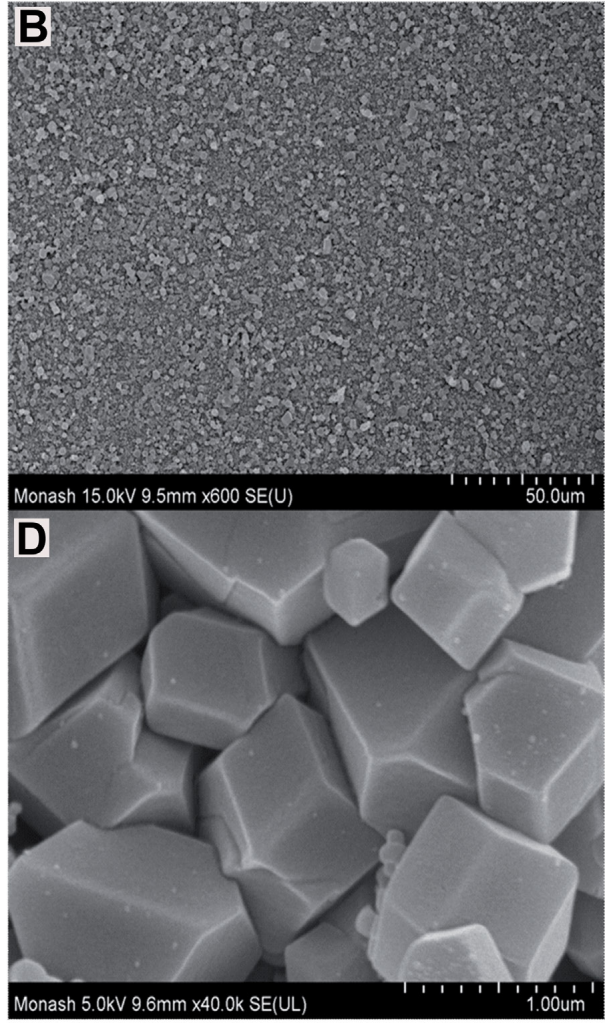

(b)

Figure 37. (a) SEM images of the cross-sections of continuous ZIF-8 membranes grown on PES (A); 5 wt \% ZIF-8/PES MMM (C), and $10 \mathrm{wt} \%$ ZIF-8/PES MMM (E); (b) SEM images of the surface of the ZIF-8 membrane grown on an MMM: low (B) and high (D) magnification. Adapted with permission from [242]. Copyright, 2014, The Royal Society of Chemistry.

Another important development in 2014 was the suppression of aging in MMMs that was reported in the work of C. H. Lau, et al. [243]. In this work, three highly permeable super glassy polymers 
(PTMSP, PMP, and PIM-1) and their PAF-1 MMMs were tested for $\mathrm{CO}_{2}$ permeation over a period of 240 days. Remarkably, the MMMs exhibited less than $7 \%$ decrease in permeability over the 240 days period while the pristine polymers experienced between $38 \%$ and $62 \%$ loss in permeability due to aging in the same period of time (Figure 38). This work shows that additives in MMMs have the capability to tune and freeze the packing of the polymer chains to prevent loss of free volume and gas permeability.

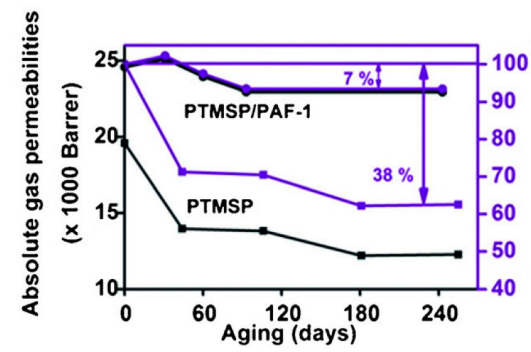

(a)

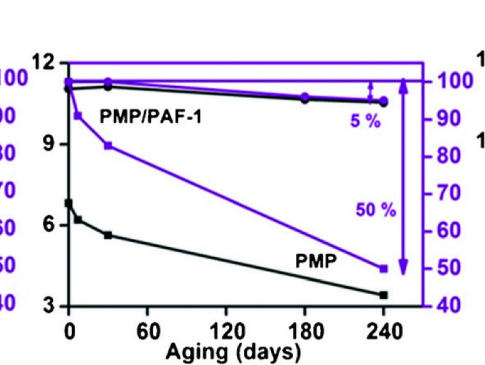

(b)

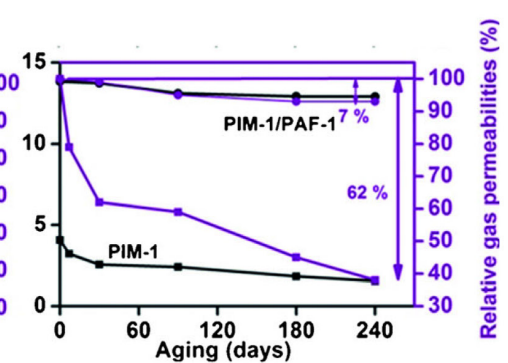

(c)

Figure 38. Absolute (black) and relative (purple) $\mathrm{CO}_{2}$ permeabilities of: (a) PAF-1/poly(1-trimethylsilil1-propyne) (PTMSP), (b) PAF-1/poly(4-methyl-1-pentyne) (PMP), and (c) PAF-1/ and PIM-1. Vertical arrows reperesent the aging degree of the pristine polymers $(\square)$ and the MMMs $(\bullet)$. Reproduced with permission from [243]. Copyright, 2014, Wiley.

The fight against membrane aging continued in 2015 with the incorporation of a series of MOPs into PTMSP to reduce aging and permeability losses. Extending on the work of E. V. Perez, et al. on the dispersion of single molecular cages in a polymer to prepare MOP-18/Matrimid ${ }^{\circledR}$ MMMs [126], M. Kitchin, et al. [244] prepared a series of MOPs to reduce membrane aging. In the work of M. Kitchin, et al., $t$-Bu-MOP (tert-butyl MOP), DEG-MOP (diethylene glycol MOP), TEG-MOP (triethylene glycol MOP), and MOP-18 (dodecane MOP) (Figure 39) were used to prepare MOP/PTMSP MMMs at $20 \mathrm{wt} \%$ MOP loadings. The pristine polymer as well as the MMMs were tested immediately and after 365 days for $\mathrm{CO}_{2}$ and $\mathrm{N}_{2}$ permeation.

As expected, the permeability of PTMSP decreased by as much as $73 \%$ whereas the permeability of the MMMs decreased between 20\% and 50\% (Figure 40a). The best results were obtained with $t$-Bu-MOP which was tested at different loadings (Figure 40a) and showed that MMMs experienced reduced aging at different rates that depended on the MOP loading. From this study it was concluded that a $20 \mathrm{wt} \% t$-Bu-MOP loading was the optimal loading which reduced aging by $20 \%$ over a period of 365 days. The authors concluded that the pore windows of $t$-Bu-MOP were large enough to intercalate the trimethylsilil side groups of PTMSP (Figure 40b) and to form an interlocked configuration that reduced chain mobility. More reports on the effects of additives in membrane aging can be found in [208,245-249].

More work on MOP-containing MMMs was reported in 2015 when J. Ma, et al. [250] prepared functionalized MOPs (e.g., MOP-SO ${ }_{3} \mathrm{Na}$ and $\mathrm{MOP}-\mathrm{OH}$ ) for MOP/PSf MMM fabrication. Owing to the solubility of MOPs in organic solvents that facilitates the preparation of MMMs [126], $\mathrm{J}$. Ma, et al. decorated the MOP pores (Figure 41a) with $-\mathrm{SO}_{3} \mathrm{Na}$ and $-\mathrm{OH}$ groups to improve the $\mathrm{CO}_{2} / \mathrm{CH}_{4}$ selectivity of the membrane by increasing the solubility for $\mathrm{CO}_{2}$. For the preparation of the MMMs, the functionalized MOPs were dissolved in NMP and then mixed with PSf solutions in NMP. MMMs with 8,12 , and $18 \mathrm{wt} \%$ MOP loadings were then dried in a vacuum oven at $50^{\circ} \mathrm{C}$ for 2 days before gas permeation experiments were performed with a $\mathrm{CO}_{2}: \mathrm{CH}_{4}$ mixture of 1:1 at 3 bar. With increasing MOP loading, MOP- $\mathrm{SO}_{3} \mathrm{Na} / \mathrm{PSf}$ MMMs exhibited gas permeability increments up to $113 \%\left(\mathrm{CO}_{2}\right)$ and $76 \%\left(\mathrm{CH}_{4}\right)$ that were attributed to the porosity of the MOP (pore size $=1.6 \mathrm{~nm}$ ), which provided new diffusion paths in the MMM, to the larger pore apertures $(0.45$ and $0.62 \mathrm{~nm})$, and to the presence of the $-\mathrm{SO}_{3} \mathrm{Na}$ polar groups that interacted more strongly with $\mathrm{CO}_{2}$ than with 
$\mathrm{CH}_{4}$. The $\mathrm{CO}_{2} / \mathrm{CH}_{4}$ separation was also increased by as much as $60 \%$, from 28 (PSf) to 45 (MMM with $12 \mathrm{wt} \%$ MOP loading) due to the preferential sorption of $\mathrm{CO}_{2}$ in the membrane. To further examine the effect of the polar $-\mathrm{SO}_{3} \mathrm{Na}$ group in the MMM, MOP-OH/PSf MMMs were also tested for $\mathrm{CO}_{2} / \mathrm{CH}_{4}$ separations. The results from this control experiment (Figure 41b) indicated that MOP-OH did not increase the $\mathrm{CO}_{2} / \mathrm{CH}_{4}$ selectivity of the MMMs, but it did increase gas permeability in a similar fashion.

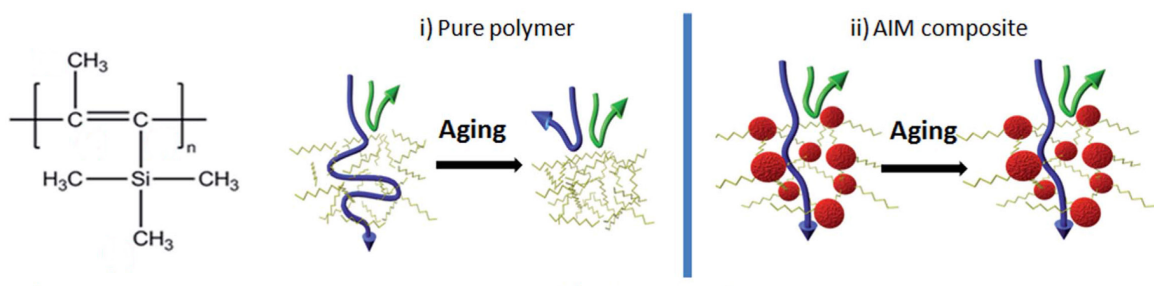

a) PTMSP repeat unit

b) Schematicillustration; aging process

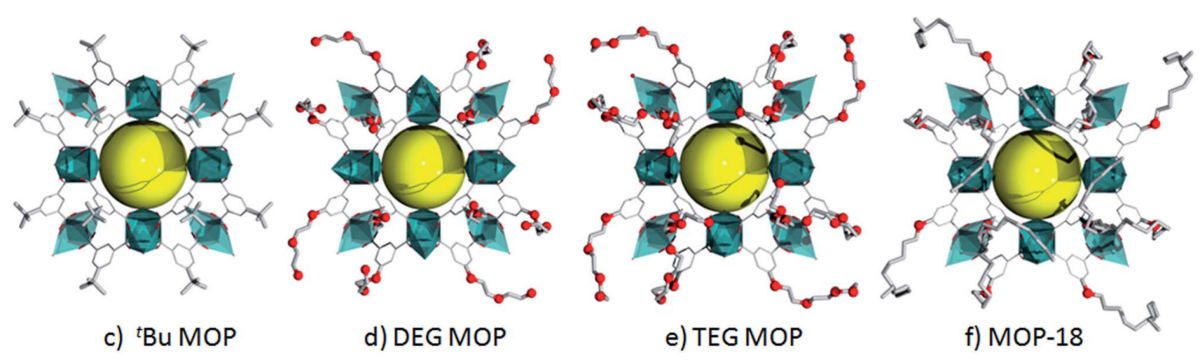

Figure 39. (a) PTMSP repeat unit; (b) schematic illustrations of (i) pure polymer exhibiting packing of polymer chains after aging; and (ii) MOP-MMM that prevents chain relaxation, maintaining membrane permeability; (c) $t$-Bu-MOP; (d) diethylene glycol-MOP (DEG-MOP); (e) triethylene glycol-MOP (TEG-MOP); and (f) MOP-18. Reproduced with permission from [244]. Copyright, 2015, The Royal Society of Chemistry.

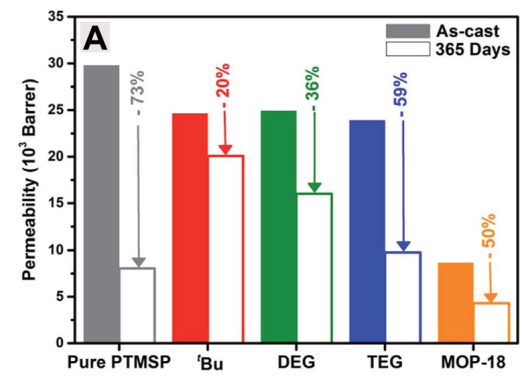

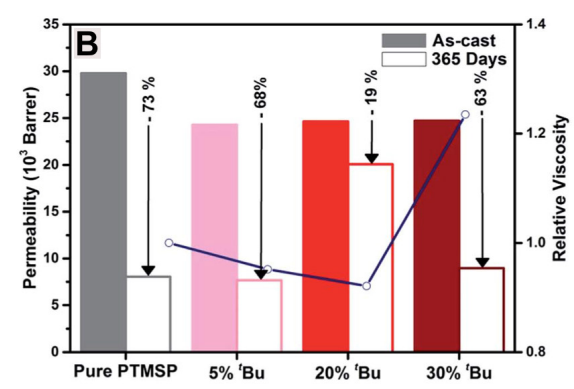

(a)
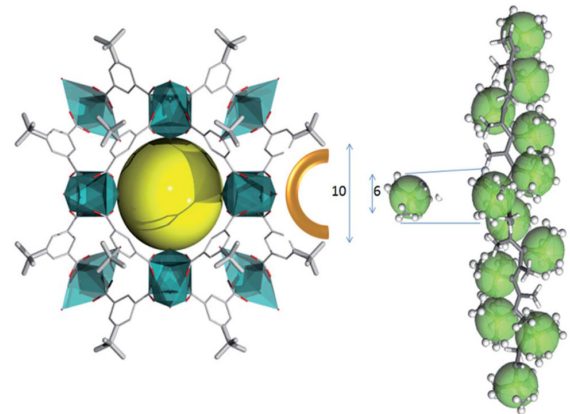

(b)

Figure 40. (a) $\mathrm{CO}_{2}$ permeability properties of $20 \mathrm{wt} \%$ MOP-loaded PTMSP membranes as cast vs. 365 days $(\mathrm{A})$ and $\mathrm{CO}_{2}$ permeability properties of $t$-Bu-PTMSP membranes of different dopant loadings as cast vs. 365 days (B); (b) The largest $t$-Bu-MOP pore windows are large enough $\left(13.671^{\circ} \mathrm{A}\right)$ to allow intercalation of PTMSP trimethylsilyl groups into the MOP pore. Reproduced with permission from [244]. Copyright, 2015, The Royal Society of Chemistry. 


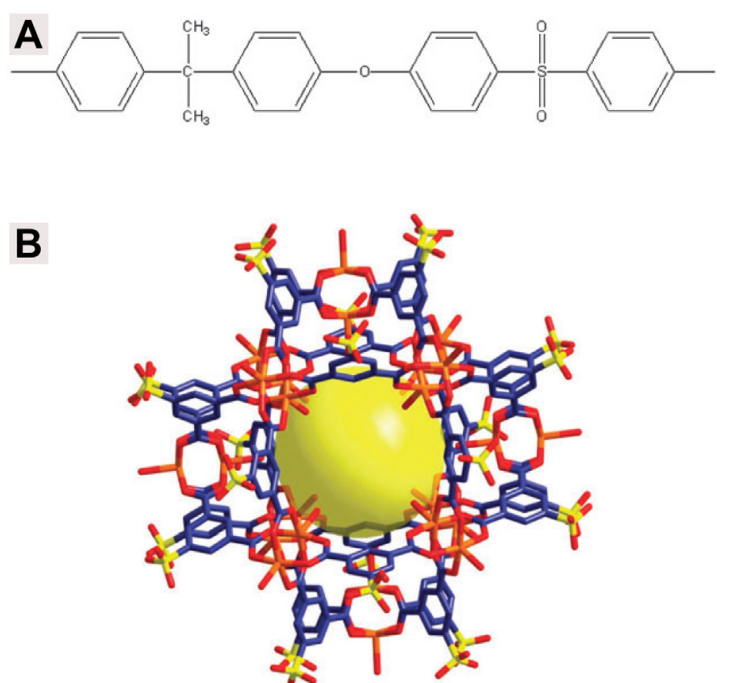

(a)

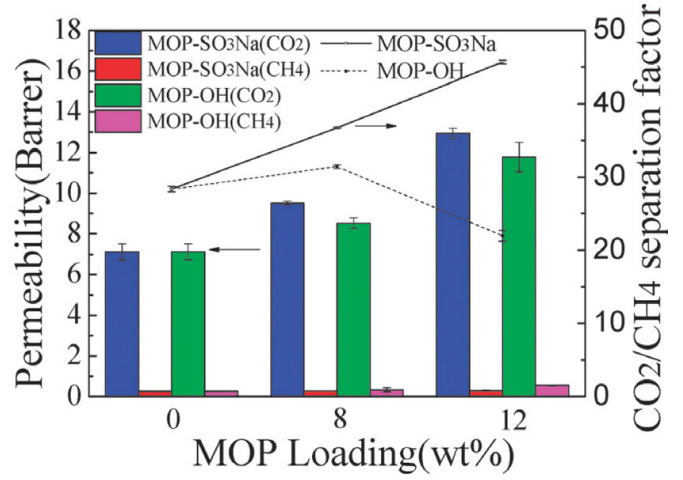

(b)

Figure 41. (a) Structures of PSf (A) and a porous metal-organic polyhedron (B); (b) $\mathrm{CO}_{2} / \mathrm{CH}_{4}(1: 1)$ gas mixture separation performance of functionalized MOP/PSf MMMs at $25^{\circ} \mathrm{C}$ and 3 bar. Adapted with permission from [250]. Copyright, 2015, The Royal Society of Chemistry.

This same year, T. Rodenas, et al. prepared Cu-BDC MOF (Figure 42) and high aspect ratio (>20) $\mathrm{Cu}$-BDC MOF nanosheets (ns) from 1,4-benzenedicarboxylic acid and $\mathrm{Cu}\left(\mathrm{NO}_{3}\right)_{2}$ in $\mathrm{DMF}$ [251] to study the effects of filler morphology on MMM performance. From AFM images, the synthesized 2D MOF crystals were measured to be $0.5-4 \mu \mathrm{m}$ in the $\mathrm{x}-\mathrm{y}$ dimension and $5-25 \mathrm{~nm}$ in the $\mathrm{z}$-dimension. The 2D MOF crystals were added to a PSf solution to prepare 2-12 wt \% 2D ns-Cu-BDC/PSf MMMs, which were then dried under vacuum at $180^{\circ} \mathrm{C}$. An identical procedure was followed to prepare control materials (e.g., PSf and isotropic, bulk type $b$-Cu-BDC/PSf or sub micrometer-sized $n c-C u-B D C /$ PSf MMMs).
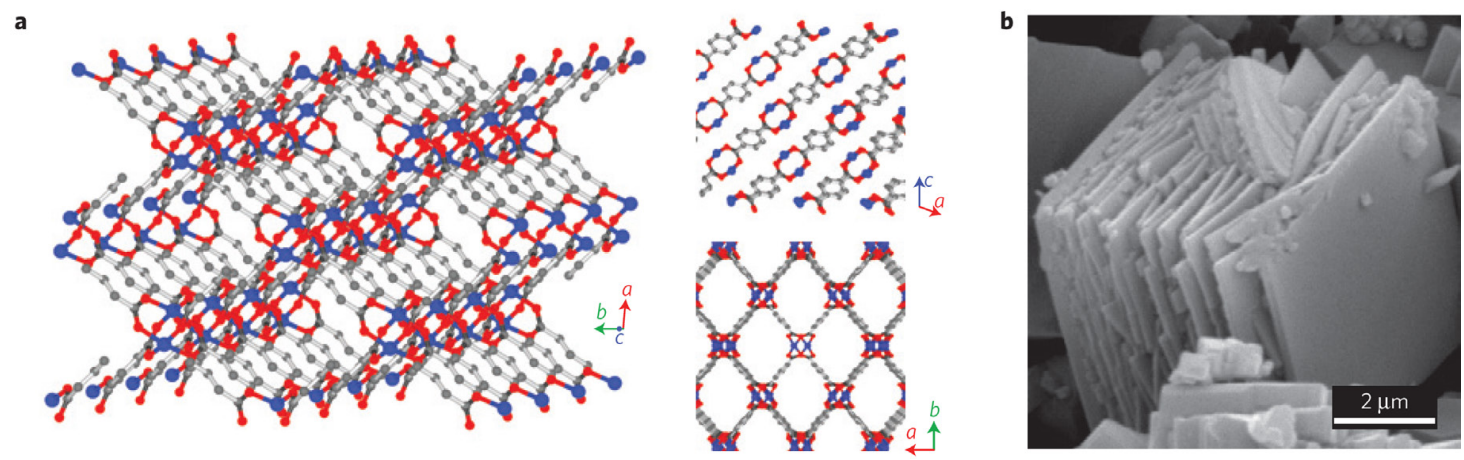

Figure 42. 3D crystalline structure of Cu-BDC MOF (a) and SEM image of bulk type Cu-BDC crystals showing a plate-like morphology (b). Adapted with permission from [251]. Copyright, 2015, Nature Publishing Group.

FIB-SEM images and tomograms (Figure 43a-d) revealed that the 8 wt \% ns-Cu-BDC/PSf MMMs exposed one order of magnitude larger surface areas than the 8 wt $\% b$-Cu-BDC/PSf MMMs, largely increasing its interaction with gas molecules. The surface-rendered views after segmentation of the different phases showed a significant difference of the nanostructure between the bulk and the nanosheet Cu-MOF/PSf MMMs. The bulk crystals left a significant portion in the MMM unoccupied (Figure 43e), whereas the nanosheet Cu-MOF was evenly distributed in the MMM (Figure 43f) and was oriented perpendicularly to the gas flux. 

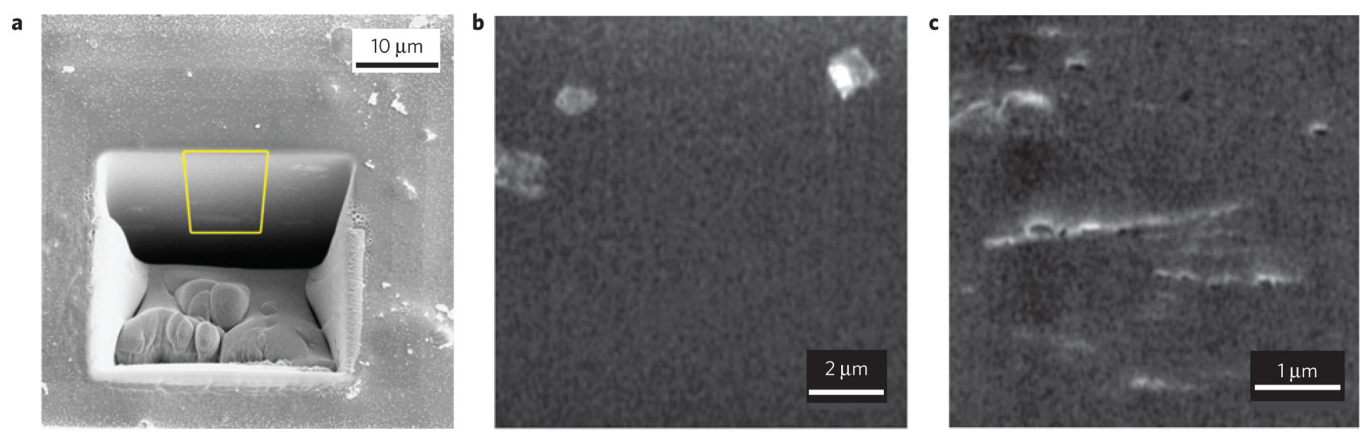

d

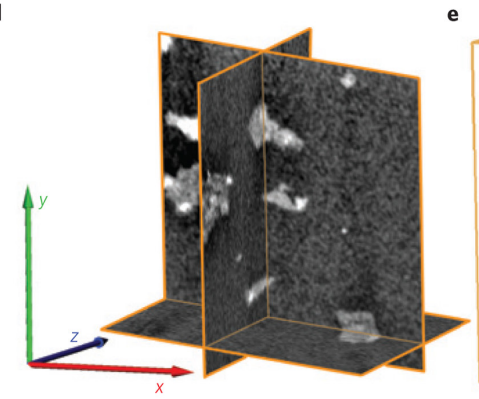

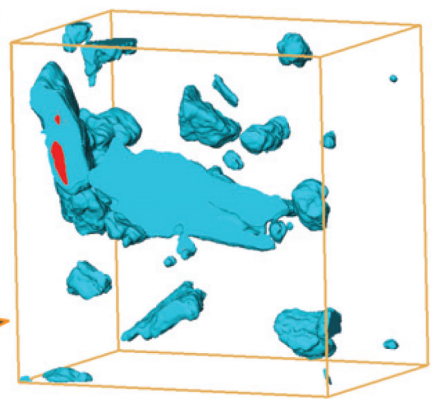

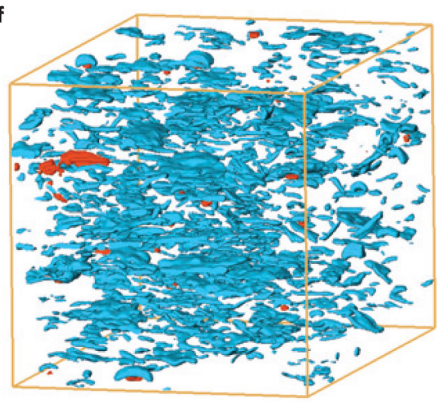

Figure 43. (a) SEM image of the trench carved in a $8 \mathrm{wt} \% \mathrm{MOF} / \mathrm{PSf}$ MMM with FIB milling; (b) SEM image of the cross-section of a 8 wt $\% b$-Cu-BDC/PSf MMM containing bulk Cu-MOF; (c) SEM image of the cross-section of a $8 \mathrm{wt} \% n s-\mathrm{Cu}-\mathrm{BDC} / \mathrm{PSf}$ MMM containing 2D nanosheets of Cu-MOF; (d) orthogonal SEM images of the cross-sections through the 3D FIB-SEM tomogram of a Cu-MOF/PSf MMM; (e,f) surface-rendered views of the segmented FIB-SEM tomograms for $b$-Cu-BDC/PSf and $n s-C u-B D C / P S f$ MMMs, respectively. The $x: y: z$ directions are 11.2:11.2:7.6 for (e) and 4.9:4.9:6.6 $\mu \mathrm{m}$ for (f) showing the MOF in blue and the voids in red. Reproduced with permission from [251]. Copyright, 2015, Nature Publishing Group.

Gas mixture separations with $\mathrm{CO}_{2}: \mathrm{CH}_{4}$ (1:1) blends (Figure 44) showed that the bulk-type Cu-BDC crystals worsened the separation properties of the MMM ( $b$-Cu-BDC/PSf) with respect to the polymer, most likely due to the generation of non-selective voids at the MOF/polymer boundary. The use of sub-micrometer-sized crystals resulted in a slight improvement in the performance of the MMM (nc-Cu-BDC/PSf), but was still inferior to that of the polymer. The best performance of the MMMs was achieved with the use of nanosheets $\left(8 \mathrm{wt} \% n s-\mathrm{Cu}\right.$-BDC/PSf) that significantly improved the $\mathrm{CO}_{2} / \mathrm{CH}_{4}$ selectivity of the PSf membrane in the range of pressures tested ( 3 to 7.5 bar). Selectivity increments of $30 \%$ to $80 \%$ (relative to PSf) and $75 \%$ to 8 times higher (relative to the $b$-Cu-BDC/PSf MMM) were observed for the $n s-\mathrm{Cu}-\mathrm{BDC} / \mathrm{PSf} \mathrm{MMM}$, which also showed a trend of increasing selectivity with increasing pressure, opposite to the polymer's selectivity trend that decays with increasing pressure due to $\mathrm{CO}_{2}$-induced plasticization of the PSf membrane. In terms of permeability, the $8 \mathrm{wt} \%$ $n s-\mathrm{Cu}-\mathrm{BDC} / \mathrm{PSf}$ MMMs exhibited a continuous decrease in $\mathrm{CO}_{2}$ permeability from 4.1 ( 3 bar) to 2.8 (7.5 bar) Barrer with increasing pressure, whereas the polymer retained the $\mathrm{CO}_{2}$ permeability at 5.8 Barrer in the range of pressures tested. Similar studies on filler morphology effects on MMM performance were also performed by Z. Kang, et al. [252] this same year and by A. Sabetghadam, et al. in 2016 [253]. Z. Kang, et al. observed that MMMs of nanosheets of the $\left[\mathrm{Cu}_{2}(\mathrm{NDC})_{2}(\mathrm{DABCO})\right]_{\mathrm{n}} \mathrm{MOF}$ in PBI had better $\mathrm{H}_{2} / \mathrm{CO}_{2}$ gas separation performance than the MMMs of nanocubes of the MOF in PBI. A. Sabetghadam, et al. also observed that MMMs of nanoparticles of $\mathrm{NH}_{2}$-MIL-53 in Matrimid ${ }^{\circledR}$ exhibited better $\mathrm{CO}_{2} / \mathrm{CH}_{4}$ separation performance than the MMMs of the nanorods or microneedles of the MOF in Matrimid ${ }^{\circledR}$. Undoubtedly, the results of these independent works indicate that the morphology of the filler plays an important role in MMM performance and it should be considered and explored in more detail in future works. 


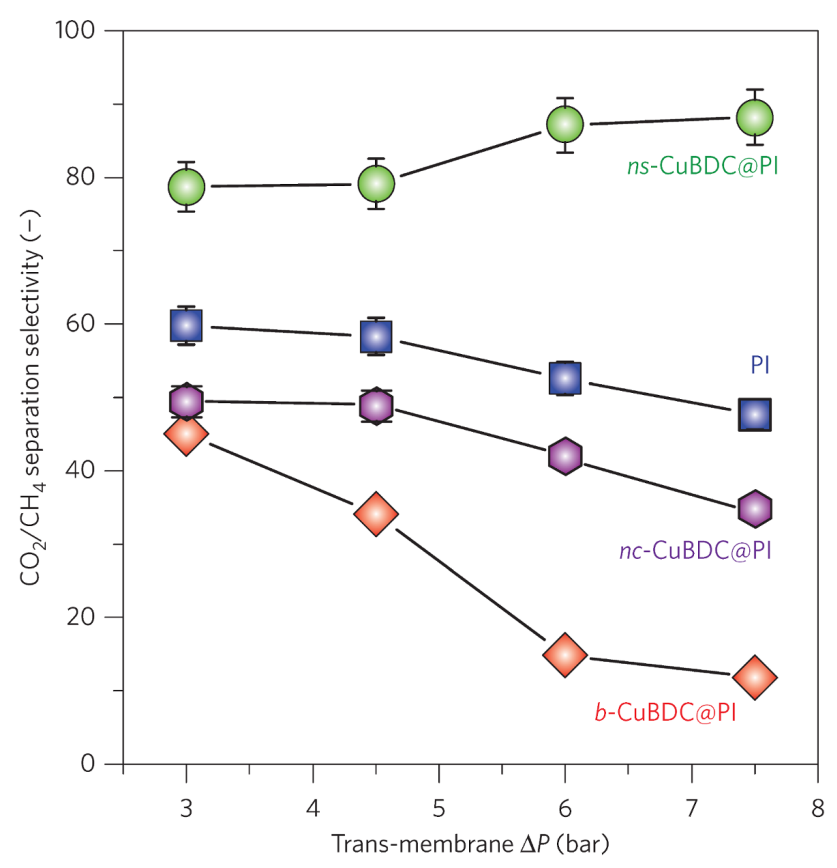

Figure 44. $\mathrm{CO}_{2}: \mathrm{CH}_{4}$ (1:1) gas mixture separation performance at $25{ }^{\circ} \mathrm{C}$ of $\mathrm{PSf}$ and the $b, n c$, $n s-\mathrm{Cu}-\mathrm{MOF} / \mathrm{PSf} \mathrm{MMMs}$ as a function of pressure. Reproduced with permission from [251]. Copyright, 2015, Nature Publishing Group.

Work to improve the MOF/polymer interface was continued in 2015 by S. R. Venna, et al. when they modified the surface of $(\mathrm{Zr}) \mathrm{UiO}-66-\mathrm{NH}_{2}$ MOF particles to improve its interaction with the polymer matrix, Matrimid ${ }^{\circledR}$ [254]. The MOF is composed of $\mathrm{Zr}_{6} \mathrm{O}_{4}(\mathrm{OH})_{4}$ clusters bridged with 2-amino-1,4-benzenedicarboxylates that form triangularly shaped pore apertures of $0.6 \mathrm{~nm}$. ( $\mathrm{Zr})$ UiO-66- $-\mathrm{NH}_{2}$ was used due to its water, chemical, and thermal stability, and its ability to undergo post-synthesis chemical modification without degradation. The authors rationalized that the $\mathrm{MOF} /$ polymer interface could be improved by analyzing the structure of the polymer to determine the functional groups that could form an ideal interface with the MOF and then chemically modify the surface of the MOF with such functional groups. The authors prepared four MOFs (Figure 45) having polar, non-polar, or aromatic surface functional groups: neat $(\mathrm{Zr}) \mathrm{UiO}-66-\mathrm{NH}_{2}(\mathrm{I})$, aromatic-modified $(\mathrm{Zr}) \mathrm{UiO}-66-\mathrm{NH}_{2}\left(\mathrm{I}_{\mathrm{PA}}\right)$, aliphatic $\mathrm{C}_{10}$-modified $(\mathrm{Zr}) \mathrm{UiO}-66-\mathrm{NH}_{2}\left(\mathrm{I}_{\mathrm{C} 10}\right)$, and acid-modified $(\mathrm{Zr})$ UiO-66- $\mathrm{NH}_{2}$ ( $\mathrm{I}_{\mathrm{SA}}$ ). The synthesized MOFs were activated with Soxhlet extraction for 7 day with $\mathrm{Cl}_{2} \mathrm{CH}_{2}$. The degree of functionalization of the MOFs was calculated from LCMS, XPS, and ${ }^{1} \mathrm{H}$ NMR data: the percentages of functionalized ligands obtained were $2 \%-6 \%$ for $\mathrm{I}_{\mathrm{PA}}, 2 \%-5 \%$ for $\mathrm{I}_{\mathrm{C} 10}$, and $16 \%-32 \%$ for $\mathrm{I}_{\mathrm{SA}}$. Owing to the size of the phenyl and alkyl chains that limit their diffusion into the channels of the MOF, the authors expected the surface functionalization for $\mathrm{I}_{\mathrm{PA}}$ and $\mathrm{I}_{\mathrm{C} 10}$ to be low. The higher level of $\mathrm{I}_{\mathrm{SA}}$ functionalities, however, indicated that some internal functionalization occurred along with surface functionalization. MMMs of Matrimid ${ }^{\circledR}$ and $(\mathrm{Zr}) \mathrm{UiO}-66-\mathrm{NH}_{2}$ (and its functionalized derivatives) with loadings of 12 to $40 \mathrm{wt} \%$ were prepared with an initial priming of the MOF with a polymer solution. The MMMs were cast on glass, dried at $100^{\circ} \mathrm{C}$, and then annealed at $225^{\circ} \mathrm{C}$ for $2 \mathrm{~h}$ in a vacuum oven. Pure $\mathrm{CO}_{2}$ and $\mathrm{N}_{2}$ gas permeation studies were performed at room temperature and 1.38 bar. The permeabilities and $\mathrm{CO}_{2} / \mathrm{N}_{2}$ selectivities of the polymer and the $23 \mathrm{wt} \%(\mathrm{Zr})$ UiO-66- $\mathrm{NH}_{2}\left(\mathrm{I}, \mathrm{I}_{\mathrm{PA}}, \mathrm{I}_{\mathrm{C} 10}, \mathrm{I}_{\mathrm{SA}}\right) /$ Matrimid ${ }^{\circledR}$ MMMs are shown in Figure 46a. The results indicated that $\mathrm{CO}_{2}$ permeability increased largely for all MMMs with respect to the polymer, but only the MMMs containing the neat and the $\mathrm{I}_{\mathrm{PA}}$-functionalized MOF exhibited increased $\mathrm{CO}_{2} / \mathrm{N}_{2}$ selectivity relative to the polymer, which was attributed to the formation of a defect-free interface between the MOF and the polymer and the improved surface diffusion of $\mathrm{CO}_{2}$, since it adsorbed more favorably to the MOF than did $\mathrm{N}_{2}$. 


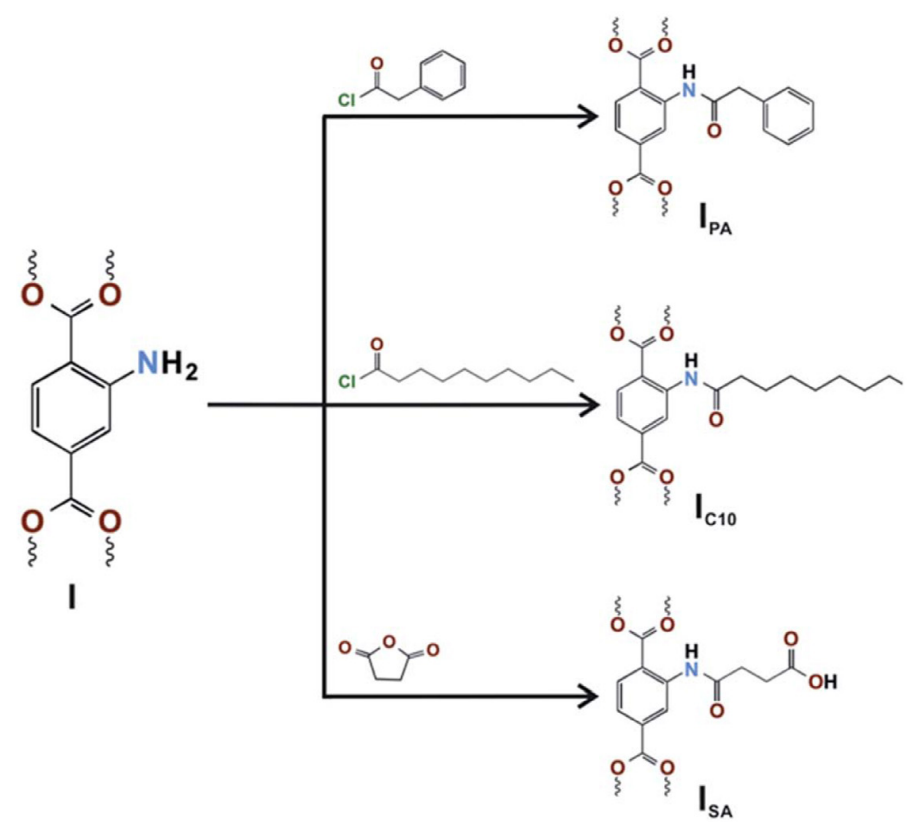

Figure 45. Post-synthesis modification of $(\mathrm{Zr}) \mathrm{UiO}-66-\mathrm{NH}_{2}$ (I) for functionalization at the $-\mathrm{NH}_{2}$ functional group of the linker with aromatic $\left(\mathrm{I}_{\mathrm{PA}}\right)$, aliphatic $\mathrm{C}_{10}\left(\mathrm{I}_{\mathrm{C} 10}\right)$, and acid $\left(\mathrm{I}_{\mathrm{SA}}\right)$ terminal functional groups. Reproduced with permission from [254]. Copyright, 2015, The Royal Society of Chemistry.

The authors also concluded that MMMs containing the $\mathrm{I}_{\mathrm{C} 10}$ and $\mathrm{I}_{\mathrm{SA}}$ functionalities did not increase $\mathrm{CO}_{2} / \mathrm{N}_{2}$ selectivities because of the defects created at the MOF/polymer interface due to incompatibilities between the polymer and the $\mathrm{I}_{\mathrm{C} 10}$ and $\mathrm{I}_{\mathrm{SA}}$ functional groups on the MOF. Additional testing with 12,23 , and 40 wt $\%(\mathrm{Zr}) \mathrm{UiO}-66-\mathrm{NH}_{2}\left(\mathrm{I}, \mathrm{I}_{\mathrm{PA}}\right) /$ Matrimid $^{\circledR} \mathrm{MMMs}$ revealed that the membranes increased the permeability for $\mathrm{CO}_{2}$ with increasing MOF loadings (Figure 46b). $\mathrm{CO}_{2} / \mathrm{N}_{2}$ selectivities, however, reached a maximum at $23 \mathrm{wt} \%$ and then declined at $40 \mathrm{wt} \%$ signaling the presence of interfacial defects induced by the agglomeration of the MOF crystals at high loadings.

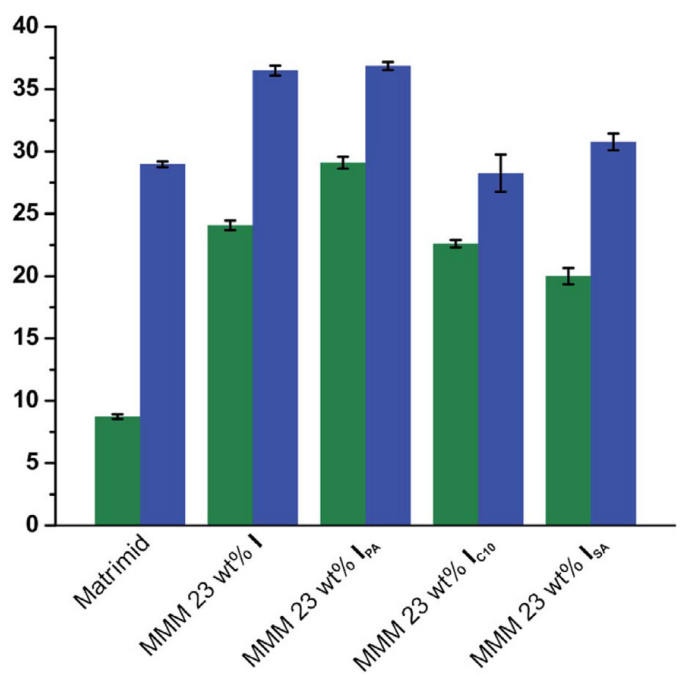

(a)

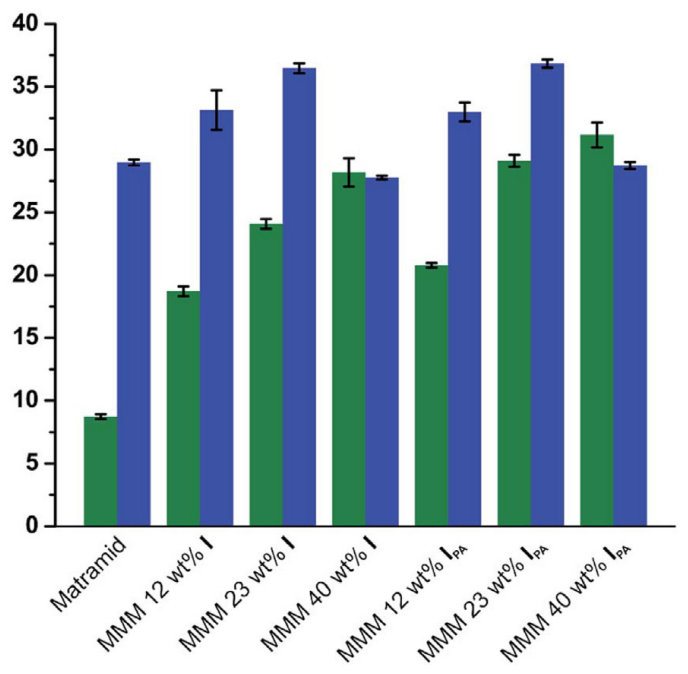

(b)

Figure 46. (a) $\mathrm{CO}_{2}$ permeabilities (green) and $\mathrm{CO}_{2} / \mathrm{N}_{2}$ ideal selectivities for the polymer and the 23 wt \% (Zr) UiO-66- $\mathrm{NH}_{2}$ (I, $\mathrm{I}_{\mathrm{PA}}, \mathrm{I}_{\mathrm{C} 10}, \mathrm{I}_{\mathrm{SA}}$ )/Matrimid ${ }^{\circledR}$ MMMs; (b) $\mathrm{CO}_{2}$ permeabilities (green) and $\mathrm{CO}_{2} / \mathrm{N}_{2}$ ideal selectivities for the polymer and the 12, 23, and 40 wt \% (Zr) UiO-66-NH (I, I $\mathrm{PA}_{\text {A }}$ /Matrimid ${ }^{\circledR}$ MMMs. Reproduced with permission from [254]. Copyright, 2015, The Royal Society of Chemistry. 
A novel approach for the preparation of polymers that inherently incorporate controlled porosity came from the work of Z. Zhang, et al. in 2015 with the synthesis of polyMOFs [255]. Since the first examples of the preparation of MOF-based MMMs, the aim was to disperse perfectly the crystallites in the polymer matrix without aggregation and voids at the interface. Several strategies have been used to attempt to achieve this goal, e.g., priming the crystals with dilute polymer solutions [165], extensive sonication, chemical functionalization of the organic ligands of the MOFs [250,254], and the use of porous single molecular cages in the form of metal organic polyhedras or MOPs [126]. Each of them achieved a certain degree of success that ultimately relied on the physical interaction between the distinct phases (MOF-polymer). In the work of Zhang, et al., polymer chains that include the carboxylated organic ligands of MOFs in the backbone are reacted with metal ions (Figure 47a and 47b-top), generating MOF unit cells in situ that are chemically bound to the polymer. The hybrid material effectively incorporates porosity from the in situ synthesized MOF and is termed a polymer-MOF hybrid or a polyMOF. In this approach, the polymer chains are effectively the organic linkers or polymer ligands of the MOF. The pore size of $\mathrm{Zn}$-pbdc-7a (a polyMOF with 7 methylene groups between terephthalates, Figure $47 \mathrm{~b}$-top) and $\mathrm{Zn}$-pbdc-8a (a polyMOF with 8 methylene groups between terephthalates), calculated by DFT methods from $\mathrm{N}_{2}$ sorption isotherms, were $0.7 \mathrm{~nm}$ and $0.9 \mathrm{~nm}$, respectively. The authors were also able to synthesize Zn-pbdc-7a and Zn-pbdc-8a into $20 \mu \mathrm{m}$ thick crystalline films that showed an intergrowth network of crystallites with morphologies distinctive of the polymer ligands, as was observed by SEM (Figure 47b-bottom). Although the preparation of this new type of material for gas separation is promising and provides an exciting new path in the quest for a perfect membrane, the mechanical properties and the performance of these membranes in gas separations are still to be determined.

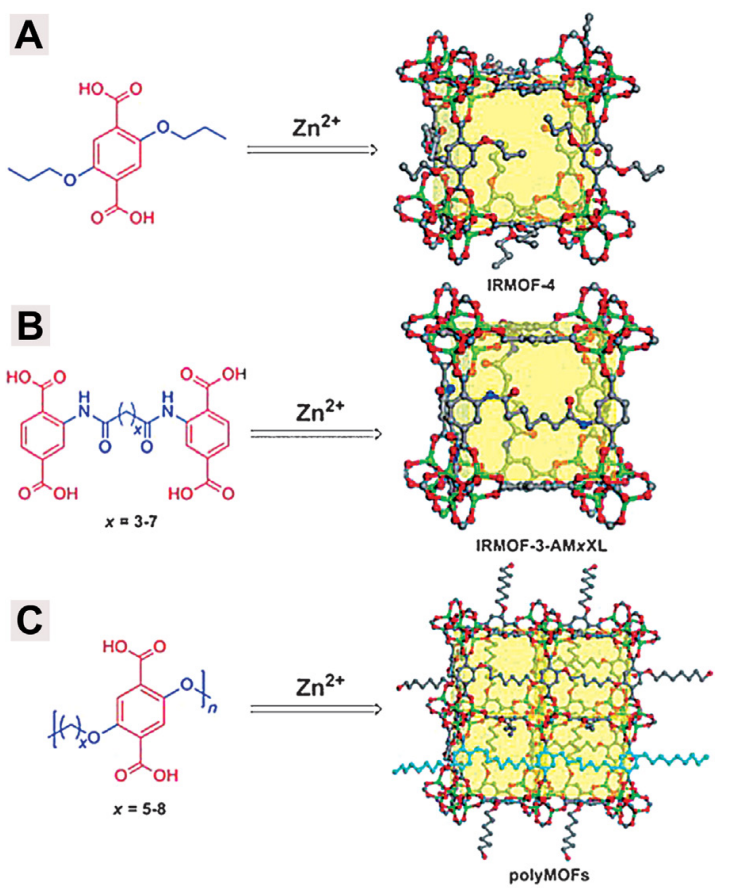

(a)
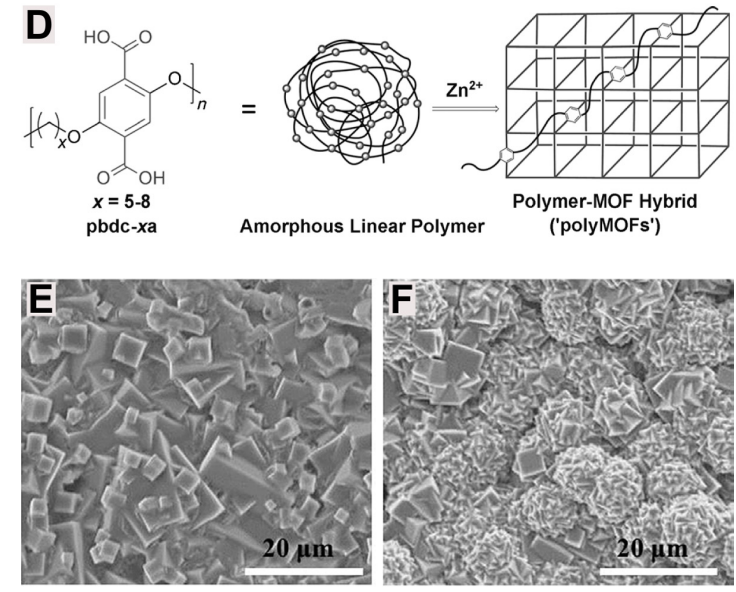

(b)

Figure 47. (a) Isoreticular metal-organic framework (IRMOF) derivatives showing the evolution of the organic ligands from simple (A) to crosslinked (B) to polymeric ligands (C); (b) Strategy to convert the linear polymer into a porous crystalline polyMOF (D) and SEM images (E,F) of the film morphology of Zn-pbdc-7a (E) and Zn-pbdc-8a (F). Adapted with permission from [255]. Copyright, 2015, Wiley.

Another contribution made in 2015 towards the industrial utilization of MMMs came from the work of E. V. Perez, et al. with the testing of 20 wt \% (Al) $\mathrm{NH}_{2}-\mathrm{MIL}-53 /$ VTEC ${ }^{\mathrm{TM}}$ MMMs at pressures 
that ranged from 5 to 30 bar and at temperatures that ranged from 35 to $300{ }^{\circ} \mathrm{C}$, achieving $\mathrm{H}_{2} / \mathrm{CO}_{2}$ mixture selectivities of 7.5 [128]. Their work provided evidence that MMMs could be sufficiently mechanically robust to perform gas separations under combined extreme conditions of pressure and temperature, increasing permeability and selectivity (relative to the polymer) for $\mathrm{H}_{2}: \mathrm{CO}_{2}$ (1:1) mixtures and also retaining selectivity for measurements using pure gases of $\mathrm{H}_{2}$ and $\mathrm{CO}_{2}$. Gas permeation of the polymer and MMMs using pure gases showed that the membranes retained a $\mathrm{H}_{2} / \mathrm{CO}_{2}$ selectivity between 5.3 and 8.3 at up to $250{ }^{\circ} \mathrm{C}$, whereas at $300{ }^{\circ} \mathrm{C}$ the selectivity dropped to 4.0 for the polymer and to 5.8 for the MMM. $\mathrm{H}_{2}$ permeability increased from $5\left(35^{\circ} \mathrm{C}\right)$ to $84\left(300^{\circ} \mathrm{C}\right)$ Barrer for VTEC ${ }^{\mathrm{TM}}$ and remained constant within the pressure range tested (5 to 30 bar) at each temperature. The MMMs exhibited increased $\mathrm{H}_{2}$ permeability from $5\left(35^{\circ} \mathrm{C}\right)$ to 150 Barrer $\left(300^{\circ} \mathrm{C}\right)$, which remained constant within the pressure range (5-30 bar) at each testing temperature. Testing the MMMs with $\mathrm{H}_{2}$ and $\mathrm{CO}_{2}$ at these conditions $\left(30 \mathrm{bar}\right.$ and $300{ }^{\circ} \mathrm{C}$ ) is already remarkable progress for MOF-based MMMs because it proves that the $\mathrm{MOF} /$ polymer interface is strong enough to perform molecular sieving and to prevent the formation of defects. The fact that the MMMs retained $\mathrm{H}_{2} / \mathrm{CO}_{2}$ selectivities of 5.8 (Knudsen selectivity $\mathrm{H}_{2} / \mathrm{CO}_{2}=4.7$ ) at temperatures above the $\mathrm{T}_{\mathrm{g}}$ of the polymer indicates that the MOF contributes to or enhances the mechanical strength of the polymer. Gas mixture experiments at $250{ }^{\circ} \mathrm{C}$ and 30 bar showed that the $\mathrm{H}_{2} / \mathrm{CO}_{2}$ selectivity depended largely on the membrane stage cut $(\theta)$. At a $\theta$ of 1.0 (no retentate removal or $100 \% \mathrm{H}_{2}$ recovery), the $\mathrm{CO}_{2}$ polarization on the surface of the membrane changed the feed composition dramatically, which reduced the $\mathrm{H}_{2} / \mathrm{CO}_{2}$ selectivity of the polymer from 8.1 (ideal) to 2.9 (mixture) and the MMM's from 8.3 (ideal) to 4.4 (mixture). Reducing $\theta$ to $<0.2\left(<20 \% \mathrm{H}_{2}\right.$ recovery) resulted in an improvement in the $\mathrm{H}_{2} / \mathrm{CO}_{2}$ separation of the membranes for gas mixtures. The $\mathrm{H}_{2} / \mathrm{CO}_{2}$ selectivities for the polymer increased from $2.9(\theta=1.0)$ to $7.2(\theta=0.1)$ and for the MMM from $4.4(\theta=1.0)$ to $7.5(\theta=0.1)$. The benefits of incorporating the MOF into the polymer were evident since the MMM outperformed the polymer in both its permeability and selectivity properties with pure gases and gas mixtures.

New developments in the preparation of MMMs came in 2016 from the work of X. Cao, et al. with the preparation of COF-LZU1/PVAm MMMs on porous PSf ultrafiltration membranes for the separation of $\mathrm{CO}_{2} / \mathrm{H}_{2}$ [256]. Although COFs are not hybrid organic-inorganic frameworks, but rather pure covalently-bound organic frameworks that may contain boron, triazines, or imines [257], they share similar properties with MOFs. Both materials form 2D or 3D crystalline frameworks with defined porosities and gas sorption capacities that depend on the nature of the organic component. COF-LZU1, an imine-based and water stable 2D COF, was made from the reaction of 1,3,5-triformylbenzene with 1,4-diaminobenzene and mixed with PVAm in an aqueous solution. The polymer and the $10 \mathrm{wt} \%$ COF-LZU1/PVAm MMM were tested for gas separation with $\mathrm{H}_{2}: \mathrm{CO}_{2}$ (60:40 volume) mixtures at $25^{\circ} \mathrm{C}$ and at pressures from 1.5 to 10 bar. The gas separation performance of the MMM was superior to that of PVAm in both flux and $\mathrm{CO}_{2} / \mathrm{H}_{2}$ selectivity. $\mathrm{CO}_{2}$ flux increased from 100 GPU (PVAm, 1.5 bar) to 396 GPU (MMM, 1.5 bar) and declined to 286 GPU (MMM) as the pressure increased to 10 bar. The $\mathrm{CO}_{2}$ flux remained unchanged for PVAm over the range of pressures studied. The $\mathrm{CO}_{2} / \mathrm{H}_{2}$ selectivity for the MMM decreased from 15 to 12.5 with increasing pressure, but it remained higher than for PVAm $\left(\mathrm{CO}_{2} / \mathrm{H}_{2}=11\right)$. The authors attribute the improved performance of the MMM to the porosity introduced by the COF and the amino functionality in the pores that preferentially adsorbs $\mathrm{CO}_{2}$. Another COF-based MMM study released this year came from Z. Kang, et al. with the preparation of MMMs containing exfoliated 2D COFs (NUS2 and NUS3, Figure 48a) [258]. NUS2 and NUS3 are layered, porous materials made from 1,3,5-triformylphloroglucinol (NUS2) or 1,3,5-triformylphloroglucinol and 5-diethoxy-terephthalo-hydrazide (NUS3), as depicted in Figure 48a. The layered COFs were exfoliated into nanosheets or even monolayers with high aspect ratios by suspending them with stirring and sonication in $\mathrm{CHCl}_{3}$ or NMP before their incorporation into Ultem ${ }^{\mathrm{TM}}$ or PBI. The 10, 20, and $30 \mathrm{wt} \% \mathrm{COF}$ MMMs were then dried at $200{ }^{\circ} \mathrm{C}$ in a vacuum oven before permeability tests with $\mathrm{H}_{2}, \mathrm{CH}_{4}, \mathrm{CO}_{2}$, and a (1:1) $\mathrm{H}_{2}: \mathrm{CO}_{2}$ mixture were performed at $35^{\circ} \mathrm{C}$ and at pressures from 2 to 5 bar. The authors attempted to determine the degree of dispersion and orientation 
of the COF nanosheets in the MMMs, but due to the similarities in chemical composition between the COFs and the polymers, they could not obtain conclusive evidence. SEM images of the membrane cross-sections, however, revealed the presence of polymer veins due to plastic deformation from the strong COF/polymer interaction for both NUS2 and NUS3-based MMMs (Figure 48b). Pure gas permeation indicated that the MMMs exhibited their best separation and permeability performance at $20 \mathrm{wt} \%$ loading. Higher loadings negatively affected the performance of the MMMs for both $\mathrm{CO}_{2} / \mathrm{CH}_{4}$ and $\mathrm{H}_{2} / \mathrm{CO}_{2}$ separations (Figure 49). At $20 \mathrm{wt} \%$ NUS2 and NUS3/Ultem ${ }^{\mathrm{TM}} \mathrm{MMMs}$, the $\mathrm{H}_{2}$ and $\mathrm{CO}_{2}$ permeabilities increased significantly with respect to the polymer, increasing the $\mathrm{CO}_{2} / \mathrm{CH}_{4}$ and $\mathrm{H}_{2} / \mathrm{CO}_{2}$ selectivities (Figure $49 \mathrm{a}-\mathrm{d}$ ). The increased permeability was attributed to the porosity introduced by the COF in the MMM, which is clearly observed in Figure 49a-d, where MMMs containing NUS3 (1.8 nm pore aperture) exhibit superior $\mathrm{CO}_{2}$ permeabilities than MMMs containing NUS2 (0.8 nm pore aperture) and Ultem ${ }^{\mathrm{TM}}$. The $20 \mathrm{wt} \%$ NUS3-PBI MMMs exhibited a $\mathrm{H}_{2}$ diffusivity 17-fold that of PBI (Figure 49e,f).

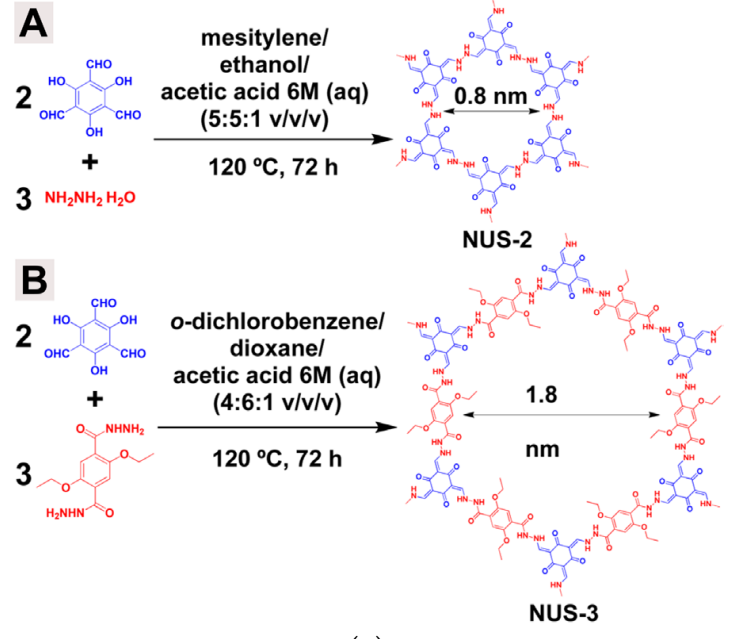

(a)

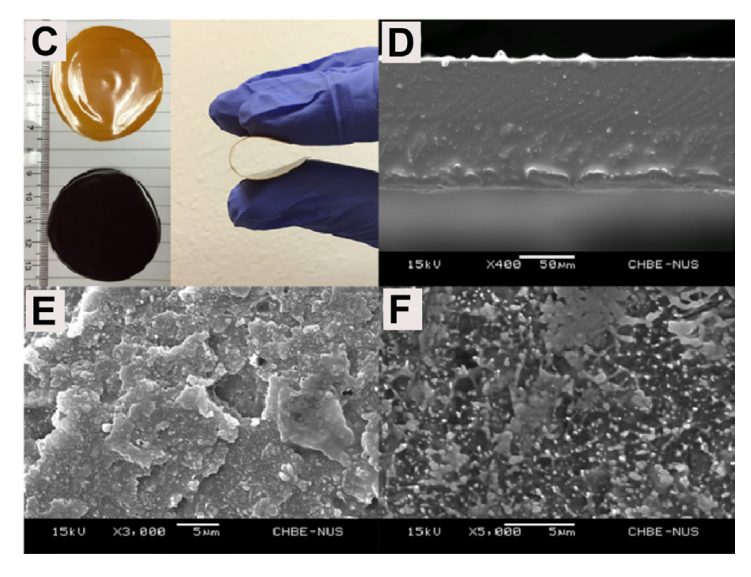

(b)

Figure 48. (a) Synthesis procedures and structures of the 2D covalen organic frameworks (COFs), NUS2 (A) and NUS3 (B); (b) Optical images (C) of a 20 wt \% NUS2/Ultem ${ }^{\text {TM }}$ (brown) and a 20 wt \% NUS3/Ultem ${ }^{\mathrm{TM}}$ (black) MMMs, and SEM images of the cross-sections of Ultem ${ }^{\mathrm{TM}}$ (D); 20 wt \% NUS2/Ultem ${ }^{\mathrm{TM}}(\mathbf{E})$; and a 20 wt \% NUS3/Ultem ${ }^{\mathrm{TM}}(\mathbf{F})$. Adapted with permission from [258]. Copyright, 2016, American Chemical Society.

Gas mixture separation properties of the MMMs with $\mathrm{H}_{2} / \mathrm{CO}_{2}$ blends showed that $\mathrm{H}_{2}$ permeability decreased by $20 \%$ to $30 \%$ for all MMMs relative to the pure gases. $\mathrm{The}_{2} / \mathrm{CO}_{2}$ selectivity of the NUS2-based MMMs decreased from 5.8 to 5.0 for the Ultem ${ }^{\mathrm{TM}}$ MMMs and from 31.4 to 18.8 for the PBI MMMs (Figure 49).

As the amount of work related to MOF-based MMMs increased in recent years, the measurement of the mechanical properties of MOF-based MMMs became more important for the understanding of the MOF/polymer interactions. In 2016, E. M. Mahdi, et al. [209] and S. J. D. Smith, et al. [208] reported on the thermomechanical, stress-strain, and viscoelastic properties of MMMs and the effects of aging on mechanical properties. E. M. Mahdi, et al. performed a detailed study of these properties on ZIF-8/polyurethane MMMs and concluded that for this system the interactions between the ZIF and the polymer were tenue since the hyperelastic and viscoelastic characteristics of polyurethane were retained upon ZIF-8 incorporation. These interactions were mostly a collection of uniform and weak H-bonds, van der Waals forces, and $\pi-\pi$ stacking interactions that produced a "mobile" free volume in the MMM due to the mobility of the ZIF-8 particles in the MMM when the ZIF loading was less than $20 \mathrm{wt} \%$. At higher loadings of ZIF-8, however, the increased amount of the weak interactions formed more rigid composite that suppressed the mobility of the ZIF/polymer interface 
causing a decline in ductility and toughness. S. J. D. Smith, et al. [208] extended the mechanical analyses of MMMs by studying the effects of aging on the mechanical properties of MMMs as seen in Figure 50. In this study, PIM-1, Matrimid ${ }^{\circledR}$, and PTMSP were used as polymer matrices to prepare MMMs with fumed silica, PAF-1, UiO-66, and $\mathrm{Ti}_{5} \mathrm{UiO}-66$ additives at $10 \mathrm{wt} \%$ loadings. As is shown in Figure 51, the incorporation of the nano-additives reduced the stress and strain at failure of the as-cast MMMs. MMMs containing PAF-1 and fumed silica showed identical losses in mechanical performance regardless of the polymer matrix used. It was concluded that polymer-additive interactions strongly influence local physical aging and determine the properties of the MMMs, additionally, they can slow physical aging too. By comparing the properties of the additives in different polymers, it was observed that the polymer largely determined the mechanical properties of the MMM since Matrimid ${ }^{\circledR}$ MMMs were stronger than PIM-1 and PTMSP MMMs containing the same additives. The mechanical properties of the pure polymer membranes decreased with aging, specifically, the membranes became more brittle as they aged. As the membranes aged, Young's modulus increased with time but differed with the type of additive used, for example, Ti $i_{5} \mathrm{UiO}-66 / \mathrm{PIM}-1$ MMMs exhibited higher modulus than PAF-1/PIM-1 MMMs and PIM-1 membranes but PAF-1/PIM-1 MMMs showed less modulus values than PIM-1 membranes.
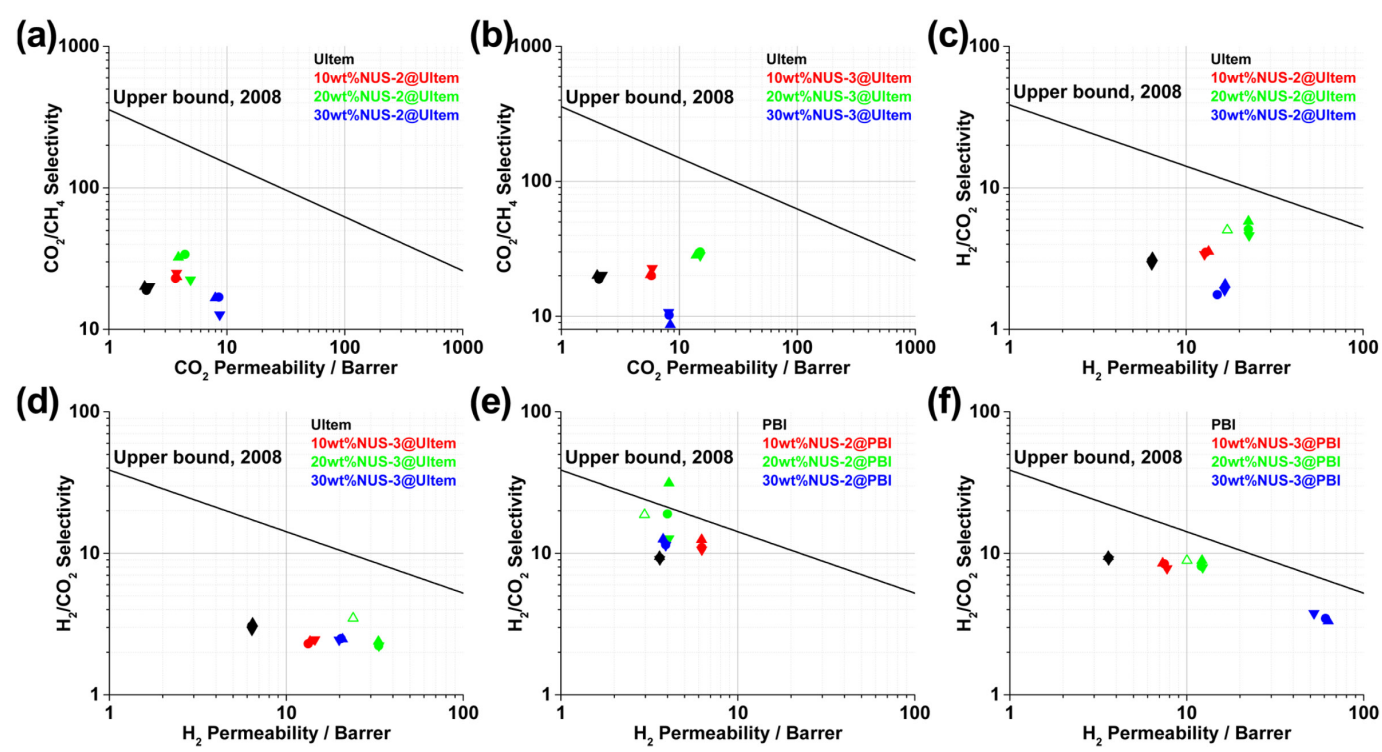

Figure 49. Pure gas (solid symbols) and gas mixture (open symbols) selectivities of NUS2 and NUS3/Ultem ${ }^{\mathrm{TM}}$ and PBI MMMs: $\mathrm{CO}_{2} / \mathrm{CH}_{4}$ separation with NUS2/Ultem ${ }^{\mathrm{TM}}$ (a) and with NUS3/Ultem ${ }^{\mathrm{TM}}$ (b); $\mathrm{H}_{2} / \mathrm{CO}_{2}$ separation with NUS2/Ultem ${ }^{\mathrm{TM}}$ (c) and with NUS3/Ultem ${ }^{\mathrm{TM}}(\mathbf{d}) ; \mathrm{H}_{2} / \mathrm{CO}_{2}$ separation with NUS2/PBI (e) and NUS3/PBI (f). $\boldsymbol{\nabla}=2$ bar, $\bullet=3.5$ bar, $\boldsymbol{\Lambda}=5$ bar. Reprinted with permission from [258]. Copyright, 2016, American Chemical Society. 


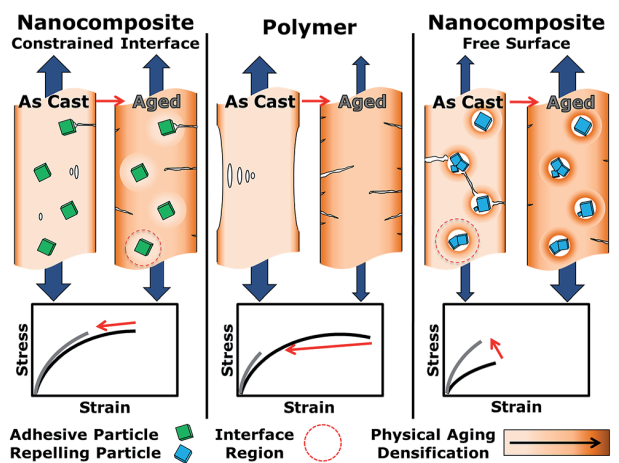

Figure 50. Fracture mechanisms of aged MMMs with different additive interface environments compared to freshly cast polymer embrittlement. Adhesive interaction reduces crack propagation, leading to better performance over the embrittled aged polymer. Repulsive interaction initially compromise film properties; however the localized increased aging rate isolates defects and leads to mechanical stability. Reproduced with permission from [208]. Copyright, 2016, The Royal Society of Chemistry.
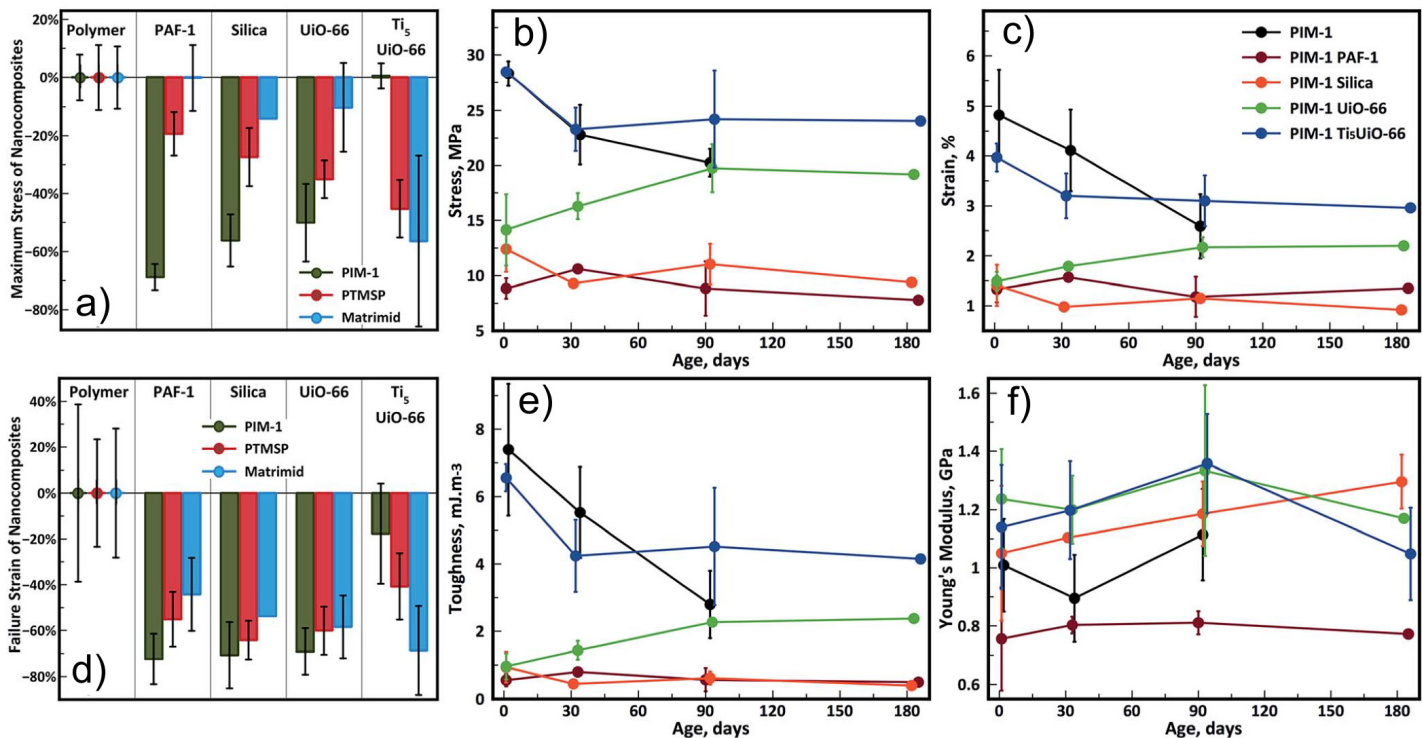

Figure 51. Effect of nanoparticle addition on maximum tensile stress (a) and strain at failure (d) of as-cast polymer composite films. Comparison of stress (b); strain (c); toughness (e); and modulus (f) of PIM-1 based nanocomposites with age. Pure PIM-1 films became too fragile for testing after 90 day. Adapted with permission from [208]. Copyright, 2016, The Royal Society of Chemistry.

The previously described advances made in the MOF-based MMM field are shown in Figure 52. The chronological evolution of this type of MMM is certainly promising and exciting and shows the attention that this type of material has received from the scientific community. Additionally, the reader is directed to several reviews of MOF-based MMMs [134,206,207,259-265] that present the most significant developments and challenges in this field. 


\begin{tabular}{|c|c|c|}
\hline MOF-based MMMs Progress & Year & Contributors \\
\hline $\mathrm{Cu}-\mathrm{MOF} / \mathrm{PAET}$ MMMs for gas separations & 2004 & H. Yehia, et al. [120] \\
\hline $\mathrm{Cu}_{3} \mathrm{BTC}_{2} / \mathrm{PDMS}$ and $\mathrm{Mn}(\mathrm{HCOO})_{2} / \mathrm{PSf}$ MOF-MMMs & 2006 & A. Car, et al. [122] \\
\hline MOF/polyimide MMM for gas separations: MOF-5/Matrimid ${ }^{\circledR}$ MMMs & 2006 & E. V. Perez, et al. [123] \\
\hline $\mathrm{Cu}-\mathrm{MOF} / \mathrm{PDMS} / \mathrm{POT} / \mathrm{PAET}$ MMMs for gas separations & 2006 & C. Barcena [203] \\
\hline $\begin{array}{r}\mathrm{Cu}-\mathrm{BPY}-\mathrm{HFS} / \text { Matrimid }{ }^{\circledR} \mathrm{MMMs} \text { for gas separations and mechanical } \\
\text { analysis of Cu-BPY-HFS/Matrimid }{ }^{\circledR} \text { MMMs }\end{array}$ & 2008 & Y. Zhang, et al. [204] \\
\hline MOF-5/Cu-MOF/MOP-18/Matrimid ${ }^{\circledast}$ MMMs for gas separations & 2009 & E. V. Perez, et al. $[124,125]$ \\
\hline $\mathrm{Cu}-\mathrm{TPA} / \mathrm{PVAc}$ MMMs for gas separation & 2010 & R. Adams, et al. [210] \\
\hline ZIF-90/Ultem ${ }^{\mathrm{TM}} /$ Matrimid $^{\circledR} / 6$ FDA-DAM MMMs for gas separations & 2010 & T.-H. Bae, et al. [127] \\
\hline $\mathrm{CO}_{2}$ diffusion in ZIF-8/PSf MMMs by pulsed field gradient NMR & 2010 & K. Diaz, et al. [211] \\
\hline Cu-based MOF hollow fiber MMM & 2010 & J. Hu, et al. [212] \\
\hline Atomistic and continuum modeling of MOF-based MMMs & 2010 & S. Keskin, et al. $[213,214]$ \\
\hline Tortuosity in ZIF-8/Matrimid ${ }^{\circledR}$ MMMs for gas separations & 2010 & Ma. J. Ordoñez, et al. [216] \\
\hline Asymmetric MIL-53/Matrimid ${ }^{\circledR}$ MMMs for gas separations & 2011 & S. Basu, et al. [218] \\
\hline $\begin{array}{r}\text { ZIF-8/PMPS MMMs for } \mathrm{C}_{2}-\mathrm{C}_{5} \text { alcohols recovery from water by } \\
\text { organophilic pervaporation }\end{array}$ & 2011 & X. L. Liu, et al. [38] \\
\hline $\begin{array}{r}\text { Colloidal ZIF-7/PBI MMMs for } \mathrm{H}_{2} / \mathrm{CO}_{2} \text { separations: improved } \\
\text { dispersion of } \mathrm{ZIF} \text { in polymer }\end{array}$ & 2011 & T. Yang, et al. [205] \\
\hline $\mathrm{NH}_{2}$-functionalized MIL-53/PSf MMMs for gas separations & 2011 & B. Zornoza, et al. [219] \\
\hline Combination of MOF and zeolites in MMMs: synergistic effects & 2011 & B. Zornoza, et al. [221] \\
\hline Water stable MIL-101/PSf MMMs for $\mathrm{O}_{2} / \mathrm{N}_{2}$ separations & 2012 & H. B. T. Jeazet, et al. [222] \\
\hline ZIF-8/Ultem ${ }^{\mathrm{TM}}$ hollow fiber MMMs for $\mathrm{CO}_{2} / \mathrm{N}_{2}$ separations & 2012 & Y. Dai, et al. [223] \\
\hline $\begin{array}{r}\mathrm{H}_{2} / \mathrm{CO}_{2} \text { separation with ZIF-8/PBI hollow fiber MMMs at elevated } \\
\text { temperatures }\end{array}$ & 2012 & T. Yang, et al. [224] \\
\hline $\mathrm{C}_{3} \mathrm{H}_{6} / \mathrm{C}_{3} \mathrm{H}_{8}$ separation with ZIF-8/6FDA-DAM MMMs & 2012 & C. Zhang, et al. [11] \\
\hline ZIF-8/PIM-1 MMMs for gas separations and PALS study & 2013 & A. F. Bushell, et al. [225] \\
\hline $\begin{array}{r}\text { PALS study of MIL-101/PSf MMMs for the correlation of permeability } \\
\text { with free volume }\end{array}$ & 2013 & H. B. T. Jeazet, et al. [229] \\
\hline $\begin{array}{r}\text { Interfacial } \mathrm{MOF} / \text { polymer adsorption equilibrium effects on gas } \\
\text { permeation models: Finite element analysis }\end{array}$ & 2013 & T. Singh, et al. [230] \\
\hline Room temperature ionic liquid/ZIF-8 MMMs for gas separations & 2013 & L. Hao, et al. [233] \\
\hline Reverse $\mathrm{CO}_{2} / \mathrm{H}_{2}$ selective MIL-53/PMP MMMs & 2014 & R. Abedini, et al. [234] \\
\hline $\begin{array}{r}\text { Comparative gas permeation study of ZIF-8, polymer (PMPS), and the } \\
\text { ZIF-8/PMPS membranes }\end{array}$ & 2014 & L. Diestel, et al. [235] \\
\hline Drying temperature effects on MMM gas permeabilities & 2014 & C. Duan, et al. [237] \\
\hline Impact of ZIF particle size on $\mathrm{MMM} \mathrm{CO}_{2} / \mathrm{CH}_{4}$ separation & 2014 & N. A. Nordin, et al. [238] \\
\hline $\begin{array}{l}\text { MOP-18/Matrimid }{ }^{\circledast} \text { MMMs for gas separations: molecular level } \\
\text { dispersion, high pressure gas permeation, and mechanical analysis }\end{array}$ & 2014 & E. V. Perez, et al. [126] \\
\hline High pressure gas permeation with MOF-based MMMs & 2014 & S. Shahid, et al. $[239,240]$ \\
\hline FIB-SEM and 3D visualization of MOF dispersion in MMM & 2014 & T. Rodenas, et al. [241] \\
\hline ZIF-8 membrane growth on ZIF-8-based MMM supports & 2014 & Z. Y. Yeo, et al. [242] \\
\hline Aging cessation in PAF-1/PTMSP, PMP, PIM-1 MMMs & 2014 & C. H. Lau, et al. [243] \\
\hline Aging reduction in MOP/PTMSP MMMs & 2015 & M. Kitchin, et al. [244] \\
\hline Functionalized MOPs MMMs for gas separations & 2015 & J. Ma, et al. [250] \\
\hline $\begin{array}{r}\text { Two-dimensional Cu-BTC MOF nanosheet MMMs: effect of filler } \\
\text { morphology on gas permeation }\end{array}$ & 2015 & T. Rodenas, et al. [251] \\
\hline MOF surface functionalization for improved compatibility & 2015 & S. R. Venna, et al. [254] \\
\hline $\begin{array}{r}\mathrm{H}_{2} / \mathrm{CO}_{2} \text { separations with } \mathrm{NH}_{2}-\mathrm{MIL}-53 / \mathrm{VTEC}^{\mathrm{TM}} \mathrm{MMMs} \text { at high pressure } \\
\text { and high temperature }\left(30 \mathrm{bar} \text { and } 300{ }^{\circ} \mathrm{C}\right) \text { and thermomechanical } \\
\text { analyses of MMMs up to } 300^{\circ} \mathrm{C}\end{array}$ & 2015 & E. V. Perez, et al. [128] \\
\hline Polymer-MOF hybrid materials: polyMOFs & 2015 & Z. Zhang, et al. [255] \\
\hline $\mathrm{COF} /$ poly(vinyl amine) MMMs for gas separations & 2016 & X. Cao, et al. [256] \\
\hline Exfoliated 2D COFs in Ultem ${ }^{T M}$ and $\mathrm{PBI}$ for $\mathrm{H}_{2}$ separations & 2016 & Z. Kang, et al. [258] \\
\hline $\begin{array}{r}\text { Thermomechanical, strain-stress, and viscoelastic properties of ZIF- } \\
\text { 8/polyurethane MMMs }\end{array}$ & 2016 & E. M. Mahdi, et al. [209] \\
\hline Effects of aging on mechanical properties of MMMs & 2016 & S. J. D. Smith, et al. [208] \\
\hline
\end{tabular}

Figure 52. Chronological progress for MOF-based MMMs. 


\section{Future Directions}

By focusing on reported MMMs based on inorganic fillers, the following future directions of the field can be envisioned. Although gas separation membranes are usually commercialized as hollow fiber membranes, reports of inorganic materials based hollow fiber membranes are just a handful. Extensive research on improving mechanical properties, chemical inertness of such MMMs will be the focus of the researchers in the field. Moreover, the combination of zeolites and carbon based materials in the preparation of MMMs with improved gas separation capabilities could be another research topic in the future.

The challenges for MOF-based MMMs to overcome are more evident and specific as the evolution of this type of membranes progresses. In contrast to inorganic-based MMMs where additive/polymer incompatibilities are a major concern, in MOF-based MMMs polymer rigidification around the MOF particles, presumably due to strong interactions, is a concern since it isolates the MOF and reduces its interactions with gas molecules. The ability to control and tune the MOF/polymer interface is a necessity for this type of membranes. The effects of filler size, morphology, and particle aspect ratio on membrane performance is also an emerging topic that could lead to improvements in membrane performances once their effects are understood. Another topic that deserves attention is suppression of membrane aging for industrial applications, extending the lifetime of the separation properties of membranes over a reasonable period of time could make polymer-based membranes attractive in industrial gas separations. Initial work on this topic has started but more development is needed.

\section{Conclusions}

From the early observations of the water and $\mathrm{CO}_{2}$ permeation phenomena in membranes made of pig bladders in the mid-1700s, to the first report of an MMM using dense inorganic additives in 1912, to the incorporation of porous molecular sieves in 1971, and to the incorporation of porous MOFs in 2004, the field of MMMs has experienced an enormous progress.

To improve gas separation characteristics, researchers have fabricated polymer-based MMMs containing inorganic additives, including zeolites and carbon-based materials. Carbon molecular sieves, carbon nanotubes, and graphene were studied as carbon-based additives for MMMs. However, owing to poor interactions between the polymers and the additives, these membranes showed poor mechanical properties. Therefore, researchers have tried to improve the interactions by using different strategies. Some have explored the interactions of several different polymers with a certain zeolite. Modification of the chemical structures of the additives as well as the polymers has been employed in order to improve the interactions. Both zeolites and carbon-based additives have been chemically modified in fabricating MMMs, which showed improvements not only in mechanical properties but also in gas separation properties.

The MOF-based MMM technology has evolved rapidly owing to the potential these materials bring to the MMM field. Significant work was oriented to the understanding and improvement of the $\mathrm{MOF} /$ polymer interface. Of paramount importance is the effect this interface has on gas transport, and this is where there is still work to be done. Polymer rigidification at the interface, pore blockage, non-selective voids, and particle aggregation are some of the main challenges MMMs face before industrial application. In this review, the work of several scholars that have addressed these challenges has been presented. The authors of this work believe there is still more work to be done to fully understand and control these parameters before the full potential of MOFs can be realized in an MMM. The majority of the works presented herein showed an increase in gas permeation and relatively constant selectivity with increasing MOF loadings that was attributed to the porosity of the MOFs in the MMMs. The selectivities, however, seemed to still be controlled by the polymer (with a few exceptions), and little contribution was observed from the MOF, which may be the next area of concerted focus. Another important aspect of the art is the testing of MOF-based MMMs under real world conditions. Gas permeability and selectivity properties generally change when the membranes are exposed to gas mixtures and contaminants in the feed as well as to increasing temperatures that 
could render the most promising membranes unsuitable for industrial applications. Additionally, as higher pressures may be needed in these applications, the mechanical robustness of the membranes needs to be addressed without overlooking required fluxes. As it can be seen, there is still much to be done before MMMs can be employed in industrial gas separations, but the growing interest and dedication of membranologists is catching up.

Acknowledgments: This material is based upon work supported by the National Science Foundation under Grant No. CBET-1403950.

Author Contributions: All the authors contributed equally to this work. E.V.P. collected and analyzed the literature and wrote the article, the history of membranes, and the evolution of MOF-based MMMs; C.K. wrote the evolution of inorganic materials-based MMMs; J.P.F., K.J.B., and I.H.M. assisted with the manuscript.

Conflicts of Interest: The authors declare no conflict of interest.

\section{Abbreviations}

The following abbreviations are used in this manuscript:

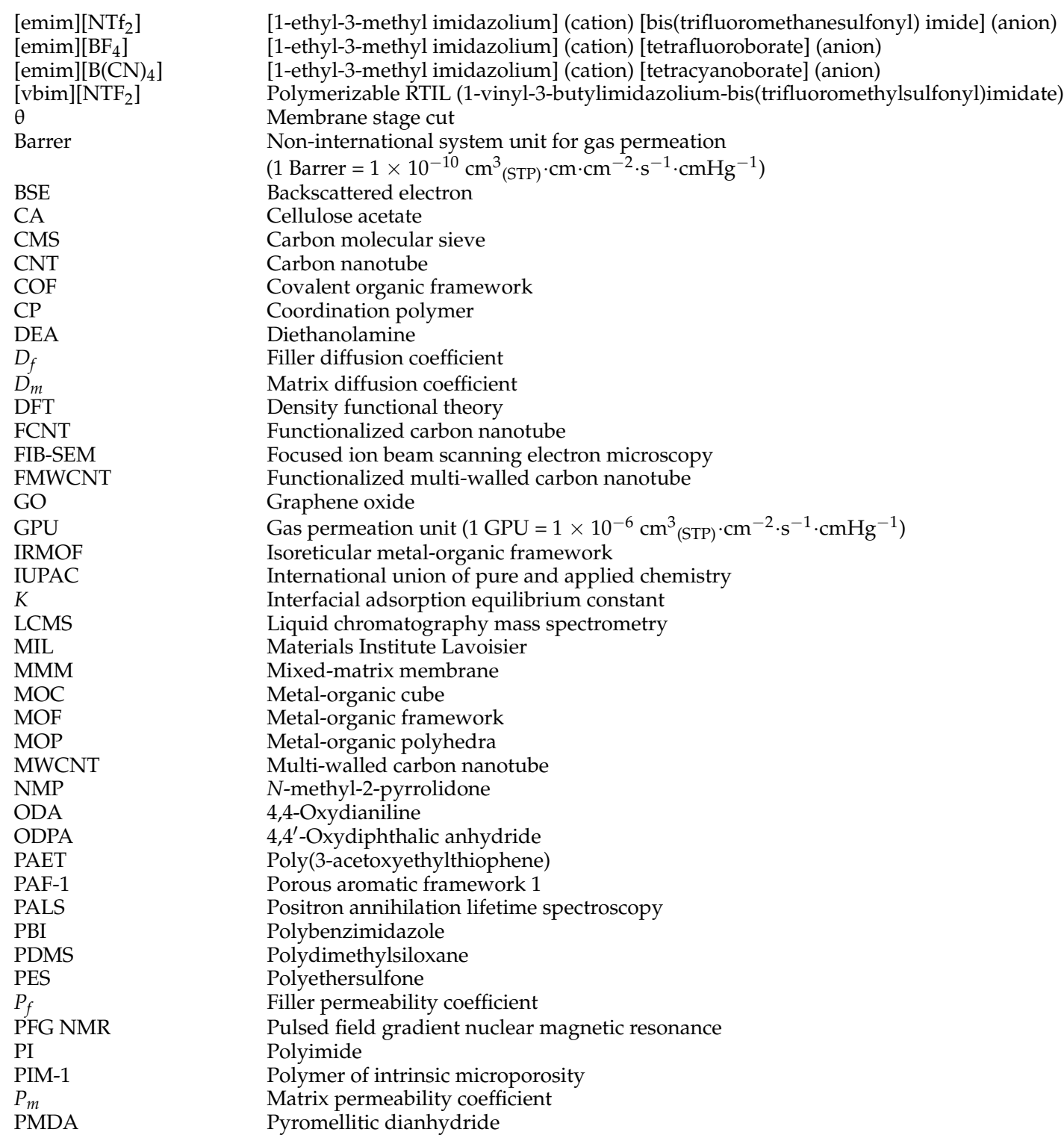




$\begin{array}{ll}\text { PMP } & \text { Poly(4-methyl-1-pentyne) } \\ \text { PMP-2 } & \text { Poly(4-methyl-2-pentyne) } \\ \text { PMPS } & \text { Polymethylphenylsiloxane } \\ \text { PolyRTILs } & \text { Polymerizable room temperature ionic liquids } \\ \text { PPEES } & \text { Poly(1,4-phenylene ether-ether-sulfone) } \\ \text { PPZ } & \text { Polyphosphazene } \\ \text { PS } & \text { Polystyrene } \\ \text { PSf } & \text { Polysulfone } \\ \text { PTMSP } & \text { Poly(1-trimethylsilil-1-propyne) } \\ \text { PVAc } & \text { Poly(vinyl acetate) } \\ \text { PVAm } & \text { Poly(vinyl amine) } \\ \text { PVPy } & \text { Polyvinylpyrrolidone } \\ \text { RTILs } & \text { Room temperature ionic liquids } \\ \text { SAPO-34 } & \text { Silicoaluminophosphate } \\ \text { SBS } & \text { Poly(styrene-b-butadiene-b-styrene) } \\ \text { SBU } & \text { Secondary building unit } \\ \text { SEM } & \text { Scanning electron microscopy } \\ \text { SPEEK } & \text { Sulfonated poly(ether ether ketone) } \\ \text { SPES } & \text { Sulfonated polyethersufone } \\ \text { SWCNT } & \text { Single-walled carbon nanotube } \\ \text { TEM } & \text { Transmission electron microscopy } \\ \text { Tg } & \text { Glass transition temperature } \\ \text { TGA } & \text { Thermogravimetric analysis } \\ \text { TMPDA } & \text { 2,4,6-Trimethyl-1,3-phenylenediamine } \\ \text { XRD } & \text { Powder X-ray diffraction } \\ \text { ZIF } & \text { Zeolitic imidazolate framework } \\ \text { XPS } & \text { X-ray photoelectron spectroscopy } \\ & \\ & \end{array}$

\section{References}

1. Henis, J.M.S.; Tripodi, M.K. The developing technology of gas separating membranes. Science 1983, 220, 11-17. [CrossRef] [PubMed]

2. Parkinson, G.; Ushio, S.; Lewald, R. Membranes widen roles in gas separations. Chem. Eng. 1984, 16, 14-19.

3. Babita, K.; Sridhar, S.; Raghavan, K.V. Membrane reactors for fuel cell quality hydrogen through WGSR-Review of their status, challenges and opportunities. Int. J. Hydrog. Energy 2011, 36, 6671-6688. [CrossRef]

4. Diniz da Costa, J.C.; Reed, G.P.; Thambimuthu, K. High temperature gas separation membranes in coal gasification. Energy Procedia 2009, 1, 295-302. [CrossRef]

5. Fang, M.; Wu, C.; Yang, Z.; Wang, T.; Xia, Y.; Li, J. ZIF-8/PDMS mixed matrix membranes for propane/nitrogen mixture separation: Experimental result and permeation model validation. J. Membr. Sci. 2015, 474, 103-113. [CrossRef]

6. Gallucci, F.; Fernandez, E.; Corengia, P.; van Sint Annaland, M. Recent advances on membranes and membrane reactors for hydrogen production. Chem. Eng. Sci. 2013, 92, 40-66. [CrossRef]

7. Marano, J.J.; Ciferino, J.P. Integration of Gas Separation Membranes with IGCC Identifying the Right Membrane for the Right Job. Energy Procedia 2009, 1, 361-368. [CrossRef]

8. Ploegmakers, J.; Japip, S.; Nijmeijer, K. Mixed matrix membranes containing MOFs for ethylene/ethane separation-Part B: Effect of $\mathrm{Cu}_{3} \mathrm{BTC}_{2}$ on membrane transport properties. J. Membr. Sci. 2013, 428, 331-340. [CrossRef]

9. Ploegmakers, J.; Japip, S.; Nijmeijer, K. Mixed matrix membranes containing MOFs for ethylene/ethane separation Part A: Membrane preparation and characterization. J. Membr. Sci. 2013, 428, 445-453. [CrossRef]

10. Shoko, E.; McLellan, B.; Dicks, A.L.; da Costa, J.C.D. Hydrogen from coal: Production and utilisation technologies. Int. J. Coal Geol. 2006, 65, 213-222. [CrossRef]

11. Zhang, C.; Dai, Y.; Johnson, J.R.; Karvan, O.; Koros, W.J. High performance ZIF-8/6FDA-DAM mixed matrix membrane for propylene/propane separations. J. Membr. Sci. 2012, 389, 34-42. [CrossRef]

12. Han, S.-S.; Park, J.-H.; Kim, J.-N.; Cho, S.-H. Propylene recovery from propylene/propane/nitrogen mixture by PSA process. Adsorption 2005, 11, 621-624. [CrossRef] 
13. Silva, F.A.D.; Rodrigues, A.E. Propylene/propane separation by vacuum swing adsorption using $13 \mathrm{X}$ zeolite. AlChE J. 2001, 47, 341-357. [CrossRef]

14. Eldridge, R.B. Olefin/paraffin separation technology: A review. Ind. Eng. Chem. Res. 1993, 32, $2208-2212$. [CrossRef]

15. Rege, S.U.; Yang, R.T. Propane/propylene separation by pressure swing adsorption: Sorbent comparison and multiplicity of cyclic steady states. Chem. Eng. Sci. 2002, 57, 1139-1149. [CrossRef]

16. Habgood, D.C.C.; Hoadley, A.F.A.; Zhang, L. Techno-economic analysis of gasification routes for ammonia production from Victorian brown coal. Chem. Eng. Res. Des. 2015, 102, 57-68. [CrossRef]

17. Hellman, A.; Honkala, K.; Dahl, S.; Christensen, C.H.; Nørskov, J.K. Ammonia synthesis: State of the bellwether reaction. In Comprehensive Inorganic Chemistry II (Second Edition); Poeppelmeier, J.R., Ed.; Elsevier: Amsterdam, The Netherlands, 2013; pp. 459-474.

18. Driscoll, D.; Morreale, B.; Headley, L. NETL Test Protocol: Testing of Hydrogen Separation Membranes; U.S. Department of Energy (DOE): Washington, DC, USA; National Energy Technology Laboratory (NETL): Pittsburgh, PA, USA, 2008.

19. Stiegel, G.J.; Ramezan, M. Hydrogen from coal gasification: An economical pathway to a sustainable energy future. Int. J. Coal Geol. 2006, 65, 173-190. [CrossRef]

20. Miller, L.C.; Cicero, D.C.; Ackiewicz, M. Hydrogen from Coal Program: Research, Development, and Demonstration Plan for the Period 2009 through 2016; U.S. Department of Energy (DOE): Washington, DC, USA; National Energy Technology Laboratory (NETL): Pittsburgh, PA, USA, 2009.

21. Angelini, P.; Armstrong, T.; Counce, R.; Griffith, W.; Klasson, T.; Muralidharan, G.; Narula, C.; Sikka, V.; Closset, G.; Keller, G.; et al. Materials for Separation Technologies: Energy and Emission Reduction Opportunities; Oak Ridge National Laboratory: Washington, WA, USA, 2005; p. 118.

22. Sholl, D.S.; Lively, R.P. Seven chemical separations to change the world. Nature 2016, 532, 435-437. [CrossRef] [PubMed]

23. Graham, T. Notice of the singular inflation of a bladder. Q. J. Sci. Lit. Art 1829, 2, 88-89.

24. Graham, T. Notice of the singular inflation of a bladder. J. Membr. Sci. 1995, 100. [CrossRef]

25. Graham, T. On the absorption and dialytic separation of gases by colloid septa. Philos. Trans. R. Soc. Lond. 1866, 156, 399-439. [CrossRef]

26. Graham, T. LV. On the absorption and dialytic separation of gases by colloid septa. Philos. Mag. Ser. 4 1866, 32, 401-420.

27. Graham, T. On the absorption and dialytic separation of gases by colloid septa Part I.-Action of a septum of caoutchouc. J. Membr. Sci. 1995, 100, 27-31. [CrossRef]

28. Wijmans, J.G.; Baker, R.W. The solution-diffusion model: A review. J. Membr. Sci. 1995, 107, 1-21. [CrossRef]

29. Yasuda, H. Units of gas permeability constants. J. Appl. Polym. Sci. 1975, 19, 2529-2536. [CrossRef]

30. Su, Z.; Chen, J.H.; Sun, X.; Huang, Y.; Dong, X. Amine-functionalized metal organic framework $\left(\mathrm{NH}_{2}\right.$-MIL-125(Ti)) incorporated sodium alginate mixed matrix membranes for dehydration of acetic acid by pervaporation. RSC Adv. 2015, 5, 99008-99017. [CrossRef]

31. Jin, H.; Liu, X.; Ban, Y.; Peng, Y.; Jiao, W.; Wang, P.; Guo, A.; Li, Y.; Yang, W. Conversion of xylose into furfural in a MOF-based mixed matrix membrane reactor. Chem. Eng. J. 2015. [CrossRef]

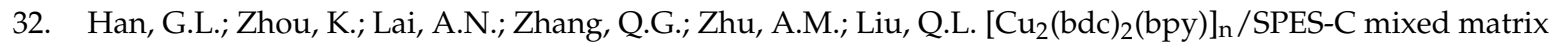
membranes for separation of methanol/methyl tert-butyl ether mixtures. J. Membr. Sci. 2014, 454, 36-43. [CrossRef]

33. Liu, S.; Liu, G.; Shen, J.; Jin, W. Fabrication of MOFs/PEBA mixed matrix membranes and their application in bio-butanol production. Sep. Purif. Technol. 2014, 133, 40-47. [CrossRef]

34. Zhao, C.; Wang, N.; Wang, L.; Huang, H.; Zhang, R.; Yang, F.; Xie, Y.; Ji, S.; Li, J.-R. Hybrid membranes of metal-organic molecule nanocages for aromatic/aliphatic hydrocarbon separation by pervaporation. Chem. Commun. 2014. [CrossRef] [PubMed]

35. Liu, S.; Liu, G.; Zhao, X.; Jin, W. Hydrophobic-ZIF-71 filled PEBA mixed matrix membranes for recovery of biobutanol via pervaporation. J. Membr. Sci. 2013, 446, 181-188. [CrossRef]

36. De la Iglesia, O.; Sorribas, S.; Almendro, E.; Zornoza, B.; Tellez, C.; Coronas, J. Metal-organic framework MIL-101(Cr) based mixed matrix membranes for esterification of ethanol and acetic acid in a membrane reactor. Renew. Energy 2016, 88, 12-19. [CrossRef] 
37. Zhu, L.; Yu, H.; Zhang, H.; Shen, J.; Xue, L.; Gao, C.; van der Bruggen, B. Mixed matrix membranes containing MIL-53(Al) for potential application in organic solvent nanofiltration. RSC Adv. 2015, 5, 73068-73076. [CrossRef]

38. Liu, X.-L.; Li, Y.-S.; Zhu, G.-Q.; Ban, Y.-J.; Xu, L.-Y.; Yang, W.-S. An organophilic pervaporation membrane derived from metal-organic framework nanoparticles for efficient recovery of bio-alcohols. Angew. Chem. Int. Ed. 2011, 50, 10636-10639. [CrossRef] [PubMed]

39. Sorribas, S.; Kudasheva, A.; Almendro, E.; Zornoza, B.; de la Iglesia, O.; Tellez, C.; Coronas, J. Pervaporation and membrane reactor performance of polyimide based mixed matrix membranes containing MOF HKUST-1. Chem. Eng. Sci. 2015, 124, 37-44. [CrossRef]

40. Kudasheva, A.; Sorribas, S.; Zornoza, B.; Tellez, C.; Coronas, J. Pervaporation of water/ethanol mixtures through polyimide based mixed matrix membranes containing ZIF-8, ordered mesoporous silica and ZIF-8-silica core-shell spheres. J. Chem. Technol. Biotechnol. 2015, 90, 669-677. [CrossRef]

41. Amirilargani, M.; Sadatnia, B. Poly(vinyl alcohol)/zeolitic imidazolate frameworks (ZIF-8) mixed matrix membranes for pervaporation dehydration of isopropanol. J. Membr. Sci. 2014, 469, 1-10. [CrossRef]

42. Shi, G.M.; Yang, T.; Chung, T.S. Polybenzimidazole (PBI)/zeolitic imidazolate frameworks (ZIF-8) mixed matrix membranes for pervaporation dehydration of alcohols. J. Membr. Sci. 2012, 415-416, 577-586. [CrossRef]

43. Ying, Y.; Xiao, Y.; Ma, J.; Guo, X.; Huang, H.; Yang, Q.; Liu, D.; Zhong, C. Recovery of acetone from aqueous solution by ZIF-7/PDMS mixed matrix membranes. RSC Adv. 2015, 5, 28394-28400. [CrossRef]

44. Fan, H.; Shi, Q.; Yan, H.; Ji, S.; Dong, J.; Zhang, G. Simultaneous spray self-assembly of highly loaded ZIF-8-PDMS nanohybrid membranes exhibiting exceptionally high biobutanol-permselective pervaporation. Angew. Chem. Int. Ed. 2014, 53, 5578-5582. [CrossRef] [PubMed]

45. Yan, H.; Li, J.; Fan, H.; Ji, S.; Zhang, G.; Zhang, Z. Sonication-enhanced in situ assembly of organic/inorganic hybrid membranes: Evolution of nanoparticle distribution and pervaporation performance. J. Membr. Sci. 2015, 481, 94-105. [CrossRef]

46. Wee, L.H.; Li, Y.; Zhang, K.; Davit, P.; Bordiga, S.; Jiang, J.; Vankelecom, I.F.J.; Martens, J.A. Submicrometer-sized ZIF-71 filled organophilic membranes for improved bioethanol recovery: Mechanistic in-sights by Monte Carlo simulation and FTIR spectroscopy. Adv. Funct. Mater. 2015, 25, 516-525. [CrossRef]

47. Sue, Y.-C.; Wu, J.-W.; Chung, S.-E.; Kang, C.-H.; Tung, K.-L.; Wu, K.C.W.; Shieh, F.-K. Synthesis of hierarchical micro/mesoporous structures via solid-aqueous interface growth: Zeolitic imidazolate framework-8 on siliceous mesocellular foams for enhanced pervaporation of water/ethanol mixtures. ACS Appl. Mater. Interfaces 2014, 6, 5192-5198. [CrossRef] [PubMed]

48. Kang, C.-H.; Lin, Y.-F.; Huang, Y.-S.; Tung, K.-L.; Chang, K.-S.; Chen, J.-T.; Hung, W.-S.; Lee, K.-R.; Lai, J.-Y. Synthesis of ZIF-7/chitosan mixed-matrix membranes with improved separation performance of water/ethanol mixtures. J. Membr. Sci. 2013, 438, 105-111. [CrossRef]

49. Li, Y.; Wee, L.H.; Martens, J.A.; Vankelecom, I.F.J. ZIF-71 as a potential filler to prepare pervaporation membranes for bio-alcohol recovery. J. Mater. Chem. A 2014, 2, 10034-10040. [CrossRef]

50. Hua, D.; Ong, Y.K.; Wang, Y.; Yang, T.; Chung, T.-S. ZIF-90/P84 mixed matrix membranes for pervaporation dehydration of isopropanol. J. Membr. Sci. 2014, 453, 155-167. [CrossRef]

51. Baker, R.W. Future directions of membrane gas separation technology. Ind. Eng. Chem. Res. 2002, 41, 1393-1411. [CrossRef]

52. Baker, R.W.; Low, B.T. Gas separation membrane materials: A perspective. Macromolecules 2014, 47, 6999-7013. [CrossRef]

53. Moore, T.T.; Koros, W.J. Gas sorption in polymers, molecular sieves, and mixed matrix membranes. J. Appl. Polym. Sci. 2007, 104, 4053-4059. [CrossRef]

54. Husain, S.; Koros, W.J. Mixed matrix hollow fiber membranes made with modified HSSZ-13 zeolite in polyetherimide polymer matrix for gas separation. J. Membr. Sci. 2007, 288, 195-207. [CrossRef]

55. Aroon, M.A.; Ismail, A.F.; Matsuura, T.; Montazer-Rahmati, M.M. Performance studies of mixed matrix membranes for gas separation: A review. Sep. Purif. Technol. 2010, 75, 229-242. [CrossRef]

56. Nasir, R.; Mukhtar, H.; Man, Z.; Mohshim, D.F. Material advancements in fabrication of mixed-matrix membranes. Chem. Eng. Technol. 2013, 36, 717-727. [CrossRef]

57. Lloyd, D.R.; Kinzer, K.E.; Tseng, H.S. Microporous membrane formation via thermally induced phase separation. I. Solid-liquid phase separation. J. Membr. Sci. 1990, 52, 239-261. [CrossRef] 
58. Van de Witte, P.; Dijkstra, P.J.; van den Berg, J.W.A.; Feijen, J. Phase separation processes in polymer solutions in relation to membrane formation. J. Membr. Sci. 1996, 117, 1-31. [CrossRef]

59. Kim, S.S.; Lloyd, D.R. Microporous membrane formation via thermally-induced phase separation. III. Effect of thermodynamic interactions on the structure of isotactic polypropylene membranes. J. Membr. Sci. 1991, 64, 13-29. [CrossRef]

60. Lloyd, D.R.; Kim, S.S.; Kinzer, K.E. Microporous membrane formation via thermally-induced phase separation. II. Liquid-liquid phase separation. J. Membr. Sci. 1991, 64, 1-11. [CrossRef]

61. Koros, W.J.; Böddeker, K.W.; Fane, A.G.; Lonsdale, H.K. The early history of membrane science: Selected papers celebrating volume 100. J. Membr. Sci. 1995, 100, 1-68.

62. Böddeker, K.W. Commentary: Tracing membrane science. J. Membr. Sci. 1995, 100, 65-68. [CrossRef]

63. Böddeker, K.W. Tracing membrane science, an historical account. In Liquid Separations with Membranes: An Introduction to Barrier Interference; Springer Berlin Heidelberg: Berlin/Heidelberg, Germany, 2008; pp. 113-119.

64. Nollet, M.1.A. Sur les causes du bouillonnement des liquides. Hist. Acad. Sci. 1748, 57-104.

65. Nollet, J.A. Investigations on the causes for the ebullition of liquids. J. Membr. Sci. 1995, 100, 1-3. [CrossRef]

66. Dutrochet, M. Nouvelles observations sur l'endosmose et l'exosmose, et sur la cause de ce double phenomene. Ann. Chim. Phys. 1827, 35, 393-400.

67. Dutrochet, R.H. New observations on endosmosis and exosmosis, and on the cause of this dual phenomenon. J. Membr. Sci. 1995, 100, 5-7. [CrossRef]

68. Mitchell, J.K. On the penetrativeness of fluids. Am. J. Med. Sci. 1830, 7, 36-67. [CrossRef]

69. Mitchell, J.K. On the penetrativeness of fluids. J. Membr. Sci. 1995, 100, 11-16. [CrossRef]

70. Graham, T. XXVII. On the law of the diffusion of gases. Philos. Mag. Ser. 3 1833, 2. [CrossRef]

71. Graham, T. On the law of the diffusion of gases. J. Membr. Sci. 1995, 100, 17-21. [CrossRef]

72. Graham, T. LVIII. On the law of the diffusion of gases. Philos. Mag. Ser. 3 1833, 2, 351-358.

73. Graham, T. XLIV. On the law of the diffusion of gases. Philos. Mag. Ser. 3 1833, 2, 269-276.

74. Fick, A. Uber diffusion. Pogg. Ann. Phys. Chem. 1855, 94, 59-86. [CrossRef]

75. Fick, A. On liquid diffusion. Philos. Mag. Ser. 4 1855, 10, 30-39. [CrossRef]

76. Fick, A. On liquid diffusion. J. Membr. Sci. 1995, 100, 33-38. [CrossRef]

77. Wroblewski, S.V. Ueber die natur der absorption der gase. Ann. Phys. 1879, 244, 29-52. [CrossRef]

78. Van't Hoff, J.H. The role of osmotic pressure in the analogy between solutions and gases. J. Membr. Sci. 1995, 100, 39-44. [CrossRef]

79. Van't Hoff, J.H. Die rolle des osmotischen druckes in der analogie zwischen losungen und gasen. Z. Phys. Chem. 1887, 1, 481-508.

80. Van't Hoff, J.H. The role of osmotic pressure in the analogy between solutions and gases. In The Modern Theory of Solution: Memoirs by Pfeffer, van't Hoff, Arrhenius, and Raoult; Jones, H.C., Ed.; Harper \& Brothers Publishers: New York, NY, USA; London, UK, 1899; pp. 11-42.

81. Van't Hoff, J.H. The function of osmotic pressure in the analogy between solutions and gases. Philos. Mag. Ser. 5 1888, 26, 81-105. [CrossRef]

82. Bigelow, S.L.; Gemberling, A. Collodion membranes. J. Am. Chem. Soc. 1907, 29, 1576-1589. [CrossRef]

83. Bigelow, S.L.; Gemberling, A. Collodion membranes. J. Membr. Sci. 1995, 100, 57-59. [CrossRef]

84. Kundt, A.; Warburg, E. Ueber reibung und wärmeleitung verdünnter gase. Ann. Phys. 1875, 231, 337-365. [CrossRef]

85. Warburg, E. Ueber die gleitung der gase an glaswänden. Ann. Phys. 1876, 235, 399-415. [CrossRef]

86. Christiansen, C. Die atmolytische strömung der gase. Ann. Phys. 1890, 277, 565-587. [CrossRef]

87. Knudsen, M. Die gesetze der molekularströmung und der inneren reibungsströmung der gase durch röhren. Ann. Phys. 1909, 333, 75-130. [CrossRef]

88. Knudsen, M. The laws of molecular flow and of inner friction flow of gases through tubes. J. Membr. Sci. 1995, 100, 23-25. [CrossRef]

89. Donnan, F.G. Theorie der membrangleichgewichte und membranpotentiale bei vorhandensein von nicht dialysierenden elektrolyten. Ein beitrag zur physikalisch-chemischen physiologie. Z. Elektrochem. Angew. Phys. Chem. 1911, 17, 572-581.

90. Donnan, F.G. Theory of membrane equilibria and membrane potentials in the presence of non-dialysing electrolytes. A contribution to physical-chemical physiology. J. Membr. Sci. 1995, 100, 45-55. [CrossRef] 
91. Steinitzer, F. Das verhalten von kautschuk zu kohlensaure. Gummi Ztg. 1912, 26, 1626-1628.

92. Kober, P.A. Pervaporation, perstillation and percrystallization. J. Membr. Sci. 1995, 100, 61-64. [CrossRef]

93. Kober, P.A. Pervaporation, perstillation and percrystallization. J. Am. Chem. Soc. 1917, 39, 944-948. [CrossRef]

94. Edwards, J.D.; Pickering, S.F. Permeability of rubber to gases. Sci. Pap. Bur. Stand. 1920, 387, 327-362. [CrossRef]

95. Kovacs, A.J. Transition vitreuse dans les polymères amorphes. Etude phénoménologique. Adv. Polym. Sci. 1963, 3, 394-507.

96. Illers, V.K.H. Einfluß der thermischen vorgeschichte auf die eigenschaften von polyvinylchlorid. Makromol. Chem. 1969, 127, 1-33. [CrossRef]

97. Petrie, S.E.B. Thermal behavior of annealed organic glasses. J. Polym. Sci. B Polym. Phys. 1972, 10, 1255-1272. [CrossRef]

98. Petrie, S.E.B. The effect of excess thermodynamic properties versus structure formation on the physical properties of glassy polymers. J. Macromol. Sci. Phys. B 1976, 12, 225-247. [CrossRef]

99. Struik, L.C.E. Physical aging in amorphous polymers and other materials. Elsevier: Amsterdam, The Netherlands, 1978; p. 229.

100. Tant, M.R.; Wilkes, G.L. An overview of the nonequilibrium behavior of polymer glasses. Polym. Eng. Sci. 1981, 21, 874-895. [CrossRef]

101. Tant, M.R.; Wilkes, G.L. Physical aging studies of semicrystalline poly(ethylene terephthalate). J. Appl. Polym. Sci. 1981, 26, 2813-2825. [CrossRef]

102. Toi, K.; Ito, T.; Ikemoto, I. Effect of aging and conditioning on the gas transport of poly(vinyl acetate). J. Polym. Sci. Polym. Lett. Ed. 1985, 23, 525-529. [CrossRef]

103. Cangialosi, D.; Boucher, V.M.; Alegria, A.; Colmenero, J. Physical aging in polymers and polymer nanocomposites: Recent results and open questions. Soft Matter 2013, 9, 8619-8630. [CrossRef]

104. Daynes, H.A. The process of diffusion through a rubber membrane. Proc. R. Soc. Lond. A Math. Phys. Eng. Sci. 1920, 97, 286-307. [CrossRef]

105. Venable, C.S.; Fuwa, T. The solubility of gases in rubber and rubber stock and effect of solubility on penetrability. J. Ind. Eng. Chem. 1922, 14, 139-142. [CrossRef]

106. Ohya, T.; Davey, W.C. Permeability of rubber mixings. Inst. Rubber Ind. Trans. 1929, 5, 27-30.

107. Morris, V.N. Permeability of rubber to air II-Effect of stretch, thickness, milling, compounding ingredients, kind of crude rubber, and temperature of vulcanization. Ind. Eng. Chem. 1931, 23, 837-843. [CrossRef]

108. Amerongen, G.J.V. The effect of fillers on the permeability of rubber to gases. Rubber Chem. Technol. 1955, 28, 821-832. [CrossRef]

109. Melikhova, N.A.; Reitlinger, S.A.; Kuzina, E.N. Effect of fillers on the gas-permeability of synthetic rubbers. Soviet Rubber Technol. 1959, 18, 34-38.

110. Christen, G.; Fabre, A.; Faure, A. Membrane Hétérogène Pour le Fractionnement de Mélanges Fluides, et Son Emploi. France Patent 2,079,460 (A5), 1971.

111. Paul, D.R.; Kemp, D.R. The diffusion time lag in polymer membranes containing adsorptive fillers. J. Polym. Sci. Polym. Symp. 1973, 41, 79-93. [CrossRef]

112. Kemp, D.R.; Paul, D.R. Gas sorption in polymer membranes containing adsorptive fillers. J. Polym. Sci. Polym. Phys. Ed. 1974, 12, 485-500. [CrossRef]

113. Paul, D.R. Effect of immobilizing adsorption on the diffusion time lag. J. Polym. Sci. B Polym. Phys. 1969, 7, 1811-1818. [CrossRef]

114. Te Hennepe, H.J.C.; Bargeman, D.; Mulder, M.H.V.; Smolders, C.A. Zeolite-filled silicone rubber membranes. Part 1: Membrane preparation and pervaporation results. J. Membr. Sci. 1987, 35, 39-55. [CrossRef]

115. Kulprathipanja, S.; Neuzil, R.W.; Li, N.N. Separation of Fluids by Means of Mixed Matrix Membranes. U.S. Patent 4,740,219, 26 April 1988.

116. Kulprathipanja, S.; Funk, E.W.; Kulkarni, S.S.; Chang, Y.A. Separation of a Monosaccharide with Mixed Matrix Membranes. U.S. Patent 4,735,193A, 5 April 1988.

117. Robeson, L.M. Correlation of separation factor versus permeability for polymeric membranes. J. Membr. Sci. 1991, 62, 165-185. [CrossRef]

118. Robeson, L.M. The upper bound revisited. J. Membr. Sci. 2008, 320, 390-400. [CrossRef]

119. Mahajan, R.; Koros, W.J. Factors controlling successful formation of mixed-matrix gas separation materials. Ind. Eng. Chem. Res. 2000, 39, 2692-2696. [CrossRef] 
120. Yehia, H.; Pisklak, T.J.; Ferraris, J.P.; Balkus, K.J., Jr.; Musselman, I.H. Methane facilitated transport using copper (II) biphenyl dicarboxylate-triethylenediamine poly(3-acetoxyethylthiophene) mixed matrix membranes. Polym. Prepr. (Am. Chem. Soc. Div. Polym. Chem.) 2004, 45, 35-36.

121. Li, Y.; Chung, T.-S.; Cao, C.; Kulprathipanja, S. The effects of polymer chain rigidification, zeolite pore size and pore blockage on polyethersulfone (PES)-zeolite A mixed matrix membranes. J. Membr. Sci. 2005, 260, 45-55. [CrossRef]

122. Car, A.; Stropnik, C.; Peinemann, K.-V. Hybrid membrane materials with different metal-organic frameworks (MOFs) for gas separation. Desalination 2006, 200, 424-426. [CrossRef]

123. Perez, E.V.; Balkus, K.J., Jr.; Ferraris, J.P.; Musselman, I.H. Mixed-matrix membranes for gas separation using metal-organic frameworks. PMSE Prepr. 2006, 95, 815-816.

124. Perez, E.V.; Balkus, K.J., Jr.; Ferraris, J.P.; Musselman, I.H. Mixed-matrix membranes containing MOF-5 for gas separations. J. Membr. Sci. 2009, 328, 165-173. [CrossRef]

125. Perez, E.V. Mixed-Matrix Membranes for Gas Separation Using Metal-Organic Frameworks. Ph.D. Thesis, The University of Texas at Dallas, Richardson, TX, USA, 2009.

126. Perez, E.V.; Balkus, K.J., Jr.; Ferraris, J.P.; Musselman, I.H. Metal-organic polyhedra 18 mixed-matrix membranes for gas separation. J. Membr. Sci. 2014, 463, 82-93. [CrossRef]

127. Bae, T.-H.; Lee, J.S.; Qiu, W.; Koros, W.J.; Jones, C.W.; Nair, S. A high-performance gas-separation membrane containing submicrometer-sized metal-organic framework crystals. Angew. Chem. Int. Ed. 2010, 49, 9863-9866. [CrossRef] [PubMed]

128. Perez, E.V.; Kalaw, G.J.D.; Ferraris, J.P.; Balkus, K.J., Jr.; Musselman, I.H. High temperature and high pressure $\mathrm{H}_{2} / \mathrm{CO}_{2}$ separations with $\mathrm{NH}_{2}-\mathrm{MIL}-53 /$ VTEC $^{\mathrm{TM}}$ mixed-matrix membranes. In Proceedings of the 25th North American Membrane Society Meeting-NAMS 2015, Boston, MA, USA, 30 May-3 June 2015.

129. Te Hennepe, H.J.C. Zeolite Filled Polymeric Membranes: A New Concept in Separation Science. Ph.D. Thesis, University of Twente, Enschede, The Netherlands, 1988.

130. Te Hennepe, H.J.C.; Bargeman, D.; Mulder, M.H.V.; Smolders, C.A. Permeation through zeolite filled silicone rubber membranes. Stud. Surf. Sci. Catal. 1988, 39, 411-420.

131. Te Hennepe, H.J.C.; Mulder, M.H.V.; Smolders, C.A.; Bargeman, D.; Schröder, G.A.T. Pervaporation Process and Membrane. U.S. Patent 4,925,562, 15 May 1990.

132. Te Hennepe, H.J.C.; Boswerger, W.B.F.; Bargeman, D.; Mulder, M.H.V.; Smolders, C.A. Zeolite-filled silicone rubber membranes Experimental determination of concentration profiles. J. Membr. Sci. 1994, 89, 185-196. [CrossRef]

133. Bastani, D.; Esmaeili, N.; Asadollahi, M. Polymeric mixed matrix membranes containing zeolites as a filler for gas separation applications: A review. J. Ind. Eng. Chem. 2013, 19, 375-393. [CrossRef]

134. Dong, G.; Li, H.; Chen, V. Challenges and opportunities for mixed-matrix membranes for gas separation. J. Mater. Chem. A 2013, 1, 4610-4630. [CrossRef]

135. Chung, T.-S.; Jiang, L.Y.; Li, Y.; Kulprathipanja, S. Mixed matrix membranes (MMMs) comprising organic polymers with dispersed inorganic fillers for gas separation. Prog. Polym. Sci. 2007, 32, 483-507. [CrossRef]

136. Goh, P.S.; Ismail, A.F.; Sanip, S.M.; Ng, B.C.; Aziz, M. Recent advances of inorganic fillers in mixed matrix membrane for gas separation. Sep. Purif. Technol. 2011, 81, 243-264. [CrossRef]

137. Sterzel, H.-J.; Sanner, A. Membranes of Organic Polymers Which Contain Crystalline Carrier Compounds, and Their Preparation. U.S. Patent 4,973,606A, 27 November 1990.

138. Drago, R.S.; Balkus, K.J. Cobalt(II)-facilitated transport of dioxygen in a polystyrene membrane. Inorg. Chem. 1986, 25, 716-718. [CrossRef]

139. Süer, M.G.; Baç, N.; Yilmaz, L. Gas permeation characteristics of polymer-zeolite mixed matrix membranes. J. Membr. Sci. 1994, 91, 77-86. [CrossRef]

140. Battal, T.; Bac, N.; Yilmaz, L. Effect of feed composition on the performance of polymer-zeolite mixed matrix gas separation membranes. Sep. Sci. Technol. 1995, 30, 2365-2384. [CrossRef]

141. Tantekin-Ersolmaz, S.B.; Atalay-Oral, C.; Tatlier, M.; Erdem-Senatalar, A.; Schoeman, B.; Sterte, J. Effect of zeolite particle size on the performance of polymer-zeolite mixed matrix membranes. J. Membr. Sci. 2000, 175, 285-288. [CrossRef]

142. Mahajan, R.; Burns, R.; Schaeffer, M.; Koros, W.J. Challenges in forming successful mixed matrix membranes with rigid polymeric materials. J. Appl. Polym. Sci. 2002, 86, 881-890. [CrossRef] 
143. Merkel, T.C.; Freeman, B.D.; Spontak, R.J.; He, Z.; Pinnau, I.; Meakin, P.; Hill, A.J. Ultrapermeable, reverse-selective nanocomposite membranes. Science 2002, 296, 519-522. [CrossRef] [PubMed]

144. Hill, R.J. Diffusive permeability and selectivity of nanocomposite membranes. Ind. Eng. Chem. Res. 2006, 45, 6890-6898. [CrossRef]

145. Scholz, H.P.; Tassler, W.; Wiesegard, H.; Schoenmeier, A.; Wrabetz, G.; Plogsties, H.D.; Gross, M.; Opitz, H.; Theer, W.; Finger, G.D. Verfahren und Vorrichtung zur Abtrennung, Anreicherung und Reinigung von Bestandteilen Eines Gasgemisches Durch Permeation. Patent DE2,248,801 A1, 12 April 1973.

146. Li, Y.; Chung, T.-S.; Huang, Z.; Kulprathipanja, S. Dual-layer polyethersulfone (PES)/BTDA-TDI/MDI co-polyimide (P84) hollow fiber membranes with a submicron PES-zeolite beta mixed matrix dense-selective layer for gas separation. J. Membr. Sci. 2006, 277, 28-37. [CrossRef]

147. Zhang, Y.; Balkus, K.J., Jr.; Musselman, I.H.; Ferraris, J.P. Mixed matrix membranes composed of Matrimid and carbon aerogel and carbon aerogel+zeolite composite nanoparticles. PMSE Prepr. 2006, 95, 812-814.

148. Zhang, Y.; Musselman, I.H.; Ferraris, J.P.; Balkus, K.J. Gas permeability properties of mixed-matrix Matrimid membranes containing a carbon aerogel: A material with both micropores and mesopores. Ind. Eng. Chem. Res. 2008, 47, 2794-2802. [CrossRef]

149. Zhang, Y.; Balkus, K.J., Jr.; Musselman, I.H.; Ferraris, J.P. Mixed-matrix membranes composed of Matrimid and mesoporous ZSM-5 nanoparticles. J. Membr. Sci. 2008, 325, 28-39. [CrossRef]

150. Huang, Z.; Li, Y.; Wen, R.; Teoh, M.M.; Kulprathipanja, S. Enhanced gas separation properties by using nanostructured PES-Zeolite 4A mixed matrix membranes. J. Appl. Polym. Sci. 2006, 101, 3800-3805. [CrossRef]

151. Li, Y.; Chung, T.-S.; Kulprathipanja, S. Novel $\mathrm{Ag}^{+}$-zeolite/polymer mixed matrix membranes with a high $\mathrm{CO}_{2} / \mathrm{CH}_{4}$ selectivity. AlChE J. 2007, 53, 610-616. [CrossRef]

152. Yave, W.; Shishatskiy, S.; Abetz, V.; Matson, S.; Litvinova, E.; Khotimskiy, V.; Peinemann, K.-V. A novel poly(4-methyl-2-pentyne) $/ \mathrm{TiO}_{2}$ hybrid nanocomposite membrane for natural gas conditioning: Butane/methane separation. Macromol. Chem. Phys. 2007, 208, 2412-2418. [CrossRef]

153. Matteucci, S.; Kusuma, V.A.; Sanders, D.; Swinnea, S.; Freeman, B.D. Gas transport in $\mathrm{TiO}_{2}$ nanoparticle-filled poly(1-trimethylsilyl-1-propyne). J. Membr. Sci. 2008, 307, 196-217. [CrossRef]

154. Ward, J.K.; Koros, W.J. Crosslinkable mixed matrix membranes with surface modified molecular sieves for natural gas purification: II. Performance characterization under contaminated feed conditions. J. Membr. Sci. 2011, 377, 82-88. [CrossRef]

155. Nik, O.G.; Chen, X.Y.; Kaliaguine, S. Amine-functionalized zeolite FAU/EMT-polyimide mixed matrix membranes for $\mathrm{CO}_{2} / \mathrm{CH}_{4}$ separation. J. Membr. Sci. 2011, 379, 468-478. [CrossRef]

156. Joly, C.; Goizet, S.; Schrotter, J.C.; Sanchez, J.; Escoubes, M. Sol-gel polyimide-silica composite membrane: Gas transport properties. J. Membr. Sci. 1997, 130, 63-74. [CrossRef]

157. Gomes, D.; Nunes, S.P.; Peinemann, K.-V. Membranes for gas separation based on poly(1-trimethylsilyl-1propyne)-silica nanocomposites. J. Membr. Sci. 2005, 246, 13-25. [CrossRef]

158. Ahn, J.; Chung, W.J.; Pinnau, I.; Song, J.; Du, N.; Robertson, G.P.; Guiver, M.D. Gas transport behavior of mixed-matrix membranes composed of silica nanoparticles in a polymer of intrinsic microporosity (PIM-1). J. Membr. Sci. 2010, 346, 280-287. [CrossRef]

159. Takahashi, S.; Paul, D.R. Gas permeation in poly(ether imide) nanocomposite membranes based on surface-treated silica. Part 1: Without chemical coupling to matrix. Polymer 2006, 47, 7519-7534. [CrossRef]

160. Takahashi, S.; Paul, D.R. Gas permeation in poly(ether imide) nanocomposite membranes based on surface-treated silica. Part 2: With chemical coupling to matrix. Polymer 2006, 47, 7535-7547. [CrossRef]

161. Rubio, C.; Zornoza, B.; Gorgojo, P.; Tellez, C.; Coronas, J. Separation of $\mathrm{H}_{2}$ and $\mathrm{CO}_{2}$ containing mixtures with mixed matrix membranes based on layered materials. Curr. Org. Chem. 2014, 18, 2351-2363. [CrossRef]

162. Jeong, H.-K.; Krych, W.; Ramanan, H.; Nair, S.; Marand, E.; Tsapatsis, M. Fabrication of polymer/selective-flake nanocomposite membranes and their use in gas separation. Chem. Mater. 2004, 16, 3838-3845. [CrossRef]

163. Defontaine, G.; Barichard, A.; Letaief, S.; Feng, C.; Matsuura, T.; Detellier, C. Nanoporous polymer-Clay hybrid membranes for gas separation. J. Colloid Interface Sci. 2010, 343, 622-627. [CrossRef] [PubMed]

164. Choi, S.; Coronas, J.; Jordan, E.; Oh, W.; Nair, S.; Onorato, F.; Shantz, D.F.; Tsapatsis, M. Layered silicates by swelling of AMH-3 and nanocomposite membranes. Angew. Chem. Int. Ed. 2008, 47, 552-555. [CrossRef] [PubMed] 
165. Li, Y.; Krantz, W.B.; Chung, T.-S. A novel primer to prevent nanoparticle agglomeration in mixed matrix membranes. AlChE J. 2007, 53, 2470-2475. [CrossRef]

166. Jha, P.; Way, J.D. Carbon dioxide selective mixed-matrix membranes formulation and characterization using rubbery substituted polyphosphazene. J. Membr. Sci. 2008, 324, 151-161. [CrossRef]

167. Khan, A.L.; Cano-Odena, A.; Gutierrez, B.; Minguillon, C.; Vankelecom, I.F.J. Hydrogen separation and purification using polysulfone acrylate-zeolite mixed matrix membranes. J. Membr. Sci. 2010, 350, 340-346. [CrossRef]

168. Marsh, N.; Khan, A.L.; Klaysom, C.; Gahlaut, A.; Li, X.; Vankelecom, I.F.J. Euromembrane Conference 2012: SPEEK and functionalized mesoporous MCM-41 mixed-matrix membranes for gas separation. Procedia Eng. 2012, 44, 1902-1905.

169. Khan, A.L.; Klaysom, C.; Gahlaut, A.; Li, X.; Vankelecom, I.F.J. SPEEK and functionalized mesoporous MCM-41 mixed matrix membranes for $\mathrm{CO}_{2}$ separations. J. Mater. Chem. 2012, 22, 20057-20064. [CrossRef]

170. Buonomenna, M.G.; Yave, W.; Golemme, G. Some approaches for high performance polymer based membranes for gas separation: Block copolymers, carbon molecular sieves and mixed matrix membranes. RSC Adv. 2012, 2, 10745-10773. [CrossRef]

171. Li, X.; Ma, L.; Zhang, H.; Wang, S.; Jiang, Z.; Guo, R.; Wu, H.; Cao, X.; Yang, J.; Wang, B. Synergistic effect of combining carbon nanotubes and graphene oxide in mixed matrix membranes for efficient $\mathrm{CO}_{2}$ separation. J. Membr. Sci. 2015, 479, 1-10. [CrossRef]

172. Corbin, D.R.; Foley, H.C.; Shiflett, M.B. Mixed Matrix Nanoporous Carbon Membranes. U.S. Patent 6,740,143, 25 May 2004.

173. Koros, W.J.; Vu, D.Q.; Mahajan, R.; Miller, S.J. Carbon Molecular Sieves and Methods for Making the Same. U.S. Patent 6,562,110, 13 May 2002.

174. Vu, D.Q.; Koros, W.J.; Miller, S.J. Mixed matrix membranes using carbon molecular sieves. I. Preparation and experimental results. J. Membr. Sci. 2003, 211, 311-334. [CrossRef]

175. Tin, P.S.; Chung, T.-S.; Jiang, L.; Kulprathipanja, S. Carbon-zeolite composite membranes for gas separation. Carbon 2005, 43, 2025-2027. [CrossRef]

176. Nasir, R.; Mukhtar, H.; Man, Z.; Shaharun, M.S.; Abu Bakar, M.Z. Effect of fixed carbon molecular sieve (CMS) loading and various di-ethanolamine (DEA) concentrations on the performance of a mixed matrix membrane for $\mathrm{CO}_{2} / \mathrm{CH}_{4}$ separation. RSC Adv. 2015, 5, 60814-60822. [CrossRef]

177. Chung, T.-S.; Chan, S.S.; Wang, R.; Lu, Z.; He, C. Characterization of permeability and sorption in Matrimid ${ }^{\circledR} / C_{60}$ mixed matrix membranes. J. Membr. Sci. 2003, 211, 91-99. [CrossRef]

178. Sun, H.; Ma, C.; Wang, T.; Xu, Y.; Yuan, B.; Li, P.; Kong, Y. Preparation and characterization of $\mathrm{C}_{60}$-filled ethyl cellulose mixed-matrix membranes for gas separation of propylene/propane. Chem. Eng. Technol. 2014, 37, 611-619. [CrossRef]

179. Sears, K.; Dumée, L.; Schütz, J.; She, M.; Huynh, C.; Hawkins, S.; Duke, M.; Gray, S. Recent developments in carbon nanotube membranes for water purification and gas separation. Materials 2010, 3, 127-149. [CrossRef]

180. Kim, S.; Pechar, T.W.; Marand, E. Poly(imide siloxane) and carbon nanotube mixed matrix membranes for gas separation. Desalination 2006, 19, 330-339. [CrossRef]

181. Kumar, S.; Srivastava, S.; Vijay, Y.K. Study of gas transport properties of multi-walled carbon nanotubes/polystyrene composite membranes. Int. J. Hydrog. Energy 2012, 37, 3914-3921. [CrossRef]

182. Ismail, A.F.; Rahim, N.H.; Mustafa, A.; Matsuura, T.; Ng, B.C.; Abdullah, S.; Hashemifard, S.A. Gas separation performance of polyethersulfone/multi-walled carbon nanotubes mixed matrix membranes. Sep. Purif. Technol. 2011, 80, 20-31. [CrossRef]

183. Ahmad, A.L.; Jawad, Z.A.; Low, S.C.; Zein, S.H.S. A cellulose acetate/multi-walled carbon nanotube mixed matrix membrane for $\mathrm{CO}_{2} / \mathrm{N}_{2}$ separation. J. Membr. Sci. 2014, 451, 55-66. [CrossRef]

184. Bhole, Y.S.; Wanjale, S.D.; Kharul, U.K.; Jog, J.P. Assessing feasibility of polyarylate-clay nanocomposites towards improvement of gas selectivity. J. Membr. Sci. 2007, 306, 277-286. [CrossRef]

185. Zulhairun, A.K.; Ismail, A.F. The role of layered silicate loadings and their dispersion states on the gas separation performance of mixed matrix membrane. J. Membr. Sci. 2014, 468, 20-30. [CrossRef]

186. Tantekin-Ersolmaz, S.B.; Senorkyan, L.; Kalaonra, N.; Tatlier, M.; Erdem-Senatalar, A. n-Pentane/i-pentane separation by using zeolite-PDMS mixed matrix membranes. J. Membr. Sci. 2001, 189, 59-67. [CrossRef]

187. Pechar, T.W.; Tsapatsis, M.; Marand, E.; Davis, R. Preparation and characterization of a glassy fluorinated polyimide zeolite-mixed matrix membrane. Desalination 2002, 146, 3-9. [CrossRef] 
188. Qi, R.; Wang, Y.; Chen, J.; Li, J.; Zhu, S. Removing thiophenes from n-octane using PDMS-AgY zeolite mixed matrix membranes. J. Membr. Sci. 2007, 295, 114-120. [CrossRef]

189. Kanezashi, M.; Sano, M.; Yoshioka, T.; Tsuru, T. Extremely thin Pd-silica mixed-matrix membranes with nano-dispersion for improved hydrogen permeability. Chem. Commun. 2010, 46, 6171-6173. [CrossRef] [PubMed]

190. Hudiono, Y.C.; Carlisle, T.K.; LaFrate, A.L.; Gin, D.L.; Noble, R.D. Novel mixed matrix membranes based on polymerizable room-temperature ionic liquids and SAPO-34 particles to improve $\mathrm{CO}_{2}$ separation. J. Membr. Sci. 2011, 370, 141-148. [CrossRef]

191. Xing, R.; Ho, W.S.W. Crosslinked polyvinylalcohol-polysiloxane/fumed silica mixed matrix membranes containing amines for $\mathrm{CO}_{2} / \mathrm{H}_{2}$ separation. J. Membr. Sci. 2011, 367, 91-102. [CrossRef]

192. Buonomenna, M.G.; Golemme, G.; Tone, C.M.; de Santo, M.P.; Ciuchi, F.; Perrotta, E. Amine-functionalized SBA-15 in poly(styrene-b-butadiene-b-styrene) (SBS) yields permeable and selective nanostructured membranes for gas separation. J. Mater. Chem. A 2013, 1, 11853-11866. [CrossRef]

193. Suhaimi, H.S.M.; Khir, M.N.I.M.; Leo, C.P.; Ahmad, A.L. Preparation and characterization of polysulfone mixed-matrix membrane incorporated with palladium nanoparticles dispersed in polyvinylpyrrolidone for hydrogen separation. J. Polym. Res. 2014, 21, 1-8. [CrossRef]

194. Biradha, K.; Ramanan, A.; Vittal, J.J. Coordination polymers versus metal-organic frameworks. Cryst. Growth Des. 2009, 9, 2969-2970. [CrossRef]

195. Batten Stuart, R.; Champness Neil, R.; Chen, X.-M.; Garcia-Martinez, J.; Kitagawa, S.; Öhrström, L.; O'Keeffe, M.; Paik Suh, M.; Reedijk, J. Terminology of metal-organic frameworks and coordination polymers (IUPAC Recommendations 2013). Pure Appl. Chem. 2013, 85, 1715-1724.

196. Yaghi, O.M.; Rosi, N.L.; Eckert, J.; Eddaoudi, M.; Vodak, D.T.; Kim, J.; O’Keeffe, M. Hydrogen storage in microporous metal-organic frameworks. Science 2003, 300, 1127-1129.

197. Furukawa, H.; Kim, J.; Plass, K.E.; Yaghi, O.M. Crystal structure, dissolution, and deposition of a $5 \mathrm{~nm}$ functionalized metal-organic great rhombicuboctahedron. J. Am. Chem. Soc. 2006, 128, 8398-8399. [CrossRef] [PubMed]

198. Banerjee, R.; Phan, A.; Wang, B.; Knobler, C.; Furukawa, H.; O’Keeffe, M.; Yaghi, O.M. High-throughput synthesis of zeolitic imidazolate frameworks and application to $\mathrm{CO}_{2}$ capture. Science 2008, 319, 939-943. [CrossRef] [PubMed]

199. Huang, X.; Zhang, J.; Chen, X. $\left[\mathrm{Zn}(\text { bim })_{2}\right] \cdot\left(\mathrm{H}_{2} \mathrm{O}\right)_{1.67}$ : A metal-organic open-framework with sodalite topology. Chin. Sci. Bull. 2003, 48, 1531-1534.

200. Huang, X.C.; Lin, Y.Y.; Zhang, J.P.; Chen, X.M. Ligand-directed strategy for zeolite-type metal-organic frameworks: Zinc(II) Imidazolates with unusual zeolitic topologies. Angew. Chem. Int. Ed. 2006, 45, 1557-1559. [CrossRef] [PubMed]

201. Morris, W.; Doonan, C.J.; Furukawa, H.; Banerjee, R.; Yaghi, O.M. Crystals as molecules: Postsynthesis covalent functionalization of zeolitic imidazolate frameworks. J. Am. Chem. Soc. 2008, 130, 12626-12627. [CrossRef] [PubMed]

202. Seki, K. Design of an adsorbent with an ideal pore structure for methane adsorption using metal complexes. Chem. Commun. 2001, 1496, 1496-1497. [CrossRef]

203. Barcena, C. Gas Permeability Properties of Copper (II) Biphenyldicarboxylate-Triethylenediamine in Rubbery Mixed-Matrix Membranes. Master's Thesis, The University of Texas at Dallas, Richardson, TX, USA, 2006.

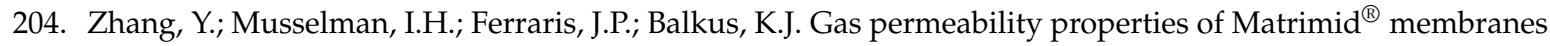
containing the metal-organic framework Cu-BPY-HFS. J. Membr. Sci. 2008, 313, 170-181. [CrossRef]

205. Yang, T.; Xiao, Y.; Chung, T.-S. Poly-/metal-benzimidazole nano-composite membranes for hydrogen purification. Energy Environ. Sci. 2011, 4, 4171-4180. [CrossRef]

206. Zornoza, B.; Tellez, C.; Coronas, J.; Gascon, J.; Kapteijn, F. Metal organic framework based mixed matrix membranes: An increasingly important field of research with a large application potential. Microporus Mesoporus Mater. 2013, 166, 67-78. [CrossRef]

207. Seoane, B.; Coronas, J.; Gascon, I.; Benavides, M.E.; Karvan, O.; Caro, J.; Kapteijn, F.; Gascon, J. Metal-organic framework based mixed matrix membranes: A solution for highly efficient $\mathrm{CO}_{2}$ capture? Chem. Soc. Rev. 2015, 44, 2421-2454. [CrossRef] [PubMed] 
208. Smith, S.J.D.; Lau, C.H.; Mardel, J.I.; Kitchin, M.; Konstas, K.; Ladewig, B.P.; Hill, M.R. Physical aging in glassy mixed matrix membranes; tuning particle interaction for mechanically robust nanocomposite films. J. Mater. Chem. A 2016, 4, 10627-10634. [CrossRef]

209. Mahdi, E.M.; Tan, J.-C. Dynamic molecular interactions between polyurethane and ZIF-8 in a polymer-MOF nanocomposite: Microstructural, thermo-mechanical and viscoelastic effects. Polymer 2016, 97, 31-43. [CrossRef]

210. Adams, R.; Carson, C.; Ward, J.; Tannenbaum, R.; Koros, W. Metal organic framework mixed matrix membranes for gas separations. Microporous Mesoporous Mater. 2010, 131, 13-20. [CrossRef]

211. Diaz, K.; Garrido, L.; Lopez-Gonzalez, M.; del Castillo, L.F.; Riande, E. $\mathrm{CO}_{2}$ transport in polysulfone membranes containing zeolitic imidazolate frameworks as determined by permeation and PFG NMR techniques. Macromolecules 2010, 43, 316-325. [CrossRef]

212. Hu, J.; Cai, H.; Ren, H.; Wei, Y.; Xu, Z.; Liu, H.; Hu, Y. Mixed-matrix membrane hollow fibers of $\mathrm{Cu}_{3}(\mathrm{BTC})_{2}$ MOF and polyimide for gas separation and adsorption. Ind. Eng. Chem. Res. 2010, 49, 12605-12612. [CrossRef]

213. Keskin, S.; Sholl, D.S. Selecting metal organic frameworks as enabling materials in mixed matrix membranes for high efficiency natural gas purification. Energy Environ. Sci. 2010, 3, 343-351. [CrossRef]

214. Keskin, S. Molecular simulation study of $\mathrm{CH}_{4} / \mathrm{H}_{2}$ mixture separations using metal organic framework membranes and composites. J. Phys. Chem. C 2010, 114, 13047-13054. [CrossRef]

215. Erucar, I.; Keskin, S. Computational methods for MOF/polymer membranes. Chem. Rec. 2016, 16, 703-718. [CrossRef] [PubMed]

216. Ordoñez, M.J.C.; Balkus, K.J., Jr.; Ferraris, J.P.; Musselman, I.H. Molecular sieving realized with ZIF-8/Matrimid ${ }^{\circledR}$ mixed-matrix membranes. J. Membr. Sci. 2010, 361, 28-37. [CrossRef]

217. Musselman, I.H.; Perez, E.V.; Ordonez, M.J.C.; Balkus, K.J., Jr.; Ferraris, J.P. Incorporation of hybrid crystalline microporous materials in mixed-matrix membranes for gas separations. Microsc. Microanal. 2010, 16, 1668-1669. [CrossRef]

218. Basu, S.; Cano-Odena, A.; Vankelecom, I.F.J. MOF-containing mixed-matrix membranes for $\mathrm{CO}_{2} / \mathrm{CH}_{4}$ and $\mathrm{CO}_{2} / \mathrm{N}_{2}$ binary gas mixture separations. Sep. Purif. Technol. 2011, 81, 31-40. [CrossRef]

219. Zornoza, B.; Martinez-Joaristi, A.; Serra-Crespo, P.; Tellez, C.; Coronas, J.; Gascon, J.; Kapteijn, F. Functionalized flexible MOFs as fillers in mixed matrix membranes for highly selective separation of $\mathrm{CO}_{2}$ from $\mathrm{CH}_{4}$ at elevated pressures. Chem. Commun. 2011, 47, 9522-9524. [CrossRef] [PubMed]

220. Nik, O.G.; Chen, X.Y.; Kaliaguine, S. Functionalized metal organic framework-polyimide mixed matrix membranes for $\mathrm{CO}_{2} / \mathrm{CH}_{4}$ separation. J. Membr. Sci. 2012, 413-414, 48-61. [CrossRef]

221. Zornoza, B.; Seoane, B.; Zamaro, J.M.; Tellez, C.; Coronas, J. Combination of MOFs and zeolites for mixed-matrix membranes. ChemPhysChem 2011, 12, 2781-2785. [CrossRef] [PubMed]

222. Jeazet, H.B.T.; Staudt, C.; Janiak, C. A method for increasing permeability in $\mathrm{O}_{2} / \mathrm{N}_{2}$ separation with mixed-matrix membranes made of water-stable MIL-101 and polysulfone. Chem. Commun. 2012, 48, 2140-2142. [CrossRef] [PubMed]

223. Dai, Y.; Johnson, J.R.; Karvan, O.; Sholl, D.S.; Koros, W.J. Ultem ${ }^{\mathrm{TM}} /$ ZIF-8 mixed matrix hollow fiber membranes for $\mathrm{CO}_{2} / \mathrm{N}_{2}$ separations. J. Membr. Sci. 2012, 401-402, 76-82. [CrossRef]

224. Yang, T.; Shi, G.M.; Chung, T.-S. Symmetric and asymmetric zeolitic imidazolate frameworks (ZIFs)/polybenzimidazole (PBI) nanocomposite membranes for hydrogen purification at high temperatures. Adv. Energy Mater. 2012, 2, 1358-1367. [CrossRef]

225. Bushell, A.F.; Attfield, M.P.; Mason, C.R.; Budd, P.M.; Yampolskii, Y.; Starannikova, L.; Rebrov, A.; Bazzarelli, F.; Bernardo, P.; Carolus Jansen, J.; et al. Gas permeation parameters of mixed matrix membranes based on the polymer of intrinsic microporosity PIM-1 and the zeolitic imidazolate framework ZIF-8. J. Membr. Sci. 2013, 427, 48-62. [CrossRef]

226. Budd, P.; Elabas, E.; Ghanem, B.; Makhseed, S.; McKeown, N.; Msayib, K.; Tattershall, C.; Wang, D. Solution-processed, organophilic membrane derived from a polymer of intrinsic microporosity. Adv. Mater. 2004, 16, 456-459. [CrossRef]

227. Budd, P.M.; Msayib, K.J.; Tattershall, C.E.; Ghanem, B.S.; Reynolds, K.J.; McKeown, N.B.; Fritsch, D. Gas separation membranes from polymers of intrinsic microporosity. J. Membr. Sci. 2005, 251, $263-269$. [CrossRef]

228. Haruyoshi, G.; Yukitaka, K. Production of 5,6,5' ,6'-Tetrahydroxy-1,1'-Spirobisindanes. Patent JP3,148,232, 1989. 
229. Jeazet, H.B.T.; Koschine, T.; Staudt, C.; Raetzke, K.; Janiak, C. Correlation of gas permeability in a metal-organic framework MIL-101(Cr)_Polysulfone mixed-matrix membrane with free volume measurements by positron annihilation lifetime spectroscopy (PALS). Membranes 2013, 3, 331-353. [CrossRef] [PubMed]

230. Singh, T.; Kang, D.-Y.; Nair, S. Rigorous calculations of permeation in mixed-matrix membranes: Evaluation of interfacial equilibrium effects and permeability-based models. J. Membr. Sci. 2013, 448, 160-169. [CrossRef]

231. Pal, R. Permeation models for mixed matrix membranes. J. Colloid Interface Sci. 2008, 317, 191-198. [CrossRef] [PubMed]

232. Vinh-Thang, H.; Kaliaguine, S. Predictive models for mixed-matrix membrane performance: A review. Chem. Rev. 2013, 113, 4980-5028. [CrossRef] [PubMed]

233. Hao, L.; Li, P.; Yang, T.; Chung, T.-S. Room temperature ionic liquid/ZIF-8 mixed-matrix membranes for natural gas sweetening and post-combustion $\mathrm{CO}_{2}$ capture. J. Membr. Sci. 2013, 436, 221-231. [CrossRef]

234. Abedini, R.; Omidkhah, M.; Dorosti, F. Hydrogen separation and purification with poly (4-methyl-1pentyne)/MIL 53 mixed matrix membrane based on reverse selectivity. Int. J. Hydrog. Energy 2014, 39, 7897-7909. [CrossRef]

235. Diestel, L.; Liu, X.L.; Li, Y.S.; Yang, W.S.; Caro, J. Comparative permeation studies on three supported membranes: Pure ZIF-8, pure polymethylphenylsiloxane, and mixed matrix membranes. Microporous Microporous Mater. 2014, 189, 210-215. [CrossRef]

236. Diestel, L.; Wang, N.; Schwiedland, B.; Steinbach, F.; Giese, U.; Caro, J. MOF based MMMs with enhanced selectivity due to hindered linker distortion. J. Membr. Sci. 2015, 492, 181-186. [CrossRef]

237. Duan, C.; Jie, X.; Liu, D.; Cao, Y.; Yuan, Q. Post-treatment effect on gas separation property of mixed matrix membranes containing metal organic frameworks. J. Membr. Sci. 2014, 466, 92-102. [CrossRef]

238. Nordin, N.A.H.M.; Ismail, A.F.; Mustafa, A.; Murali, R.S.; Matsuura, T. The impact of ZIF-8 particle size and heat treatment on $\mathrm{CO}_{2} / \mathrm{CH}_{4}$ separation using asymmetric mixed matrix membrane. RSC Adv. 2014, 4, 52530-52541. [CrossRef]

239. Shahid, S.; Nijmeijer, K. Performance and plasticization behavior of polymer-MOF membranes for gas separation at elevated pressures. J. Membr. Sci. 2014, 470, 166-177. [CrossRef]

240. Shahid, S.; Nijmeijer, K. High pressure gas separation performance of mixed-matrix polymer membranes containing mesoporous Fe(BTC). J. Membr. Sci. 2014, 459, 33-44. [CrossRef]

241. Rodenas, T.; van Dalen, M.; Garcia-Perez, E.; Serra-Crespo, P.; Zornoza, B.; Kapteijn, F.; Gascon, J. Visualizing MOF mixed matrix membranes at the nanoscale: Towards structure-performance relationships in $\mathrm{CO}_{2} / \mathrm{CH}_{4}$ separation over $\mathrm{NH}_{2}$-MIL-53(Al)@PI. Adv. Funct. Mater. 2014, 24, 249-256. [CrossRef]

242. Yeo, Z.Y.; Tan, P.Y.; Chai, S.-P.; Zhu, P.W.; Mohamed, A.R. Continuous polycrystalline ZIF-8 membrane supported on $\mathrm{CO}_{2}$-selective mixed matrix supports for $\mathrm{CO}_{2} / \mathrm{CH}_{4}$ separation. RSC Adv. 2014, 4, 52461-52466. [CrossRef]

243. Lau, C.H.; Nguyen, P.T.; Hill, M.R.; Thornton, A.W.; Konstas, K.; Doherty, C.M.; Mulder, R.J.; Bourgeois, L.; Liu, A.C.Y.; Sprouster, D.J.; et al. Ending aging in super glassy polymer membranes. Angew. Chem. Int. Ed. 2014, 53, 5322-5326. [CrossRef] [PubMed]

244. Kitchin, M.; Teo, J.; Konstas, K.; Lau, C.H.; Sumby, C.J.; Thornton, A.W.; Doonan, C.J.; Hill, M.R. AIMs: A new strategy to control physical aging and gas transport in mixed-matrix membranes. J. Mater. Chem. A 2015, 3, 15241-15247. [CrossRef]

245. Lau, C.H.; Konstas, K.; Doherty, C.M.; Kanehashi, S.; Ozcelik, B.; Kentish, S.E.; Hill, A.J.; Hill, M.R. Tailoring physical aging in super glassy polymers with functionalized porous aromatic frameworks for $\mathrm{CO}_{2}$ Capture. Chem. Mater. 2015, 27, 4756-4762. [CrossRef]

246. Smith, S.J.D.; Ladewig, B.P.; Hill, A.J.; Lau, C.H.; Hill, M.R. Post-synthetic Ti exchanged UiO-66 metal-organic frameworks that deliver exceptional gas permeability in mixed matrix membranes. Sci. Rep. 2015, 5. [CrossRef] [PubMed]

247. Malakhov, A.O.; Knyazeva, E.E.; Novitsky, E.G. Gas transport properties of LiA type zeolite-filled poly(trimethylsilylpropyne) membranes. Pet. Chem. 2015, 55, 708-715. [CrossRef]

248. DeCoste, J.B.; Denny, J.M.S.; Peterson, G.W.; Mahle, J.J.; Cohen, S.M. Enhanced aging properties of HKUST-1 in hydrophobic mixed-matrix membranes for ammonia adsorption. Chem. Sci. 2016, 6, 2711-2716. [CrossRef] 
249. Mitra, T.; Bhavsar, R.S.; Adams, D.J.; Budd, P.M.; Cooper, A.I. PIM-1 mixed matrix membranes for gas separations using cost-effective hypercrosslinked nanoparticle fillers. Chem. Commun. 2016, 52, 5581-5584. [CrossRef] [PubMed]

250. Ma, J.; Ying, Y.; Yang, Q.; Ban, Y.; Huang, H.; Guo, X.; Xiao, Y.; Liu, D.; Li, Y.; Yang, W.; et al. Mixed-matrix membranes containing functionalized porous metal-organic polyhedrons for the effective separation of $\mathrm{CO}_{2}-\mathrm{CH}_{4}$ mixture. Chem. Commun. 2015, 51, 4249-4251. [CrossRef] [PubMed]

251. Rodenas, T.; Luz, I.; Prieto, G.; Seoane, B.; Miro, H.; Corma, A.; Kapteijn, F.; Llabres i. Xamena, F.X.; Gascon, J. Metal-organic framework nanosheets in polymer composite materials for gas separation. Nat. Mater. 2015, 14, 48-55. [CrossRef] [PubMed]

252. Kang, Z.; Peng, Y.; Hu, Z.; Qian, Y.; Chi, C.; Yeo, L.Y.; Tee, L.; Zhao, D. Mixed matrix membranes composed of two-dimensional metal-organic framework nanosheets for pre-combustion $\mathrm{CO}_{2}$ capture: A relationship study of filler morphology versus membrane performance. J. Mater. Chem. 2015, 3, 20801-20810. [CrossRef]

253. Sabetghadam, A.; Seoane, B.; Keskin, D.; Duim, N.; Rodenas, T.; Shahid, S.; Sorribas, S.; Guillouzer, C.L.; Clet, G.; Tellez, C.; et al. Metal organic framework crystals in mixed-matrix membranes: Impact of the filler morphology on the gas separation performance. Adv. Funct. Mater. 2016, 26, 3154-3163. [CrossRef]

254. Venna, S.R.; Lartey, M.; Li, T.; Spore, A.; Kumar, S.; Nulwala, H.B.; Luebke, D.R.; Rosi, N.L.; Albenze, E. Fabrication of MMMs with improved gas separation properties using externally-functionalized MOF particles. J. Mater. Chem. A 2015, 3, 5014-5022. [CrossRef]

255. Zhang, Z.; Nguyen, H.T.; Miller, S.A.; Cohen, S.M. polyMOFs: A class of interconvertible polymer-metalorganic-framework hybrid materials. Angew. Chem. Int. Ed. 2015, 54, 6152-6157. [CrossRef] [PubMed]

256. Cao, X.; Qiao, Z.; Wang, Z.; Zhao, S.; Li, P.; Wang, J.; Wang, S. Enhanced performance of mixed matrix membrane by incorporating a highly compatible covalent organic framework into poly(vinylamine) for hydrogen purification. Int. J. Hydrog. Energy 2016, 41, 9167-9174. [CrossRef]

257. Ding, S.Y.; Wang, W. Covalent organic frameworks (COFs): From design to applications. Chem. Soc. Rev. 2013, 42, 548-568. [CrossRef] [PubMed]

258. Kang, Z.; Peng, Y.; Qian, Y.; Yuan, D.; Addicoat, M.A.; Heine, T.; Hu, Z.; Tee, L.; Guo, Z.; Zhao, D. Mixed matrix membranes (MMMs) comprising exfoliated 2D covalent organic frameworks (COFs) for efficient $\mathrm{CO}_{2}$ separation. Chem. Mater. 2016, 28, 1277-1285. [CrossRef]

259. Tanh Jeazet, H.B.; Staudt, C.; Janiak, C. Metal-organic frameworks in mixed-matrix membranes for gas separation. Dalton Trans. 2012, 41, 14003-14027. [CrossRef] [PubMed]

260. Yao, J.; Wang, H. Zeolitic imidazolate framework composite membranes and thin films: Synthesis and applications. Chem. Soc. Rev. 2014, 43, 4470-4493. [CrossRef] [PubMed]

261. Erucar, I.; Keskin, S. Molecular modeling of mOF-based mixed matrix membranes. Curr. Org. Chem. 2014, 18, 2364-2380. [CrossRef]

262. Erucar, I.; Yilmaz, G.; Keskin, S. Recent advances in metal-organic framework-based mixed matrix membranes. Chem. Asian J. 2013, 8, 1692-1704. [CrossRef] [PubMed]

263. Hunger, K.; Schmeling, N.; Tanh Jeazet, H.B.; Janiak, C.; Staudt, C.; Kleinermanns, K. Investigation of cross-linked and additive containing polymer materials for membranes with improved performance in pervaporation and gas separation. Membranes 2012, 2, 727-763. [CrossRef] [PubMed]

264. Li, W.; Zhang, Y.; Li, Q.; Zhang, G. Metal-organic framework composite membranes: Synthesis and separation applications. Chem. Eng. Sci. 2015, 135, 232-257. [CrossRef]

265. Rangnekar, N.; Mittal, N.; Elyassi, B.; Caro, J.; Tsapatsis, M. Zeolite membranes-A review and comparison with MOFs. Chem. Soc. Rev. 2015, 44, 7128-7154. [CrossRef] [PubMed]

(C) 2016 by the authors; licensee MDPI, Basel, Switzerland. This article is an open access article distributed under the terms and conditions of the Creative Commons Attribution (CC-BY) license (http://creativecommons.org/licenses/by/4.0/). 